Portland State University

PDXScholar

Spring 5-31-2017

\title{
Profiles of School Readiness and Implications for Children's Development of Academic, Social, and Engagement Skills
}

Elizabeth Jane Tremaine

Portland State University

Follow this and additional works at: https://pdxscholar.library.pdx.edu/open_access_etds

Part of the Elementary Education Commons, and the Psychology Commons Let us know how access to this document benefits you.

\section{Recommended Citation}

Tremaine, Elizabeth Jane, "Profiles of School Readiness and Implications for Children's Development of Academic, Social, and Engagement Skills" (2017). Dissertations and Theses. Paper 4019.

https://doi.org/10.15760/etd.5903

This Thesis is brought to you for free and open access. It has been accepted for inclusion in Dissertations and Theses by an authorized administrator of PDXScholar. Please contact us if we can make this document more accessible: pdxscholar@pdx.edu. 
Profiles of School Readiness and Implications for

Children's Development of Academic, Social, and Engagement Skills

by

Elizabeth Jane Tremaine

A thesis submitted in partial fulfillment of the requirements for the degree of

\author{
Master of Science \\ in \\ Psychology
}

Thesis Committee:

Andrew Mashburn, Chair

Ellen Skinner

Joel Steele

Portland State University

2017 
(C) 2017 Elizabeth Jane Tremaine 
Academic achievement gaps across racial, ethnic, and socioeconomic groups are apparent as soon as children enter kindergarten: racial minorities, Hispanics, and poor children begin school at a distinct disadvantage compared to their White peers from middle- and high-income families (Chatterji, 2005; Fryer, Jr. \& Levitt, 2004; Magnuson, Meyers, Ruhm, \& Waldfogel, 2004; Magnuson \& Waldfogel, 2005; Reardon, 2011). To understand these gaps at kindergarten entry, it is essential that researchers understand the skills with which children enter kindergarten.

Previous research on school readiness has been limited by variable-centered methods that separate components of school readiness (e.g., early academic skills, social skills, engagement). As each entering kindergartner possesses their own set of school readiness skills, it is not likely that school readiness skills are independent of one another. School readiness may be better conceptualized and measured as patterns of skills that children possess at the beginning of kindergarten. These detectable patterns of school readiness skills present at kindergarten entry may deferentially support development of academic and non-academic achievement outcomes, such that strengths can promote the development of weaker skills across the kindergarten year.

Within the framework of Cognitive Load Theory (Sweller, 1994), this study investigated the nature of the relations among children's school readiness skills and their associations with development of academic, social, and engagement skills across the kindergarten year. This study used a person-centered analytic technique to identify profiles of school readiness present in entering kindergartners and explored the different 
developmental trajectories of academic, social, and engagement skills of children across these profiles. Five school readiness profiles were detected: 1) Scholastic, 2) On Par, 3) Room to Grow, 4) Super Regulator, and 5) Wiggler. Membership in these profiles was predicted by key demographic variables, and membership in profiles in turn uniquely predicted change in achievement outcomes across the kindergarten year. More specifically, children in the Super Regulator profile improved notably in academic skills, which were their weaker skills at school entry, but did not show improvement in social and engagement skills as a group across the year; children in the Wiggler profile showed moderate improvements in engagement skills, social skills, and self control across the year; children in the On Par profile showed no change in social and engagement skills, while showing the most improvement in math scores across all the profiles; the social and engagement skills of children in the Scholastic profile improved moderately, while their academic skills improved the least of all the groups; and children within the Room to Grow profile showed the most growth in social and engagement skills and improved moderately in math skills, but did not show the same improvement in reading skills.

Furthermore, this study contrasted the person-centered approach described above to a more traditional, variable-centered approach. The author believes that the personcentered approach succeeded in providing findings about school readiness that can be more easily and succinctly communicated to early childhood education stakeholders than did the variable-centered approach. 
Dedication

I am happy to dedicate my thesis work to my partner, Ryan Geraghty. He supports and challenges me to broaden my understanding of the world and share it with others.

Ryan, you rock; I love you. 
An enormous thank you to my advisor, Dr. Andrew Mashburn, for his unwavering support, input, and encouragement and the members of the CEEDR lab for always actively listening.

Equally enormous thanks must go to my committee members, Drs. Ellen Skinner and Joel Steele, who have (and will, I'm sure) challenge(d) me to think outside my comfort zone and examine all possibilities.

Finally, I want to thank my partner, Ryan Geraghty, and my forever-puppy, Cheeto. They are the guardians of my dreams. 
PROFILES OF SCHOOL READINESS $\quad$ v

Title

Table of Contents

Abstract .............. i

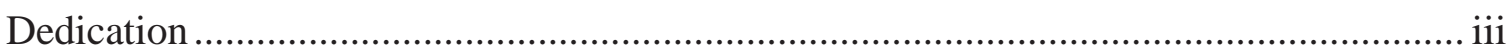

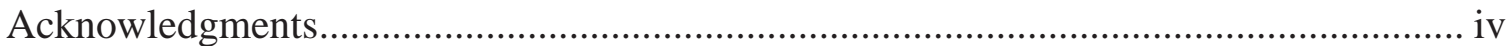

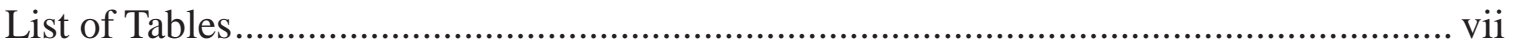

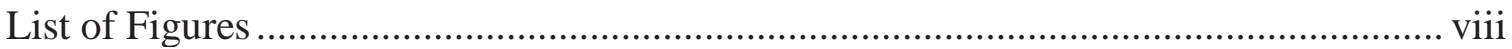

Chapter One: Problem Statement..........................................................................

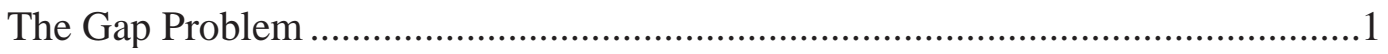

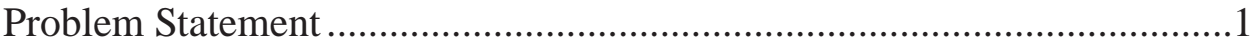

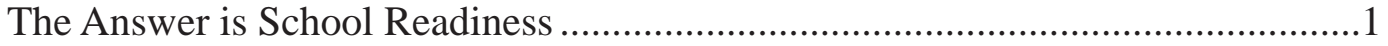

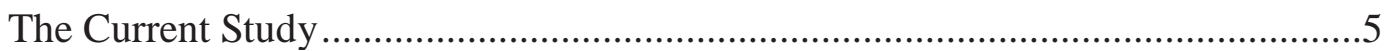

Chapter Two: Literature Review ..........................................................................6

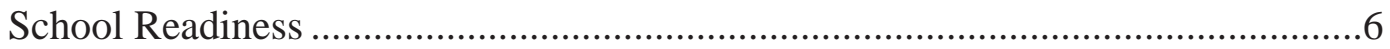

Definition of School Readiness ...........................................................6

Antecedents of School Readiness .......................................................11

Stakeholder Perspectives on School Readiness .....................................20

Developmental Perspectives of School Readiness ........................................23

Predictive Validity of School Readiness ..............................................24

Cognitive Load Theory and the Mechanisms of School Readiness..........28

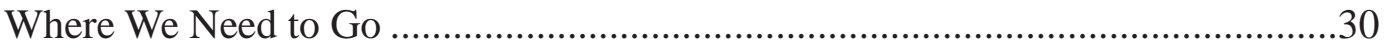

Conceptual Limitations of Previous Work .............................................30

Methodological Limitations of Previous Work.....................................31

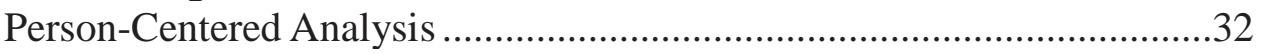

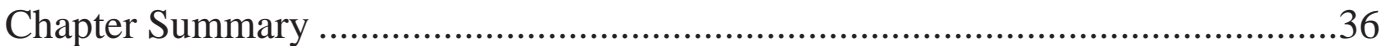

Chapter Three: Purpose of the Current Study ..............................................................38

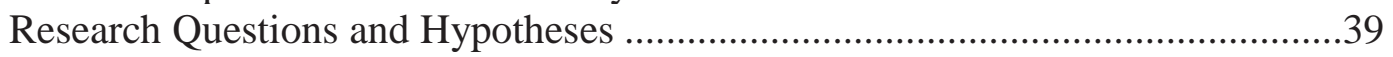

Research Question One ...................................................................39

Research Question Two ...............................................................40

Research Question Three ................................................................42

Research Question Four.....................................................................46

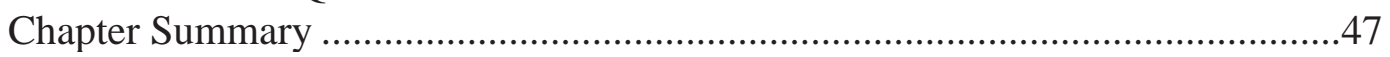

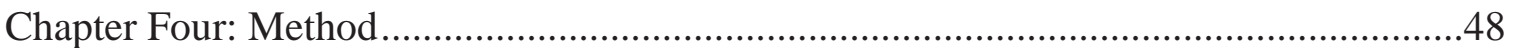

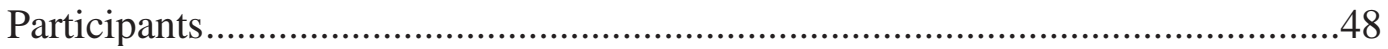

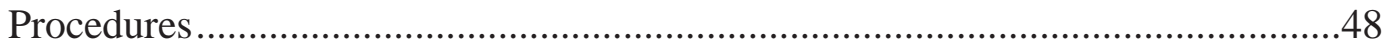

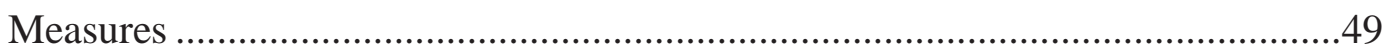

School Readiness Variables ..............................................................44

Child and Family Demographic Characteristics ...................................53

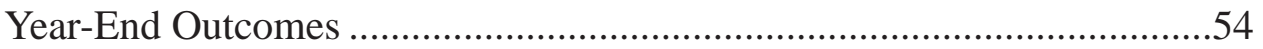

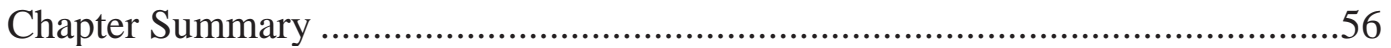

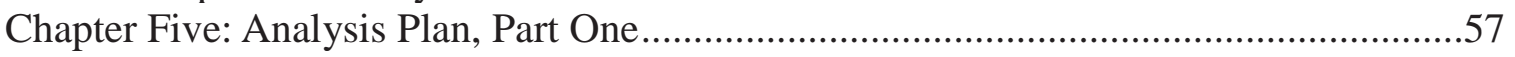

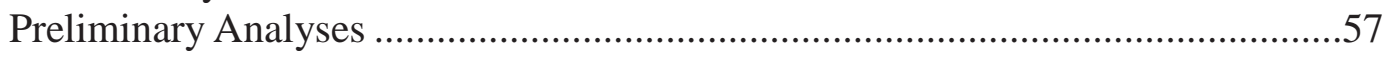

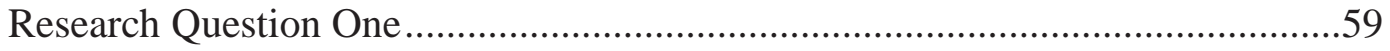

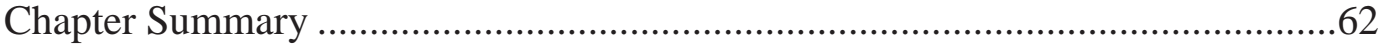


PROFILES OF SCHOOL READINESS vi

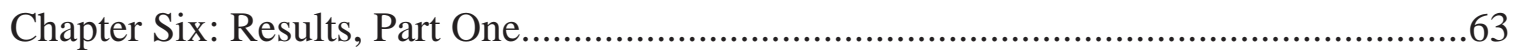

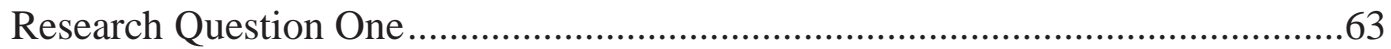

Cluster Solution Selection.................................................................6 63

Description of School Readiness Profiles.............................................66

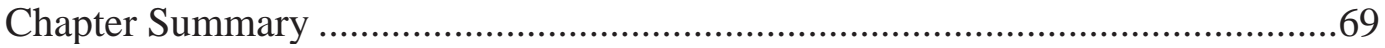

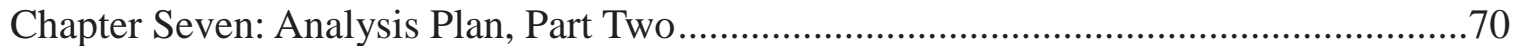

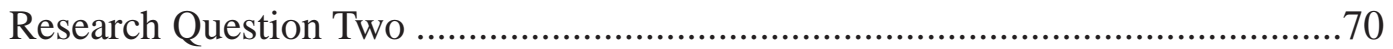

Research Question Three ............................................................................ 71

Research Question Four ......................................................................... 74

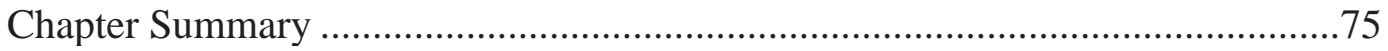

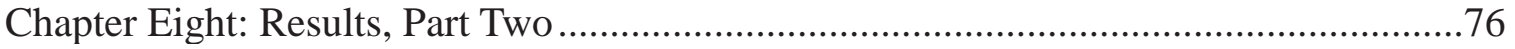

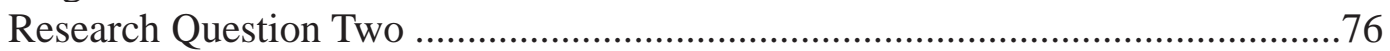

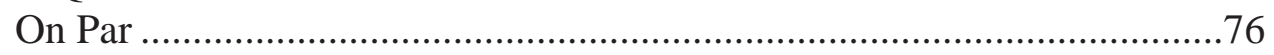

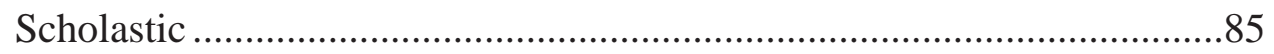

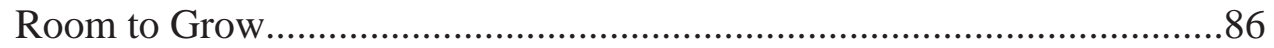

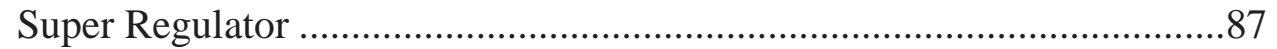

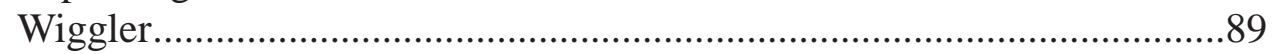

Research Questions Three and Four ..........................................................90

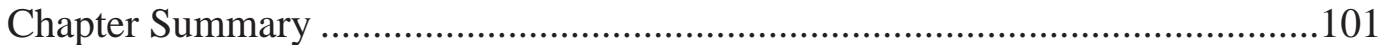

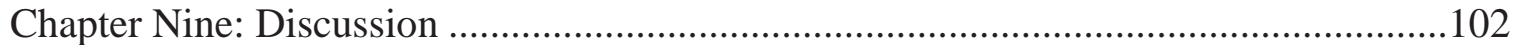

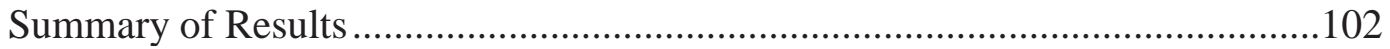

Research Question One...................................................................102

Research Question Two ...................................................................10

Research Question Three ..............................................................103

Research Question Four .................................................................105

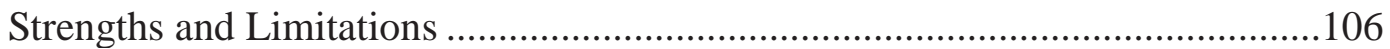

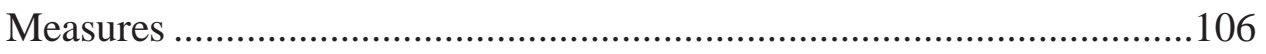

Analyses ............................................................................. 107

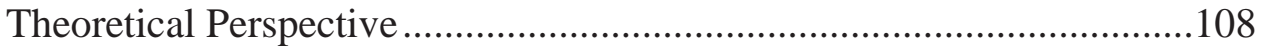

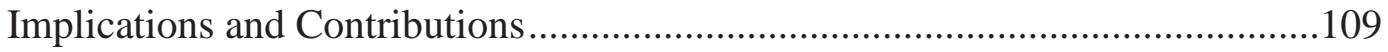

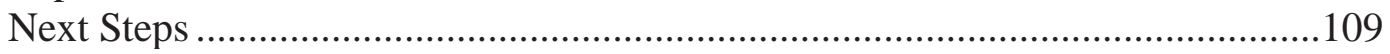

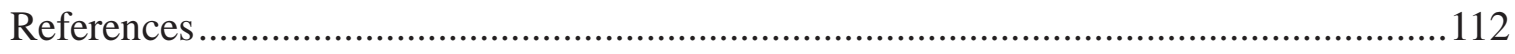

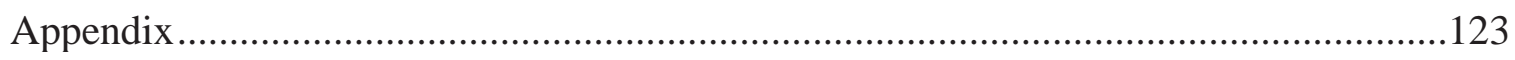

Abbreviations and Brief Descriptions of Models Available in mclust................123 
List of Tables

Table

1 Summary of National Education Goals Panel School Readiness Dimensions

2 Summary of Person-Centered School Readiness Profiles Found in

Previous Studies

3 Descriptive Statistics of School Readiness Profile Components ..............................57

4 Correlations of School Readiness Profile Components and Outcome Scores .............58

5 Descriptions of Potential Cluster Solutions .........................................................63

6 Means and Standard Deviations of School Readiness Components by Profile...........66

7 Intra-Class Correlations (ICCs) for Outcome Variables .............................................72

8 Frequencies and Percentages or Means of Demographic Variables by School Readiness Profile ............................................................................. 77

9 Multinomial Regression of Profile Assignment on Race..........................................79

10 Multinomial Regression of Profile Assignment on Ethnicity ...................................8

11 Multinomial Regression of Profile Assignment on PreK Care .................................81

12 Multinomial Regression of Profile Assignment on Sex.........................................82

13 Multinomial Regression of Profile Assignment on SES .........................................83

14 Multinomial Regression of Profile Assignment on Primary Language Spoken

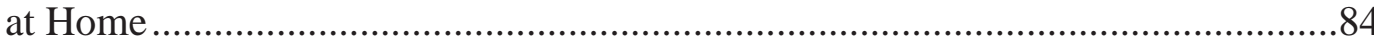

15 Person-Centered and Variable-Centered Predictive Models .....................................91

16 Secondary Person-Centered and Variables-Centered Predictive Models ....................93

17 Means and Standard Deviations of Spring Scores by Profile ..................................95 
PROFILES OF SCHOOL READINESS viii Figure Page

1 Head Start Early Learning Framework ..............................................................10

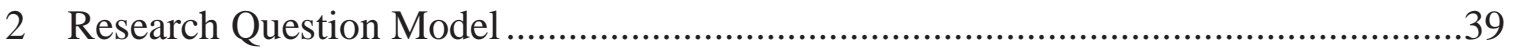

3 Theoretical Perspective for Research Question Three ............................................45

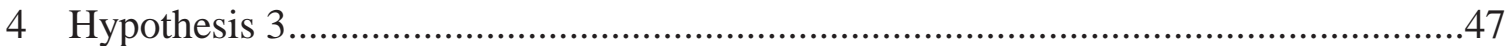

5 Histograms of School Readiness Components for Cluster Analysis ..........................50

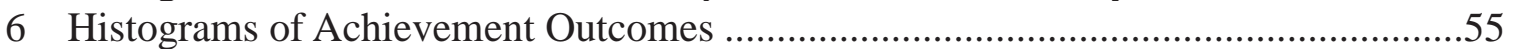

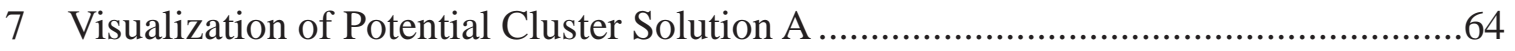

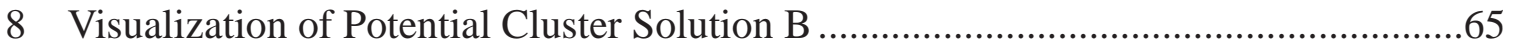

9 Visualization of Fall School Readiness Components by Profile ...............................67

10 Model Estimated Math and Reading Difference Scores by Profile ............................94

11 Model Estimates Social, Engagement, and Self Control Difference Scores

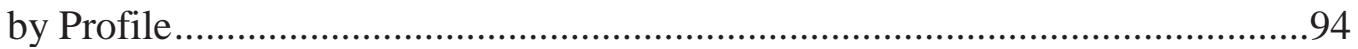

12 Fall and Spring Mean Levels of Math by Profile ................................................96

13 Fall and Spring Mean Levels of Reading by Profile..............................................96

14 Fall and Spring Mean Levels of Social Skills by Profile ...........................................97

15 Fall and Spring Mean Levels of Engagement by Profile ........................................97

16 Fall and Spring Mean Levels of Self Control by Profile .........................................98 


\section{Chapter One: Problem Statement}

\section{The Gap Problem}

Problem Statement. Academic achievement gaps exist across racial, ethnic, and socioeconomic groups as soon as children enter kindergarten: marginalized groups such as racial minorities, Hispanics, and poor children begin school at a distinct disadvantage compared to their White peers from middle- and high-income families (Chatterji, 2005; Fryer, Jr. \& Levitt, 2004; Magnuson, Meyers, Ruhm, \& Waldfogel, 2004; Magnuson \& Waldfogel, 2005; Reardon, 2011). One might suppose that once children are in school and having similar experiences, achievement disparities may disappear across time. Unfortunately, this is not the case. The size of the achievement gaps may vary across a child's educational career, but gaps themselves do not go away (Clotfelter, Ladd, \& Vigdor, 2006; Fryer, Jr. \& Levitt, 2004; Lee, 2002). Furthermore, these gaps have historically grown over time, such that the gaps of today are 30 to 40 percent larger today than they were 25 years ago (Reardon, 2011). It seems that educational policies designed to alleviate these gaps, such as the No Child Left Behind Act first implemented 2001, are not effectively changing experiences of poor, marginalized children in ways that allows them to catch up to their more advantaged peers.

\section{The Answer is School Readiness}

To begin to address the gaps that exist at school entry, researchers must first understand the skills with which children enter kindergarten. What developmental tools do children need to successfully transition into school and begin a strong trajectory of school achievement? How do children develop the skills that can help them in 
PROFILES OF SCHOOL READINESS

kindergarten prior to entering school? Are there systematic differences in the skill sets of children from different backgrounds that may begin to explain the initiation and propagation of achievement gaps across time?

Defining and exploring school readiness has been a prevalent goal of early education policy makers and researchers for the last 30 years. However, the research on entering kindergartner's school readiness skills thus far has been limited by a number of factors. First, the manner in which success in school has been defined and measured is limited almost entirely to academic achievement outcomes. While few can deny that learning how to read, write, and practice 'rithmatic is a primary goal of attending school, researchers and practitioners argue that are other potential indicators of success in school, such as the development of social and communication skills, engagement in school, involvement in school activities, attitudes toward learning, and rates of dropout (Blair \& Raver, 2015, Duncan et al., 2007; Pagani, Fitzpatrick, Archambault, \& Janosz, 2010; Raver \& Knitzer, 2002).

The focus of school readiness research on academic achievement outcomes is potentially due to the academic focus of education policy. In the last century, schools have come to be viewed as factories: standardized tests are used to measure the quality of the "product" (Callahan, 1962). Recent educational policies like No Child Left Behind and the push towards common educational standards reiterate this viewpoint by neglecting to supply non-academic standards for success (Bush Administration, 2001; Common Core State Standards Initiative, 2010). Policies like these have set an expectation for researchers to determine how to best optimize the quality of academic 
PROFILES OF SCHOOL READINESS

"product." As a result, research that gives priority to academic achievement in the school setting may likewise receive funding and publication priority. Education and

developmental researchers may be responding to policies' demand by supplying research questions in line with its priorities.

As a result, factions of both research and policy have concluded that the most important indicators of school readiness are those that support academic development primarily early academic skills (Bush Administration, 2001; Duncan et al, 2007; Raver \& Knitzer, 2002; Snow, 2006). This priority has in turn been communicated to parents and kindergarten teachers, such that kindergarten classrooms and home environments are becoming more academically focused than they used to be (Bassok, Latham, \& Rorem, 2015). This systematic change, however, is being implemented without thought to its effect on other potential indicators of school readiness, such as social-emotional skills (Raver \& Knitzer, 2002).

Another limitation of current studies of school readiness is the tendency for researchers to look at indicators of school readiness in a variable-centered manner. Individual indicators of school readiness are conceptually and methodologically isolated in an attempt to determine their unique contribution to later development (Duncan et al., 2007; Duncan \& Magnuson, 2011). While this technique can offer compelling evidence in support of individual school readiness skills, its tendency towards reductionist thinking may limit the conclusions one can make regarding school readiness as a holistic construct (Halle, Hair, Wandner, \& Chien, 2012; Wesley \& Buysse, 2003). In the practical setting of the kindergarten classroom, each child entering school has their own specific set of 
school readiness skills they bring with them every day. A child's school readiness skills may interact with each other in unique ways. By isolating the effects of certain school readiness skills at the variable level and generalizing the effect of these variables to all children, researchers may be overlooking the patterns in which school readiness skills can work together within an individual child.

The limitation of variable-centered school readiness analyses is twofold: not only can it limit the way researchers conceptualize and understand the phenomenon of school readiness, it can limit the ability for research findings to be disseminated to early education stakeholders. Kindergarten teachers do not see variables: kindergarten teachers see children. Providing kindergarten teachers, parents, politicians, and researchers with solely variable-centered research findings can limit their ability to comprehend and make practical, research-informed changes to their practices and policies based on the findings. Studies that instead examine school readiness skills at the level of the child may offer information that is more understandable, meaningful, and relevant to stakeholders in early childhood education and the kindergarten transition.

For these reasons, it is important for research on school readiness to begin a trend towards person-centered analyses. According to Roeser, Eccles, and Sameroff (2000), person-centered analytic techniques aim to detect patterns in the configurations of skill sets individuals possess. In the context of school readiness, person-centered analyses allows researchers to identify the common patterns of school readiness skills with which children enter kindergarten. This perspective is congruent with the manner in which parents and teachers view their kindergartners: as whole individuals. As the 
dissemination of research to parents, teachers, and policy makers is essential for the improvement of practice, person-centered approaches to the study of school readiness are the way of the future (Wesley \& Buysse, 2003).

\section{The Current Study}

The goal of this study was take a person-centered, multidimensional approach to the study of school readiness. Using innovative analytic techniques, I defined common patterns - or profiles - of school readiness skills that children have upon school-entry. I explored the predictive potential of these school readiness profiles, not only focusing on the academic indicators of school success, but also on children's social skills and engagement behaviors in the classroom that support the learning process. Finally, I determined if the findings of my person-centered approach to school readiness offer unique conclusions compared to a traditional variable-centered approach. The findings of this study offer intuitive conclusions about patterns of school readiness to parents, teachers, and policymakers, and provide support for a movement towards personcentered approaches to school readiness that can better influence both policy and practice. 
Chapter Two: Literature Review

Chapter One introduced school readiness as an issue of national concern and reviewed its practical importance as a focus of study. This chapter explores the evolution of school readiness as a construct in the education and psychology literatures, expanding on its predictive ability and the theoretical mechanisms of longitudinal school success. The first section of this chapter, School Readiness, describes the variety of definitions of school readiness used by policy makers, practitioners, parents, and developmental researchers and the demographic and experiential antecedents of school readiness. The second section, Developmental Perspectives of School Readiness, describes the empirical evidence of school readiness as a predictive indicator of school success. The final section, Where We Need to Go, reviews the methodological and conceptual limitations of previous work, introduces the conceptual framework of person-centered analysis, and proposes that framework as the ideal method of studying school readiness.

\section{School Readiness}

\section{Definition of School Readiness.}

In 1989, the National Education Goals Panel declared that by 2000, every child would enter school ready to learn (National Education Goals Panel, 1999). This announcement introduced the concept of school readiness to the national spotlight and sparked a growing emphasis on defining a successful entry to school by educational stakeholders, including policy makers, developmental researchers, and educators (Blair, 2002; Raver, 2002; Rimm-Kaufman, Pianta, \& Cox, 2000). There are many ways a child may be deemed ready to enter kindergarten: they may know their ABCs and 123s; they 
PROFILES OF SCHOOL READINESS

may be able to cooperate with peers; they may be able to follow directions; they may be able to hold a pencil. These different domains of development had been studied separately, but had yet to be conceptualized in a unified manner (Snow, 2006). The multidimensional nature of school readiness has made it difficult for facets of the educational community to come to a consensus about which skills a child must possess to successfully begin elementary school.

From early in its conceptualization, school readiness has been viewed multidimensionally. In 1995, the National Education Goals Panel (NEGP) outlined five dimensions of school readiness: 1) Physical well-being and motor development; 2) Social and emotional development; 3) approaches toward learning; 4) Language development; and 5) Cognition and general knowledge. A table summarizing these dimensions is included in Table 1.

The first dimension addresses a child's maturational preparedness for the kindergarten classroom. It includes indicators of physical development (e.g., rate of growth, physical fitness, and body physiology) and physical abilities (e.g., fine, gross, sensorimotor, and oral motor skills). The second dimension addresses a child's ability to interact with the adults and fellow children in the kindergarten classroom. It includes indicators of emotional development, such as knowledge of emotions in oneself and understanding those emotions in others, and indicators of social development, such as an ability to communicate with adults and cooperate and form friendships with peers.

The third dimension, approaches toward learning, is the most abstract of the five dimensions. It includes a child's learning disposition, or how they approach and engage 
Table 1

Summary of National Education Goals Panel School Readiness Dimensions

Dimension

Physical Well-Being and Physical Development - Rate of growth; physical fitness; body physiology

Motor Development

Social and Emotional

Development motor skills

Emotional De velopment - Self Concept (e.g., emotions; self-appraisal); comprehending feelings of others
Physical Abilities - Gross motor skills; fine motor skills; sensorimotor skills; oral

Social Development - Form and sustain social relationships with adults and peers; cooperate with peers; understand and identify adult roles

Approaches Toward

Learning

Predispositions - Gender; temperament; cultural patterns and values

Learning Styles - Openness to and curiosity about new tasks; initiative; task persistence; and attentiveness; reflection and interpretation; imagination and invention; cognitive styles

Language Development Verbal Language - Listening; speaking; social uses of language; vocabulary and meaning; questioning; creative use of language

Eme rging Literacy - Literature awareness; print awareness; story sense; writing process

Cognition and General

Knowledge

Physical Knowledge - Knowledge of objects in external reality learned by observation and experience with the objects

Logic-Mathematical Knowledge - Knowledge that establishes similarities, differences, and associations between objects, events, or people

Social-Conventional Knowledge - Knowledge that reflects agreed-upon conventions of society

Cognitive Capacities - Representational though; problem-solving; mathematical knowledge; social knowledge; imagination

with learning tasks in the classroom. Some examples of this dimension's indicators include openness to new tasks and challenges, imagination and innovation, and task persistence. The NEGP stress that a child's learning style is dependent upon his or her temperamental predispositions (e.g., cautious or stubborn) and family's cultural patterns and values.

The fourth dimension addresses a child's ability to communicate in the 
kindergarten classroom. It includes a child's use of verbal language (e.g., listening and speaking, vocabulary, creative use of language) and their emerging literacy skills (e.g., story sense, print awareness, ordered scribbling).

The final dimension addresses the general knowledge that a child has gained through their experiences prior to beginning kindergarten. These categories of knowledge include physical knowledge (e.g., physical properties of objects), logic-mathematical knowledge (e.g., similarities and differences between objects), social-conventional knowledge (i.e., general conventions of society), and general cognitive competencies, such as representational thought, cause and effect, and imagination.

These dimensions outlined by the NEGP have served as the basic framework for defining the phenomenon of school readiness. The majority of subsequent attempts to define school readiness have used these dimensions as their foundation. For example, the Head Start Child Development and Early Learning Framework (ELF) has expanded on the five original NEGP dimensions (Administration for Children and Families, 2015; Office of Head Start, 2012; Office of Head Start, 2011). A figure describing the ELF is included as Figure 1. The first dimension of physical well-being and motor development remained the same in the ELF's conceptualization of school readiness, focused on physical health and the development of gross and fine motor skills. The second dimension of social and emotional development also remained similar to the original NEGP dimension, focusing on social emotional competencies with adults and peers in the classroom (Office of Head Start, 2012). 
Figure 1. Head Start Early Learning Framework (Office of Head Start, 2011)

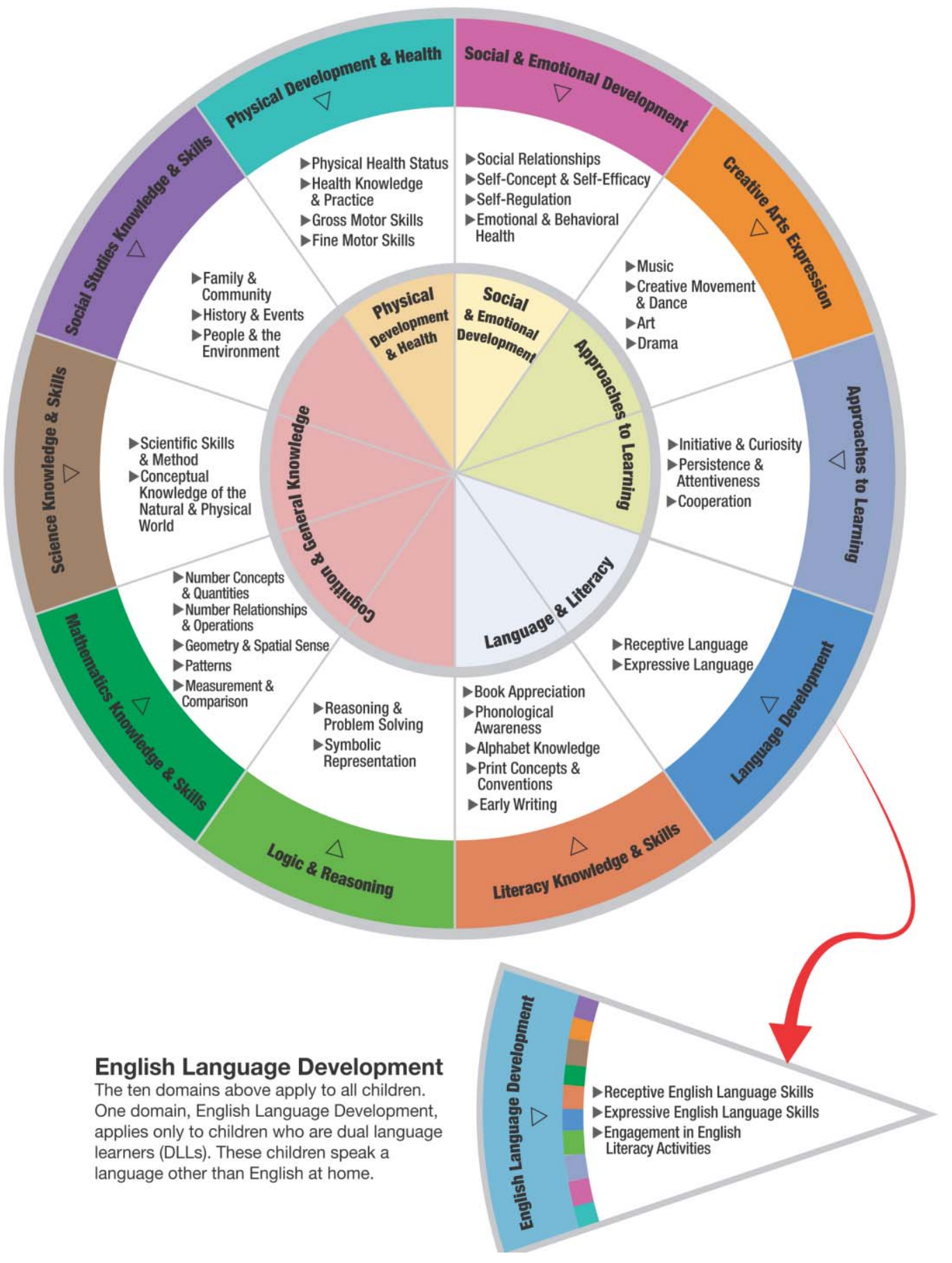

The ELF has expanded on the NEGP dimension of approaches toward learning by incorporating the developmental concepts of emotional, behavioral, and cognitive self- 
regulation. Goals within the domain of approaches toward learning set forth by the ELF include that a child "manages actions, words, and behavior with increasing independence", "sustains attention with minimal adult support", and "holds information in mind and manipulates it to perform tasks" (Administration for Children and Families, 2015, p. 18-19). This expansion not only clarifies the most abstract component of the NEGP dimensions, but also addresses the goals set forth by the 2005 NEGP publication to incorporate the (at the time) burgeoning concept of self-regulation and executive function.

NEGP's fourth dimension of Language Development remains largely the same in the ELF, but the ELF adds that children should display book appreciation (Office of Head Start, 2012) and be able to attribute meaning to early writing attempts and communicate this representative meaning to others (Administration for Children and Families, 2015).

Finally, the most recent iteration of the ELF has divided the components of the NEGP's fifth dimension of General Cognition into two sub-domains: early mathematical thought and early scientific reasoning. The first sub-domain includes both early numeracy skills (e.g., cardinality, measurement, and basic operations) and physical/spatial sense (e.g., describing and exploring objects in space). The second subdomain includes components of scientific inquiry and reasoning (e.g., comparing and contrasting observable phenomena) and problem-solving (e.g., planning; Administration for Children and Families, 2015).

\section{Antecedents of School Readiness.}

Each child entering school brings with them a metaphorical suitcase. One section 
of this suitcase includes a toolbox filled with their own set of readiness skills as defined by the NEGP and ELF; the other compartments are filled to the brim with the child's accumulated experiences that have influenced their development up to the point of school entry and built their combination of readiness skills. According to bioecological theories of development, the experiences that shape one's development are increasingly "complex reciprocal interaction[s] between an active... organism and the persons, objects, and symbols" in one's environment. (Bronfenbrenner, 1994, p. 38). Bronfenbrenner, the father of bioecological theory, called these interactions proximal processes. According to Bronfenbrenner and Morris (1998), to be effective at promoting development, proximal processes must take place on a regular basis, over an extended period of time. These activities must become more complex over time and be bidirectional, such that both the child and the person, object, or symbol must play an active role in the interaction. It is through interactions with these characteristics (or lack thereof) that children develop their set of readiness skills before entering school.

As proximal processes are dependent upon interactions between "persons, objects, and symbols" within one's environment, it stands to reason that each entering kindergartner has an entirely unique history of proximal processes, shaped by the nature and quality of their interactions with peers, adults, and materials that occurred prior to school entry. Consider Jamal: Jamal is a child of middle class parents; both of Jamal's parents have college degrees and work full-time jobs. His parents have arranged for him to attend an all-day preschool program while they are at work; his preschool teachers have training in child development and provide warm, developmentally-appropriate 
cognitive, emotional, and social stimulation for Jamal and his peers. In his preschool program, Jamal develops a familiarity with the school routines, learns how to make friends with other children his own age, and forms positive relationships with adults other than his parents. After Jamal's parents pick him up, he comes home to a safe, inviting home, has a nutritious dinner, and plays with some exciting toys before reading a bedtime story (or two) with both his parents. As time goes on, the toys at home and school become more complex and require more of Jamal's concentration; he becomes more aware of the children around him and develops a deeper understanding of other children's opinions and needs; he becomes more familiar with the plots of the stories his parents read him every night that soon he is telling the story to them. These interactions are developmentally appropriate, occur on a regular basis, are bidirectional in nature, and become more complex across time. When it comes time for Jamal to enter kindergarten, he brings the history of high quality proximal processes with him in his metaphorical suitcase.

Now, consider Sarah. Sarah is the child of a single mother who works two fulltime jobs. Her mother cannot afford to send Sarah to a center-based child care center, but Sarah's grandmother is available to watch Sarah while her mother is at work. She occasionally goes to the park with her grandmother, but since her grandmother is not as mobile as she used to be and is a bit self-conscious about her broken English, the two of them often stay home together throughout the day. There is not a lot of money for toys and other materials at home, but Sarah enjoys helping her grandmother with every-day activities like cooking and grocery shopping. During these activities, Sarah gains 
familiarity with following directions and routines, but her grandmother rarely explicitly connects these activities to skills such as counting or measuring. Sarah eats consistent meals, but these meals often consist of processed foods, and fresh vegetables make only rare appearances. Her mother mostly comes home after Sarah is already sleeping, but her grandmother puts her to bed with a story she remembers from her childhood. While Sarah's interactions with her family are warm and loving, the environment around her is relatively stagnate. Due to the family's limited financial and energy resources, there are few opportunities for Sarah to engage in activities that become increasingly complex over time. When it comes time for Sarah to enter kindergarten, she brings the history of these proximal processes - processes of inconsistent quality - with her in her metaphorical suitcase.

Jamal and Sarah will each enter kindergarten with their own combinations of school readiness skills as shaped by their preschool experiences: based on these experiences, Jamal has most likely developed skills that better prepare him for the expectations of the kindergarten classroom than Sarah. Unfortunately on the national level, there are systematic trends of discrepancies in the quality of preschool experiences across different demographic groups, particularly across racial and socioeconomic lines.

Evidence of gaps in preschool experiences by racial and socioeconomic groups. As noted in the previous chapter, gaps in indicators of school readiness exist across all dimensions as defined by the NEGP and ELF at kindergarten entry. These gaps exist across a variety of demographic categories (Janus \& Duku, 2007; Lee, 2002; Nill \& West, 2001; Reardon, 2011). This section will overview these gaps and connect them to 
the antecedent experiences that shape children prior to entering school.

Children's physical health and development prior to kindergarten are determined by a number of factors, in particular mother's pre- and post-natal health, proper nutrition, minimal exposure to harmful substances, and appropriate stimuli through which to develop gross and fine motor skills (Currie, 2005; Grissmer \& Eiseman, 2008; Grissmer, Grimm, Aiyer, Murrah, \& Steele, 2010; Janus \& Duku, 2007). These pre-kindergarten experiences are shaped in part by parental education: parents must be aware of potential health risks and developmentally appropriate practices to optimally support their child's health. These experiences are also due in part to available resources: access to quality materials such as nutritious foods and healthcare are highly dependent upon socioeconomic and community factors (Currie, 2005; Magnuson \& Waldfogel, 2005).

Unfortunately, disparities in the antecedents of physical development exist at the beginning of kindergarten across socioeconomic and, therefore, racial groups, as children of marginalized racial groups are more likely than White children to come from poor families (Currie, 2005; Grissmer \& Eiseman, 2008; Janus \& Duku, 2007; Magnuson \& Waldfogel, 2005). Families with lower incomes are more likely than other groups to live in cities and be exposed to environmental hazards; poor families receive less medical care than families living above the poverty line; poor mothers are more likely to experience their own health problems (e.g., depression) and less likely to engage in research-supported health practices (e.g., breastfeeding) than mothers with higher available incomes (Currie, 2005).

In an effort to minimize the gaps in physical health at school entry, a range of 
PROFILES OF SCHOOL READINESS

early childhood intervention programs and public policies have made an effort to provide at-risk children with health resources. Publicly-funded Head Start, for example, provides an opportunity for children of low-income families to obtain comprehensive health and nutrition services (Magnuson et al., 2004; Magnuson \& Waldfogel, 2005). National healthcare reform has made health insurance more available to low-income families (Janus \& Duku, 2007; Obama Administration, 2015b). However, to best utilize these social services, low-income parents "must be knowledgeable and tireless advocate for their children"; it is not surprising that low-income parents may struggle to procure all the services that their child is be eligible for and needs (Currie, 2005, p. 130).

Just as there exists a gap in health and physical development across racial and socioeconomic lines at school-entry, there also exists gaps in the higher-order skills of early literacy and numeracy (Chatterji, 2005; Fryer, Jr. \& Levitt, 2004; Magnuson, et al, 2004; Magnuson \& Waldfogel, 2005; Reardon, 2011). Researchers have attributed these gaps to disparities in preschool experiences across racial and socioeconomic groups. Reardon (2011) notes that parents of both middle- and low-income families have become increasingly aware of the intellectual development of their children, as policies requiring early childhood standardized testing became more ubiquitous; however, these parents differ in their actions regarding this knowledge. Middle- and upper-class parents are more likely to engage in "concerted cultivation" - or specific training - of these early academic skills than are low-income parents (Reardon, 2011, p. 19). Discrepancies in early learning opportunities are connected to both systematic differences in the quality of home learning environments (Magnuson, et al, 2004) and the quality of center-based preschool care 
PROFILES OF SCHOOL READINESS

available to members of different socioeconomic groups (Magnuson \& Waldfogel, 2005).

Children's home environments are a primary location for proximal processes that support early learning. However, across socioeconomic groups, there are systematic trends that may put children from poor families at a disadvantage. For example, children from poor families have fewer books at home and spend less time reading and having stimulating interactions with their primary caregivers (Chitterji, 2005; Magnuson et al., 2004). These differences speak to a gap in resources available to low-income and highincome families: low-income parents have lower levels of education than parents with higher incomes; they are more likely to primarily speak a language other than English, which can limit the types of interactions with their child and their ability to take advantage of services; they are more likely to have their own health issues than highincome parents; they are more likely to work non-traditional hours and may have less time and attention available for interactions with their children; they are less able to fill their homes with stimulating materials for their children (Currie, 2005; Janus \& Duku, 2007; Magnuson \& Waldfogel, 2005; Reardon, 2011; Zill \& West, 2001).

Enrollment rates in early childhood education programs are different across racial and ethnic groupings, in some surprising ways: Black children are more likely to be enrolled in center-based care programs than White children, who are in turn more likely to be enrolled than Hispanic children (Magnuson \& Waldfogel, 2005). However, the programs in which Black and Hispanic children are enrolled are different types of programs than those in which White children are enrolled. Black and Hispanic children are more likely that White children to have low-income parents, and therefore are more 
likely to attend federally-funded early childhood care programs, such as Head Start.

The inconsistent effects on early math and reading skills at school entry from publicly funded preschool programs may be due to the inconsistent quality of the program structure and proximal processes that take place within these programs. In terms of structural indicators of quality, public preschool programs are less likely to have teachers who hold four-year degrees and offer lower teacher salaries than private preschool programs (Magnuson \& Waldfogel, 2004). Numerous studies have determined that the quality of teacher and child interactions that take place in a preschool setting greatly influence child outcomes (Burchinal, Vandergrift, Pianta, \& Mashburn, 2010; Mashburn et al., 2008). It may be that structural indicators of quality, such as teacher education and pay, may constrain the quality of teacher-child interactions within public programs compared to private programs (Fryer Jr. \& Levitt, 2004; Magnuson \& Waldfogel, 2004).

\section{Evidence of sex differences in social-emotional and self-regulatory skills at}

kindergarten entry. While there are differences in the levels of social, emotional, and self-regulatory skills across socioeconomic and racial groups (Reardon, 2011) - for reasons similar to the existence of health and academic discrepancies - differences in these skills across boys and girls are also quite apparent at school entry (Matthews, Pontiz, \& Morrison, 2009; Ostrov \& Keating, 2004; Schmidt, Demulder, \& Denham, 2002).

At school entry, teachers rate boys and girls differently on a number of key social behaviors: specifically, boys are more likely to display aggressive, anxious, and 
withdrawn behaviors in the classroom than their female counterparts, and girls are more likely to comfort, help, and form friendships with their classmates than their male counterparts (Schmidt et al., 2002; Zill \& West, 2001). This is not to say that girls are not aggressive; there are, however, consistent sex differences in the type of aggression displayed in the classroom. In a study observing aggressive behavior in a preschool classroom, boys were more likely to display both physical and verbal aggression than their female counterparts. However, girls were more likely to be relationally aggressive with their peers (e.g., telling a friend to not play with another child; Ostrov \& Keating, 2004).

At school-entry, sex differences in self-regulatory skills are detected by both teachers and direct measurement. Teachers report that girls in their classrooms are better able to pay attention well and persist through tasks than boys (Zill \& West, 2001). This does not mean that there are not boys who are able to regulate their behavior well. Rather, boys are more varied in their abilities to regulate their behavior in the classroom than are girls. While the boys who are best able to regulate their behavior are on par with the girls who are best able to regulate their behavior, the boys who struggle the most are considerably worse at regulating their behavior than the girls who struggle the most with regulatory tasks (Matthews et al., 2009).

The causes of sex differences in social, emotional, and self-regulatory skills at the beginning of kindergarten are less identifiable than gaps due to socioeconomic factors. Differences in temperament across sexes are detectable shortly after birth and maintain longitudinally, suggesting a genetic influence (Else-Quest, Hyde, Goldsmith, \& Van 
Hulle, 2006). While differences in the quality of teacher- and parent-child interactions across sexes are less examined than differences across socioeconomic and racial lines, some researchers theorize that parents are more likely to engage in instructional activities with female children than male children. These systematic socialization influences may provide girls with more opportunities to practice social and self-regulatory skills than boys (Ostrov \& Keating, 2004). Whatever the reasons for these differences - innate temperament differences or socializing environmental effects - it remains that girls are more likely than boys to be able to meet the social, emotional, and self-regulatory expectations of a kindergarten classroom.

\section{Stakeholder Perspectives on School Readiness.}

While the multidimensional definition of school readiness as defined by the NEGP and the ELF are generally accepted by researchers, early learning practitioners, and policy-makers, the three groups have historically prioritized different facets of school readiness as most important for school success (Snow, 2006). In this section, I will review the perspectives of school readiness as articulated by kindergarten teachers and parents, politicians, and researchers.

Practitioners of early education tend believe that school readiness skills that impact how a child behaves in the classroom are more important for kindergarten success than early academic skills. For example, Lin, Laurence, \& Gorrell (2003) interviewed over 3,000 kindergarten teachers to examine their school readiness beliefs and found that they emphasize the need for children to be ready for the social challenges of the classroom, particularly those involving social communication. Lin et al. note that $83.9 \%$ 
PROFILES OF SCHOOL READINESS

of teachers said it is important that children "tell wants and thoughts." Kindergarten teachers also seem to have high expectations of entering kindergartners' self-regulatory skills in the classroom; Lin et al. reported that $78.6 \%$ of kindergarten teachers said that it is important that children are "not disruptive of the class", and $73.6 \%$ reported that it is important that children take turns and share at the beginning of kindergarten. It appears that teachers in this sample valued children's abilities to smoothly interact with the teachers, peers, routines, and tasks in the kindergarten classroom above their academic abilities.

Rimm-Kaufman, Pianta, and Cox (2000) similarly surveyed a large sample of kindergarten teachers on the transition into kindergarten. Again, kindergarten teachers displayed the trend of focusing on non-academic school readiness skills. For example, when asked about the skills with which their students entered the kindergarten classroom at school entry, $46.16 \%$ of teachers reported that about half their class entered kindergarten with difficulty following directions, while only $36.6 \%$ teachers report that about half the class entered kindergarten with a lack of academic skills.

Perhaps this self-regulatory deficit of incoming kindergartners has to do with conflicting school readiness beliefs between the kindergarten teachers and the parents of entering kindergartners. Diamond, Reagan, and Bandyk (2000) determined that the parents in their sample were more likely to emphasize academic skills than behavioral skills as important for school-entry, which conflicts with the priorities of kindergarten teachers, as recorded by Lin et al. (2003) and Rimm-Kauffman et al. (2000). West, Germino-Hausken, and Collins (1995) directly compared kindergarten teachers' and 
parents' understanding of the skills children need to successfully begin school. They reported that less than $10 \%$ of teachers in their sample believed it was important that children come into kindergarten counting to 20 or more, while $50 \%$ of parents viewed this as being important. This discrepancy suggests a misalignment between the goals parents have for their children prior to kindergarten and the expectations kindergarten teachers have of entering kindergartners.

Parents' opinions of school readiness not only differ from those of kindergarten teachers, they differ across parental levels of education and racial groups, as well. For example, the discrepancy noted by West, et al., (1995) varied by level of parent education, such that parents without college degrees rated the task of counting to 20 or more as more important for school readiness than did parents with college degrees. Diamond et al. (2000) also determined that non-White parents were more likely to express concern about their child being ready for kindergarten than White parents of entering kindergartners.

Government policy has a history of emphasizing the development of academic skills over other domains of development. For example, in his proposal to improve preschool education, President George W. Bush called "the development of healthy bodies, social competencies, and emotional health" an insufficient foundation for school readiness. He wrote that "to do well in school, each child must learn to understand and communicate with language, to recognize letters of the alphabet, and to hear the individual sounds in spoken language.” President Bush's well-known policy, No Child Left Behind, particularly emphasized early reading skills with the goal that all children 
would be able to read at grade level by third grade, a goal for which schools and districts would be held financially accountable (Bush Administration, 2001).

The political emphasis on academics as the strongest indicator of school readiness is not surprising, considering how success in school is defined and assessed. For example, the initiative for national educational standards, commonly referred to as the Common Core, describes solely academic standards for kindergarten students. There are no proposed standards for social-emotional or self-regulatory learning in the kindergarten classroom (Common Core State Standards Initiative, 2010).

A few recent national education policies have begun to turn attention toward nonacademic indicators of school readiness. For example, President Barack Obama's Race to the Top Early Learning Challenge focuses on providing "critical links with health, nutrition, mental health, and family support for our neediest children" (Obama Administration, 2015a). However, these policies are few and far between compared to policies that emphasize academic readiness, despite recommendations from some developmental researchers (Carlton \& Winsler, 1999; Raver \& Knitzer, 2002; Wesley \& Buysse, 2003).

\section{Developmental Perspectives of School Readiness}

School readiness and its connection to achievement outcomes has been investigated by developmental and educational researchers in a variety of ways, primarily encapsulating the school readiness dimensions of academic preparedness, 'approaches toward learning,' attention skills, and social-emotional skills at kindergarten entry. This section will provide a brief overview these longitudinal investigations and suggest a 
theoretical basis through which skills at school-entry may facilitate long-term development.

\section{Predictive Validity of School Readiness.}

Duncan and colleagues (2007) performed a robust meta-analysis exploring the predictive power of many indicators of school readiness. They obtained six data sets in which a variety of school readiness indicators were measured at school entry, including reading, math, and language achievement, attention skills - which included measures of self-regulation and approaches toward learning, depending on the study-, and socialemotional behaviors. These studies also included achievement outcomes assessed at key time points (i.e., third, fifth, or eight grade). In each of the data sets, they performed similar regression analyses, controlling for demographic characteristics.

Duncan et al. (2007) found a consistent pattern in their analyses: academic skills at school entry were the best predictors of later academic achievement. The best predictors of later reading achievement were reading skills assessed in the fall of the kindergarten year, and the best predictor of later math achievement was math skills assessed in the fall of the kindergarten year. School-entry math skills also consistently predicted later reading achievement, and vice versa.

In regards to non-academic school readiness skills, Duncan et al. (2007) found that attention skills and attention problems significantly predicted academic achievement about half the time across the studies. The coefficients of these skills assessed at schoolentry were smaller than those of the academic school-entry skills, but were the most consistent non-academic predictors of later achievement. Other non-academic school 
readiness skills were not consistent predictors of later academic achievement.

Duncan and colleagues (2007) report that, despite the admirable rigor of their meta-analysis, there exist a few notable limitations that are particularly relevant to the current study. First, they note that through their use of linear regression, they may have "over control[ed] for the academic-related impacts of attention and social-emotional skills" (p. 1440). Linear regression mathematically isolates predictors to determine their unique influence on the outcome; however, it is difficult to conceptualize early academic skills completely independent of attention skills and vice versa, particularly during developmentally-appropriate tasks for new kindergartners. For example, if a child is to successfully display her competence in early math skills, she must be able to maintain her attention to the task at hand. She also must communicate this skill to her teacher or assessor in appropriate ways; if she cannot attend to the task or communicate her knowledge in understandable ways, it may be assumed that she does not possess the knowledge, regardless of her actual competence.

Second, Duncan et al. (2007) recognize that their exclusive use of achievement outcomes may have limited their conclusions; non-academic skills may show more predictive potential for other indicators of school success or failure, such as classroom behaviors. An additional limitation lies in Duncan et al.'s conceptualization of attention skills. The measures of attention skills varied widely across the studies included in the meta-analysis. For example, Duncan et al. included measures of approaches toward learning, executive functions, and self-regulation as measures of attention skills. approaches toward learning as conceptualized by the NEGP and ELF is a complex 
dimension of school readiness that includes a child's ability to regulate their attention, behaviors, and emotions; their openness to new tasks; and their task persistence.

Including approaches toward learning measures in the attention skills category may have masked its other components.

Pagani, Fitzpatrick, Archambault, and Janosz (2010) performed a large scale replication and extension of the meta-analysis performed by Duncan et al. (2007) in a French Canadian population. Their replication findings were practically identical to the original work, providing further support for the role of early academic and attention skills. In their expansion, they addressed one of original study's limitations by adding a non-academic achievement outcome: teacher-rated engagement in the second-grade classroom. Pagani et al. (2010) found that attention and early math skills were significant predictors of classroom engagement, as they were of academic achievement outcomes. However, unlike in the case of academic achievement, children's prosocial skills were significant - if relatively small - predictors of engagement in the second-grade classroom. The findings of Pagani et al. support Duncan et al.'s (2007) concern about limiting outcomes of school readiness research solely to academic achievement. Indicators of social development at kindergarten entry show predictive power, above and beyond attention and academic skills, of important non-academic indicators of school success.

Many researchers have theorized and found support for the role of non-academic indicators of school readiness. In line with the Bronfenbrenner's bioecological theory of development, Mashburn and Pianta (2006) posit that the interactions between students 
and their teachers - and the relationships that forms from the pattern of these interactions - are the mechanisms through which children learn; the quality of the relationships that children form with their early teachers can shape children's development. Raver (2003) specifies that the quality of the relationship that form between a child and their teacher is dependent on their "ability to regulate emotions in prosocial versus antisocial ways" (p. 1). Furthermore, the quality of early teacher-child relationships, particularly the presence of negativity and conflict, are related to behavioral and academic outcomes as far out as the eighth grade (Hamre \& Pianta, 2001; Kwon, Kim, \& Sheridan, 2012; Ladd \& Burgess, 2001; Ladd, Heraldm \& Kochel, 2006). Raver and Knitze (2002) argue that, as the relationships that children are able to form with their teachers are dependent upon their own social and emotional competencies and predictors of later school success, educational policies should directly support strategies to optimize social and emotional development in the early childhood classroom.

The theoretical factor underlying non-academic school readiness skills discussed so far in this section is that of self-regulation. Attending to classroom activities requires regulation of one's attention: a child must maintain her attention on the classroom content, hold relevant rules and directions in mind while performing tasks, and inhibit her attentive impulses towards distracting stimuli (Blair, 2002). The effortful control of attention and attentional flexibility - specific regulatory aspects of attention - have been associated with later academic achievement (Blair \& Razza, 2007; Brock, RimmKaufman, Nathanson, \& Grimm, 2009; Rimm-Kauffman, Curby, Grimm, Nathanson, \& Brock, 2009). Behaving in socially appropriate ways in the classroom likewise involves 
regulation of one's emotions: when interacting with her peers and teachers, a child must

be able to judge when it is appropriate to express her emotions, regulate the expression of her emotions accordingly, and hold the emotions and opinions of others in mind (Blair 2002, Blair \& Raver, 2015). An organized emotional response to classroom stimuli characterized by well-regulated emotional responses and low emotional reactivity - can facilitate a child's ability to attend to classroom tasks and foster learning (Blair. 2002; Brock, Rimm-Kaufman, Nathanson, \& Grimm, 2009; Rimm-Kauffman, Curby, Grimm, Nathanson, \& Brock, 2009).

\section{Cognitive Load Theory and the Mechanisms of School Readiness.}

The previous section reviewed the longitudinal studies of key school readiness indicators. In the current section, informed particularly by research supporting regulation as a factor underlying kindergarten readiness, I will review a potential theoretical conceptualization of the mechanisms by which school readiness skills may impact longterm learning.

Higher-order cognitive processes that underlie and support regulatory behavior are called executive functions (EFs). EFs includes the coordination of working memory, attention, and inhibitory control for executing goal-directed activity, such as completing a classroom task (Zelazo, Carter, Reznick, \& Frye, 1997). To prepare the theoretical basis of the upcoming study, I will focus on the most fundamental of these EFs - working memory (WM).

Cognitive Load Theory (CLT) posits that there is a limit to what any one person can hold in their WM at any one time. The limited capacity of one's WM can be easily 
overwhelmed during complex learning tasks that involve multiple pieces of information.

For information to be passed into long-term memory, however, it must be processed by the WM. This means that when one's WM is overtaxed in the context of learning, longterm retention of the material may suffer (Paas, van Gog, \& Sweller, 2010).

When attempting to perform a task, there are two primary types of information held in one's WM: the information directly involved with the completion of the task (e.g., directions of the task and knowledge of how to use the materials) and extraneous information that is not related directly to the task at hand (Sweller, 1994). For a kindergarten student, an example of the former may be remembering the ways by which a kindergarten teacher wants blocks to be sorted, and an example of the latter may be remembering that it is important to keep one's hands to oneself. Extraneous information in the kindergarten classroom is often self-regulatory in nature.

If a child needs to keep a large amount of extraneous information in her WM, little WM capacity remains for essential task information. However, if a child only needs to dedicate a small amount of her WM capacity to extraneous information, there will be comparatively more capacity available to hold essential information.

I propose that it is in this way that school readiness skills may help facilitate learning across the kindergarten year. Children who enter kindergarten with key school readiness skills already developed will benefit by needing to hold less extraneous information in their WM than children who have not yet formed these skills, allowing a greater proportion of their WM capacity to be allocated towards essential classroom task information. Patterns of greater WM capacity allotted towards essential information 
PROFILES OF SCHOOL READINESS

across the kindergarten year can potentially account for long-term learning across

multiple developmental domains.

\section{Where We Need to Go}

The previous section reviewed some developmental perspectives on school readiness, highlighting the predictive validity of key school readiness skills, and proposed a potential theoretical framework for exploring the role of school readiness in developmental gains across the kindergarten year. The next section will critique the conceptual and methodological assumptions of the previous work and propose theoretical and practical solutions to these limitations.

\section{Conceptual Limitations of Previous Work.}

In past developmental explorations of school readiness, there have been inconsistent attempts to theoretically explain the mechanisms by which school readiness skills influence long-term learning. While research focused on social-emotional and selfregulatory school readiness constructs often articulates the mechanisms through which these constructs contribute to development, the same cannot be said of research primarily focused on early academic skills. Researchers rarely articulate how they believe early academic skills may influence later academic outcomes.

The vague and inconsistent conceptualization of 'approaches toward learning' is also a limitation of previous work. Recall that approaches toward learning - as described by the NEGP and ELF - is a complex dimension of school readiness that includes a child's ability to regulate their attention, behaviors, and emotions; their openness to new tasks; and their task persistence. Duncan et al. (2007) and others have included 
approaches toward learning measures primarily as indicators of attention, which may lead to overly simplistic conclusions of the concept's role in development across time.

Furthermore, school readiness skills have most often been examined independently of each other. In a practical setting, it is difficult to conceptualize children's academic skills independent of their abilities to attend to a task at hand or interact in appropriate ways with their peers. As noted by Duncan et al. (2007), there may be social-emotional and attentional components to academic skills that are difficult to detect when attempts are made to isolate the effects of these skills. There has been little conceptualization of how distinct school readiness skills may interact with one another to facilitate a child's learning. I am left wondering how different combinations of skills at school-entry may influence later development. Can the presence of certain school readiness skills compensate for the absence of or amplify the effects of others?

Finally, most attention has been paid to the role of school readiness skills in facilitating academic achievement outcomes. This limits our ability as researchers to thoroughly understand how school readiness skills contribute to the development of young children. To fully explain the role of school readiness, we must broaden our definition of school success in future work to include non-academic achievement indicators of school success.

\section{Methodological Limitations of Previous Work.}

The primary methodological limitation of previous work is the ubiquitous use of variable-centered analyses. Just as school readiness skills are often isolated conceptually, they are often statistically isolated in analyses. This tendency to isolate school readiness 
PROFILES OF SCHOOL READINESS

skills does not appropriately represent the phenomenon of school readiness as it occurs in the kindergarten classroom. Each child has a unique set of readiness skills that they bring with them when they enter kindergarten; these skills interact with one another within each child. The goal of research methods in applied settings should be to as accurately as possible represent a complex, real phenomenon. Variable-centered methods do not overtly acknowledge the way school readiness skills may interact within a child. By methodologically and conceptually isolating school readiness skills, researchers may be missing opportunities to discover mechanisms by which school readiness skills facilitate development.

\section{Person-Centered Analysis.}

The solution I propose to these conceptual and methodological limitations is to apply the use of person-centered analyses to investigate the role of school readiness in development. Person-centered analyses are analytic techniques that attempt to make the level of analysis the individual, as opposed to the individual's scores on measures of interest (a variable-centered approach). According to Roeser, Eccles, and Sameroff (2000), person-centered analytic techniques aim to show the "unique configurations" of skill sets an individual may possess (p. 448). These analyses can yield information about particular subgroups of individuals with distinct assets and vulnerabilities. In the context of school readiness, these techniques are alluring because they allow profiles of entering kindergartners to be formed based on multiple indicators of school readiness.

Until recently, the problem with person-centered analytic techniques existed at the methodological level. Cluster analyses, the primary method by which person-centered 
analyses are performed, had been based primarily on grouping heuristics (Everitt \& Hothorn, 2011). As a result, the use of cluster analysis posed some methodological conundrums, including but not limited to outcomes of analyses changing substantively depending upon the order of the data (Aldenderfer \& Blashfield, 1984). However, due to recent statistical innovations, person-centered analyses can now be more rigorously applied in the social sciences (Everitt \& Hothon, 2011).

In the past few years, researchers have started to apply person-centered analysis techniques to the context of school readiness. However, there are only a few of these studies to date, and the statistical rigor of the clustering techniques used is inconsistent. A summary of the five person-centered studies I highlight can be found in Table 2.

Konold and Pianta (2005) identified six school readiness profiles based on children's cognitive, social, and academic skills using hierarchical-agglomerative cluster analysis. Though this clustering technique is prey to the methodological conundrums I mentioned previously, Konold and Pianta were able to detect compelling patterns in school readiness. The profile names were primarily based on the strengths and weaknesses children brought with them into kindergarten (e.g., High Social Competence, Low Cognitive Ability). Though children entered with different strengths at school entry, levels of academic achievement at the end of first grade were positively predicted by membership to more than one profile; the authors suggest that this implies compensatory relations between school readiness skills. They posit that there is "more than one route to successful, or at least adequate, educational outcome" (p. 185). 
Table 2

Summary of Person-Centered School Readiness Profiles Found in Previous Studies

\begin{tabular}{|c|c|c|}
\hline Study & School Readiness Components & Profiles of School Readiness \\
\hline $\begin{array}{l}\text { Konold \& } \\
\text { Pianta (2005) }\end{array}$ & $\begin{array}{l}\text { Social } \\
\text { social skills, } \\
\text { positive engagement, } \\
\text { externalizing } \\
\text { Cognitive } \\
\text { memory for sentences, } \\
\text { incomplete words, } \\
\text { omission errors }\end{array}$ & $\begin{array}{l}\text { 1) Attention Problems } \\
\text { 2) Low Cognitive Ability } \\
\text { 3) Low/Average Social and Cognitive Skills } \\
\text { 4) Social and Externalizing Problems } \\
\text { 5) High Social Competence } \\
\text { 6) High Cognitive Ability/Mild Externalizing }\end{array}$ \\
\hline $\begin{array}{l}\text { Hair et al. } \\
(2006)\end{array}$ & $\begin{array}{l}\text { physical well-being, } \\
\text { social-emotional development, } \\
\text { language development, } \\
\text { cognition and general knowledge, } \\
\text { approaches to learning }\end{array}$ & $\begin{array}{l}\text { 1) Comprehensive Cognitive Development } \\
\text { 2) Social and Emotional Health Strengths } \\
\text { 3) Social/Emotional Risk } \\
\text { 4) Health Risk }\end{array}$ \\
\hline $\begin{array}{l}\text { McWayne et } \\
\text { al. (2009) }\end{array}$ & $\begin{array}{l}\text { general cognition, } \\
\text { approaches to learning, } \\
\text { behavior problems }\end{array}$ & $\begin{array}{l}\text { 1) Low general skill/ high approaches to learning } \\
\text { 2) Average/ low average behavior problems } \\
\text { 3) Average general skill/ high approaches to learning } \\
\text { 4) High average general skill/ averages approaches to learning } \\
\text { 5) Low approaches to learning/ high behavior problems } \\
\text { 6) Low general skill/ low approaches to learning } \\
\text { 7) High average general skill/ low behavior problems }\end{array}$ \\
\hline $\begin{array}{l}\text { Halle et al. } \\
(2012)\end{array}$ & $\begin{array}{l}\text { health, } \\
\text { approaches to learning, } \\
\text { language, } \\
\text { cognitive, } \\
\text { socio-emotional }\end{array}$ & $\begin{array}{l}\text { 1) Socio-emotional Risk } \\
\text { 2) Cognitive Risk } \\
\text { 3) Cognitive Strength } \\
\text { 4) Approaches to Learning Strength }\end{array}$ \\
\hline $\begin{array}{l}\text { Mascareno } \\
\text { et al. (2014) }\end{array}$ & $\begin{array}{l}\text { language, } \\
\text { arithmetic, } \\
\text { work attitude }\end{array}$ & $\begin{array}{l}\text { 1) Academically and socially competent } \\
\text { 2) Moderate academic skills and high social engagement } \\
\text { 3) Moderate academic and social skills } \\
\text { 4) Low academic skills and moderate social behaviors } \\
\text { 5) Moderate academic skills and socially troubled }\end{array}$ \\
\hline
\end{tabular}

Hair, Halle, Terry-Human, Lavelle, and Calkins (2006) created profiles based on the NEGP school readiness frameworks and found four distinct patterns of readiness based on children's health, social-emotional skills, and language and cognition skills. The authors found that generally the children coming in with high levels of all four school readiness skills performed better on achievement outcomes in first grade, while those with risks (particularly health risks) were at a disadvantage during first grade. Using the 
more rigorous clustering technique of Latent Class Analysis and adding attention regulation to the definition of school readiness, the same primary researchers again found four distinct profiles of readiness in Head Start children, with attentional skills and approaches toward learning tasks the most distinguishing component of the profiles (Halle, Hair, Wandner, \& Chein, 2012). Halle and colleagues examined how children transitioned between readiness profiles across time; they found the many children eventually moved into a profile defined by strengths rather than weaknesses. These findings support Konold and Pianta's conclusion that there are multiple way to success.

In 2009, McWayne, Green, and Fantuzzo compared person-centered approaches with variable-centered approaches in their study of school readiness. They used personcentered analysis to identify seven profiles of school readiness using the components of general cognition, approaches toward learning, and behavior problems. They further grouped their profiles into competent, risky, and overlapping (a mix of strengths and weaknesses) profiles. They then compared the predictability of their profiles to a traditional variable-centered approach and determined that the person-centered approach offered unique insight, particularly for the children who fell within the overlapping profiles. Children in the low general skill/low approaches toward learning profile, for example, did not come into academic trouble until the end of first grade: this finding was not apparent in their variable-centered approach.

Finally, in 2014 Mascareno, Doolaard, and Bosker performed a similar procedure with kindergartners in the Netherlands, identifying five profiles. They found that while strong social skills and classroom behaviors were not enough to fully compensate for 
PROFILES OF SCHOOL READINESS

severe academic deficits in kindergarten (as suggested in Konold \& Pianta, 2005), they

did seem to provide a boost for children with moderate academic skills. These findings

again suggest a compensatory interplay between different school readiness skills.

Though these studies have come to different conclusions depending on the methods and indicators of school readiness used, they share the primary advantage of person-centered analyses: the level of analysis is the person, not their levels on individual measures. As a result, these studies conceptualize school readiness in a way that facilitates intuitive communication to stakeholders. Teachers, politicians, and parents can better understand the findings of these studies, because they can look within real classrooms and see children who fall into these intuitive groups.

The conclusions that I draw from this section are that 1) person-centered analytic techniques are a potentially useful way to represent compensatory relations among cooccurring school readiness skills; 2) person-centered approaches to school readiness can find relationships not readily detected in variable-centered techniques; and 3) the indicators of school readiness selected and the person-centered analytic techniques used greatly influence the number and nature of school readiness profiles identified. Therefore, much thought must go into the choice of school readiness indicators and the personcentered methods utilized.

\section{Chapter Summary.}

In this chapter, I first discussed the multidimensional definitions of school readiness developed by the National Education Goals Panel and Head Start's Early Learning Framework. Summaries of these definitions are included as Table 1 and Figure 
PROFILES OF SCHOOL READINESS

1. I then reported on the school readiness perspectives of policymakers and the teachers and parents of entering kindergartners. Policy makers and parents tend to pay more attention to the academic skills of entering kindergartners than teachers, who report caring more about children's engagement in the classroom, social skills, and self regulation than do parents or policy makers (Bush Administration, 2001; Diamond et al., 2000; Lin et al., 2003; Obama Administration, 2015a; Rimm-Kaufman el al., 2000; West et al., 1995).

Next, I reviewed the predictive utility of key school readiness skills (e.g., early math, reading, social, and classroom engagement skills) as shown in previous, variablecentered research (Duncan, et al., 2007; Pagani et al., 2010) and proposed CLT as a theoretical perspective of the mechanisms by which school readiness skills may facilitate long-term learning (Paas, van Gog, \& Sweller, 2010; Sweller, 1994). I proposed that stronger school readiness skills will free WM capacity, allowing more WM capacity to be allotted toward weaker skills in day-to-day activities. Over many activities, this will result in the improvement of weaker skills across the year.

Finally, I reviewed the conceptual and methodological limitations of previous variable-centered work, highlighted person-centered approaches to the study of school readiness, and proposed person-centered analyses as a useful next step by which to continue the study school readiness. 


\section{Chapter 3: The Purpose of the Current Study}

In the previous chapter, I introduced empirical support for certain school readiness skills and discussed appropriate ways to analyze the phenomenon of school readiness. In this chapter, I outline the purpose and goals of the current study, both of which have been informed by the observations in the previous chapter.

The purpose of the current study was to describe incoming kindergarten students' school readiness skills using the person-centered analytic technique of model-based cluster analysis. I explored both the antecedents and year-end consequences of children's school readiness. In this study, I operationalized school readiness multidimensionally, consisting of early reading, math, social, and behavioral engagement skills. Instead of conceptualizing the school readiness dimension of approaches toward learning as attention skills as previous work has done (Duncan et al., 2007; Halle, Hair, Wandner, \& Chein, 2012), I conceptualized measures of approaches toward learning as observable behavioral engagement with classroom tasks and materials. I believe this conceptualization is more in line with the domain of approaches toward learning as described by the NEGP and ELF and may help avoid oversimplifying or masking its effects and mechanisms in development.

I approached these indicators of school readiness using a CLT-informed and person-centered framework. The CLT framework conceptually proposes that the presence of individual school-readiness skills may free up children's WM capacity, allowing more capacity to be allotted to the necessary demands of classroom tasks. As children come into kindergarten with combinations of school readiness skills, they may have some 
school readiness skills that are stronger than others. The CLT framework suggests that the presence of strong school readiness skills may allow more WM to be allotted to tasks requiring weaker skills, thereby compensating for their absence at school entry and supporting their development across the kindergarten year.

\section{Research Questions and Hypotheses}

In this section, I outline the research questions I address in this study and my hypotheses to those research questions. Figure 2 is a visual representation of Research Questions One, Two, and Three.

Figure 2. Research Question Model

Antecedents

\begin{tabular}{|c|}
\hline Demographic \\
Characteristics \\
SES \\
Sex \\
Race \\
Ethnicity \\
Primary Language \\
Pre-K Care Structure \\
\hline
\end{tabular}

Target Phenomenon School Readiness Profiles
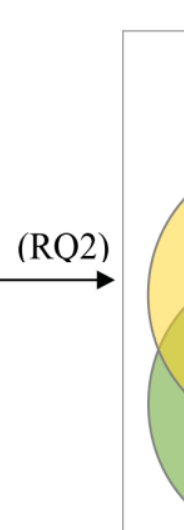

(RQ1)

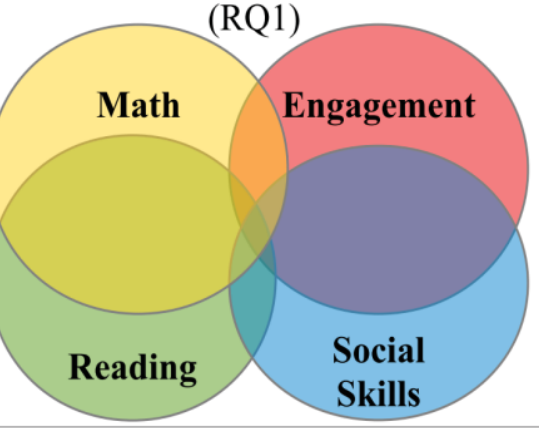

Consequences

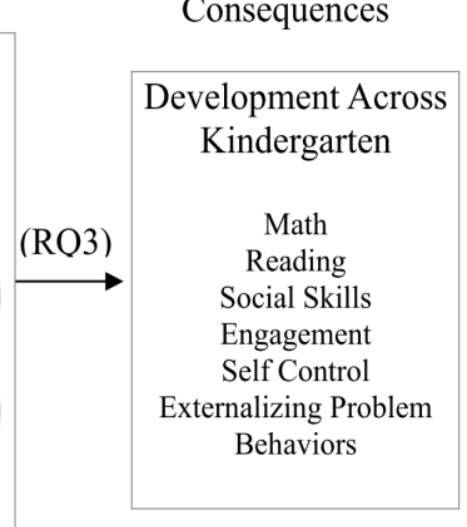

Note. Research Question Four is not modeled in this figure. Additionally, this is a conceptual model and not intended to communicate the analytic procedures used in the study.

\section{Research Question One.}

What are the profiles of children's school readiness - defined as a combination of early reading skills, early mathematics skills, social skills, and behavioral engagement at the beginning of kindergarten?

I used an exploratory analytic process to identify the profiles of school readiness. 
While no specific hypotheses were formed regarding the types of profiles that would be found (as previous person-centered studies have found anywhere from four to seven profiles), I did anticipate that the two academic skills (math and reading) and the two non-academic skills (social skills and behavioral engagement) would "hang together" within the profiles, such that children with above average math scores would also have above average reading scores and children with above average social skills would also display above average engagement at kindergarten entry. I formed the hypotheses for the following research questions around four hypothetical school readiness profiles: 1) above average math/reading and above average social/engagement, 2) above average math/reading and below average social/engagement, 3) below average math/reading and above average social/engagement, and 4) below average math/reading and below average social/engagement. These hypothetical profiles represented potential outcomes that I believed might come from the exploratory analysis.

\section{Research Question Two.}

What are the demographic characteristics of children in each of the school readiness profiles?

Hypothesis 2. The hypotheses regarding this research question are primarily based on findings of previous variable-centered research, as this literature is far more extensive than person-centered research.

Sex. Boys have been shown to be at a disadvantage in terms of social skills and behavioral regulation in kindergarten (Matthews, Pontiz, \& Morrison, 2009). Therefore, I anticipated that boys would be more likely to be viewed by their teachers at the 
PROFILES OF SCHOOL READINESS

beginning of the year is having trouble regulating their task behaviors and emotions in the classroom than girls. Because of this, I hypothesized that boys would be more likely than girls to be placed in profiles with lower social skills and behavioral engagement skills.

I anticipated no sex differences in levels of academic preparedness at the beginning of kindergarten (Matthews et al, 2009).

Race and ethnicity. Members of racial and ethnic marginalized groups tend to be at risk for low academic achievement at the beginning of kindergarten (Reardon \& Galindo, 2009; Reardon, 2011; Burchinal et al., 2011, Zill \& West, 2001). Therefore, I hypothesized that children from these groups would be more likely to be members of the profiles with lower than average reading and math skills. Similarly, members of these groups are at a disadvantage in terms of social and engagement skills (Duncan \& Magnuson, 2011); I hypothesized that children from these groups would be more likely to be belong to profiles with lower social and behavioral engagement skills than White children.

Primary language in the child's home. As American kindergarten classrooms are taught primarily in English, I believed that children who speak English as a second language would be unable to successfully communicate their academic skills in the classroom at the beginning of the year. Because of this, I hypothesized that English language learners would show up more commonly in the readiness profiles with lower reading and math skills.

Primary nonparental care during the year prior to kindergarten. Children who 
PROFILES OF SCHOOL READINESS

have received center-based nonparental care in the year prior to kindergarten would have had the advantageous experience of being in a school environment prior to beginning kindergarten. These children would have had the opportunity to learn day-to-day routines and practice appropriate social and behavioral engagement skills, and - depending on the quality of the program - gain appropriate academic stimulation. As such, I hypothesized that these children would be present in profiles with above average levels of all four readiness dimensions.

SES. I anticipated that children of low SES would be more likely to be members of the profiles with lower academic skills than their high SES counterparts. As SES is often used as a stand-in measure of the academic experiences a child has at home, I believed that children of low SES would have experienced a comparative dearth of academic stimulation prior to school entry than their high SES counterparts. It is also possible that children from low SES backgrounds may have had fewer opportunities to form relationships with adults and children outside their primary caregivers and immediate family (Matthews, Pontiz, \& Morrison, 2009; Reardon \& Galindo, 2009; Reardon, 2011; Burchinal et al., 2011, Zill \& West, 2001). As such, I also hypothesized that children from low SES backgrounds would be present in profiles with low social and behavioral engagement skills.

\section{Research Question Three.}

Are children's school readiness profiles at the beginning of kindergarten associated with their academic, social, and behavioral engagement development across the kindergarten year? If so, what is the nature of these relations? 
PROFILES OF SCHOOL READINESS

Theoretical Perspective. I hypothesized that there is a compensatory relation

between the school readiness skills, such that the presence of one school readiness skill can help support the development of those that are lacking at the beginning of the kindergarten year. This is theoretically supported by the CLT framework. Consider, for example, a group classroom task where a child is working with her peers to sort blocks into patterns. In this example, I propose that the presence of social skills can compensate for any lack of math knowledge the child may have by minimizing the amount of WM capacity allocated towards behaving appropriately with her peers. She may not need to hold social rules - such as using kind words to ask for blocks instead of taking the blocks without asking - in her WM, allowing more space for information about what constitutes a pattern. In other words, there is more space in her WM for math knowledge essential to the task at hand. In this case, the presence of social skills can support academic development by alleviating WM capacity.

Likewise, I posit that the presence of academic knowledge at the beginning of kindergarten can compensate for the lack of behavioral engagement or social skills by minimizing the amount of WM capacity allocated to information nonessential to regulatory aspects of the classroom task at hand. A child who enters school knowing her letters and numbers may not need to allocate as much of her WM capacity to the academic information required to complete a task; this means that there may be more WM capacity available for her to hold the classroom social expectations in her mind, as well as remember what task is at hand and how to engage with it appropriately. In other words, academic mastery in kindergarten can support the development of social and 
engagement development by making more WM capacity available to hold social and behavioral expectations in mind.

Furthermore, children with strong school readiness skills across the board should have plenty of WM capacity available to hold all aspects of an activity in mind. If the activities in the classroom are appropriately challenging for these students, the activities should support their development across all skill domains. On the other hand, children with weak school readiness skills across the board may need to allot all their WM capacity to the different academic and social aspects of tasks. Lacking any school readiness skill strengths may leave these children without a way to free up space in their WM, making it difficult to improve academic, social, or engagement skills.

The theoretical perspective for Research Question Three is included as Figure 3.

\section{Hypothesis 3.}

Above average math/reading and above average social/engagement. I

hypothesized that children in this profile would show strong improvement in reading, math, social, and engagement skills across the kindergarten year. I also anticipated that these children would display higher scores in all of these outcomes at the end of the year than their peers in other profiles. The presence of each of the school readiness skills at the beginning of the year would amplify the children's ability to develop across all four domains.

Below average math/reading and below average social/engagement. I hypothesized that children in this profile would show minimal improvement in reading, math, and self-regulatory skills across the kindergarten year. I also anticipated that these 
Figure 3. Theoretical Perspective for Research Question Three

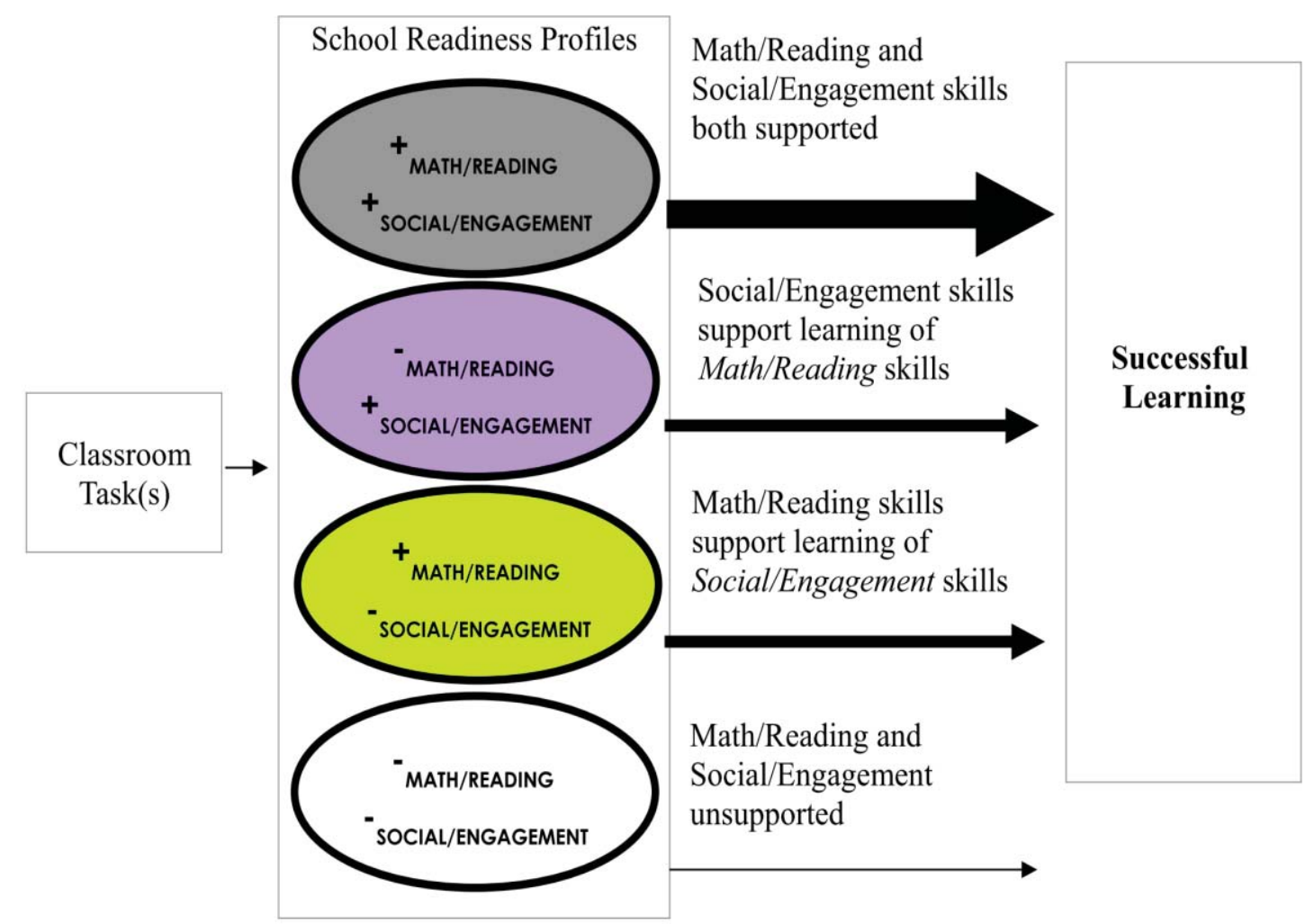

children would display lower scores in all of these outcomes at the end of the year than their peers in other profiles. Children in these profiles would have fewer personal resources available to them to help support the development of academic, social, and engagement skills.

Above average math/reading and below average social/engagement. I hypothesized that children in this profile would show relatively more improvement in social and engagement domains than in math and reading. This is because I believed their high academic preparedness would support their development of social and engagement skills, while their social skills and behavioral engagement would be less able to support further academic growth. Furthermore, I believed that children in this profile would 
display higher scores in these outcomes than their peers in the below average math/reading and below average social/engagement profile and lower scores than their peers in the above average math/reading and above average social/engagement profile. Below average math/reading and above average social/engagement. I hypothesized that children in this profile would show relatively more improvement in reading and math domains than in social skills and behavioral engagement. This is because I believed that their high social and engagement skills could support the development of their reading and math skills, while their academic skills would be unable to support further social skills and engagement growth. Furthermore, I believed that children in this profile would have higher scores in these outcomes than their peers in the below average math/reading and below average social/engagement profile and lower scores than their peers in the above average math/reading and above average social/engagement profile.

A pictorial representation of Hypothesis 3 is included as Figure 4.

\section{Research Question Four.}

Do the person-centered analysis methodologies utilized in this study offer different conclusions and implications about school readiness than a more traditional, variable-centered analytic technique?

Hypothesis 4. I hypothesized that person-centered analytic techniques would tell a more nuanced and easily interpret-able story than more traditional variable-centered techniques. 
Figure 4. Hypothesis 3

School Readiness Profiles

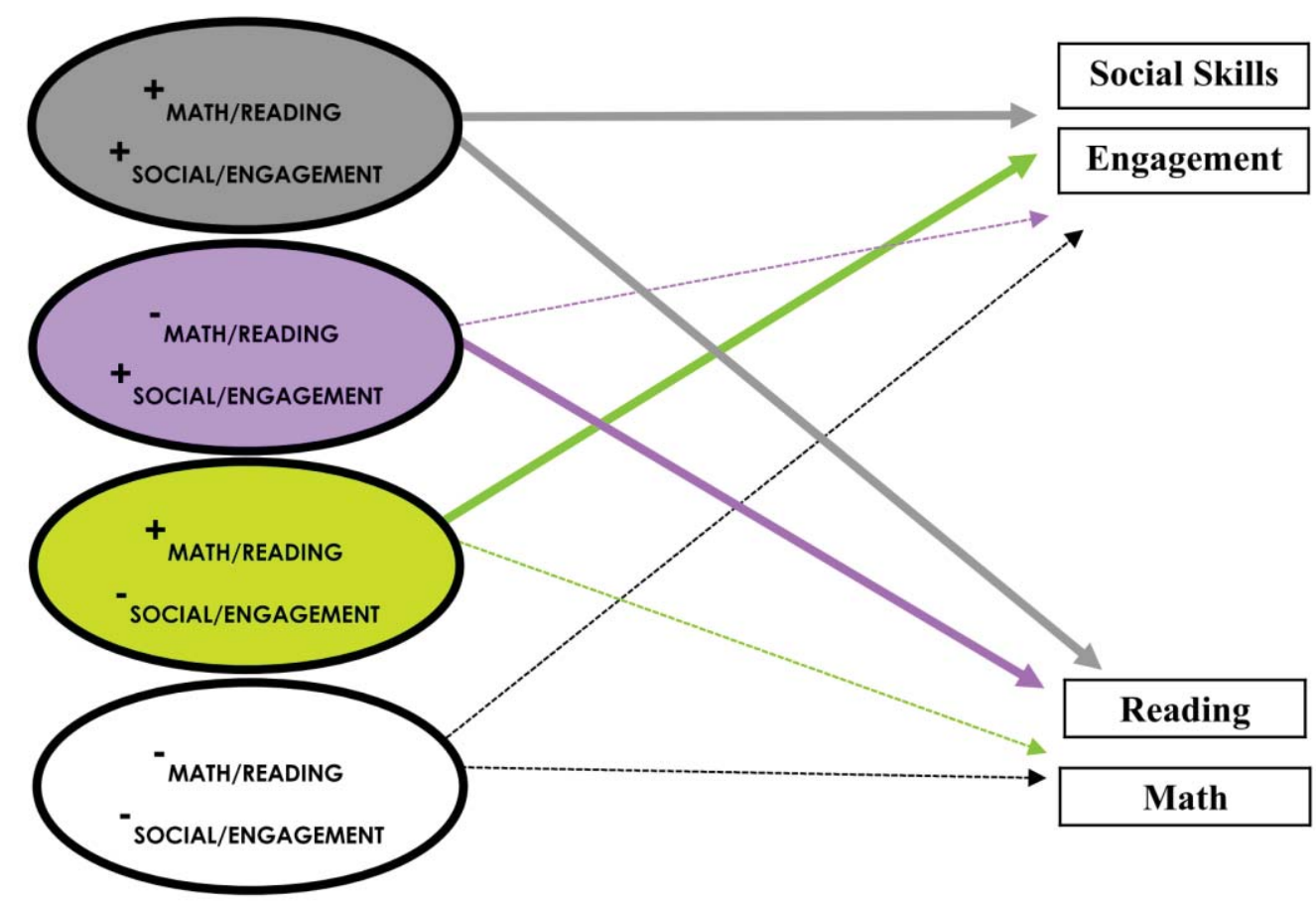

Note. Thick arrows denote growth across the kindergarten year. Dashed arrows denote minimal change across the kindergarten year.

\section{Chapter Summary.}

Chapter three described the purpose of this study. Specifically, this study utilizes a person-centered technique and the CLT framework to explore the multidimensionality of school readiness. I proposed that 1) distinct school readiness profiles would be detectable, 2) profile membership would be predictable based on key demographic characteristics, 3) profile membership would predict distinct patterns of change in academic, social, and engagement skill scores across the kindergarten year, and 4) the person-centered approach would tell a more interpret-able and compelling story than a more traditional variable-centered approach. 


\section{Chapter Four: Methods}

In the previous chapter, I reviewed the purpose of this study, listed my four research questions, and explained my hypotheses to the research questions. In the following chapter, I will provide an overview of the participants in the study, the procedures by which that data were gathered, and the measures themselves.

\section{Participants}

As part of the Early Childhood Longitudinal Study, Kindergarten Class of 201011 (ECLS-K) sponsored by Institute of Education Sciences, a nationally representative sample of children was selected from 1,319 elementary schools in the United States (1,036 public schools and 283 private schools). A total of 18,174 children from these schools - as well as their kindergarten teachers and parents - were recruited. Those included in the final sample were children who had data for all four of the school readiness variables of interest (fall math and reading scores, as well as teacher-rated social skills and engagement). I was hesitant to apply missing data techniques to the person-centered procedure used in this study. Model-based cluster analysis uses the distributions of the component variables to determine the profiles. I did not want the distributions used in the cluster analysis to be manipulated by missing data procedures such as multiple imputation. Thus, the final sample size was 12,509. This study utilized publicly available version of the ECLS-K data set (Tourangeau et al., 2015).

\section{Procedures}

\section{Direct Assessments.}

Direct assessments were conducted in the fall of 2010 and spring of 2011 on an 
individual basis by trained and certified child assessors. The direct assessments included cognitive components and took approximately 60 minutes per child.

\section{Teacher Reports.}

Kindergarten teachers were asked to complete questionnaires regarding each participating child in fall of 2010 and spring of 2011. These questionnaires included questions that addressed the child's social and self-regulatory skills and behaviors that they exhibited in the classroom.

\section{Parent/guardian Interviews.}

Parent/guardian interviews were conducted in fall of 2010 and spring of 2011. Topic addressed included information about their child (e.g., sex, race), their child's experiences (e.g., non-parental care arrangements, languages spoken at home), and themselves (e.g., income, employment status).

\section{Measures}

\section{School Readiness Variables.}

Histograms of the four school readiness variables used in this study are included as Figure 5.

Academics. Reading and mathematics skills were directly assessed on an individual basis by trained assessors in fall of 2010 in two-stages. The first stage included items ranging in difficulty (low to high). A child's performance in the first stage of the assessment determined which of second-stage tests (low, middle, or high difficulty) the child was asked to complete so that each child was administered items appropriate to his or her demonstrated ability. In each stage, the assessors presented images to the children 
Figure 5. Histograms of School Readiness Components for Cluster Analysis
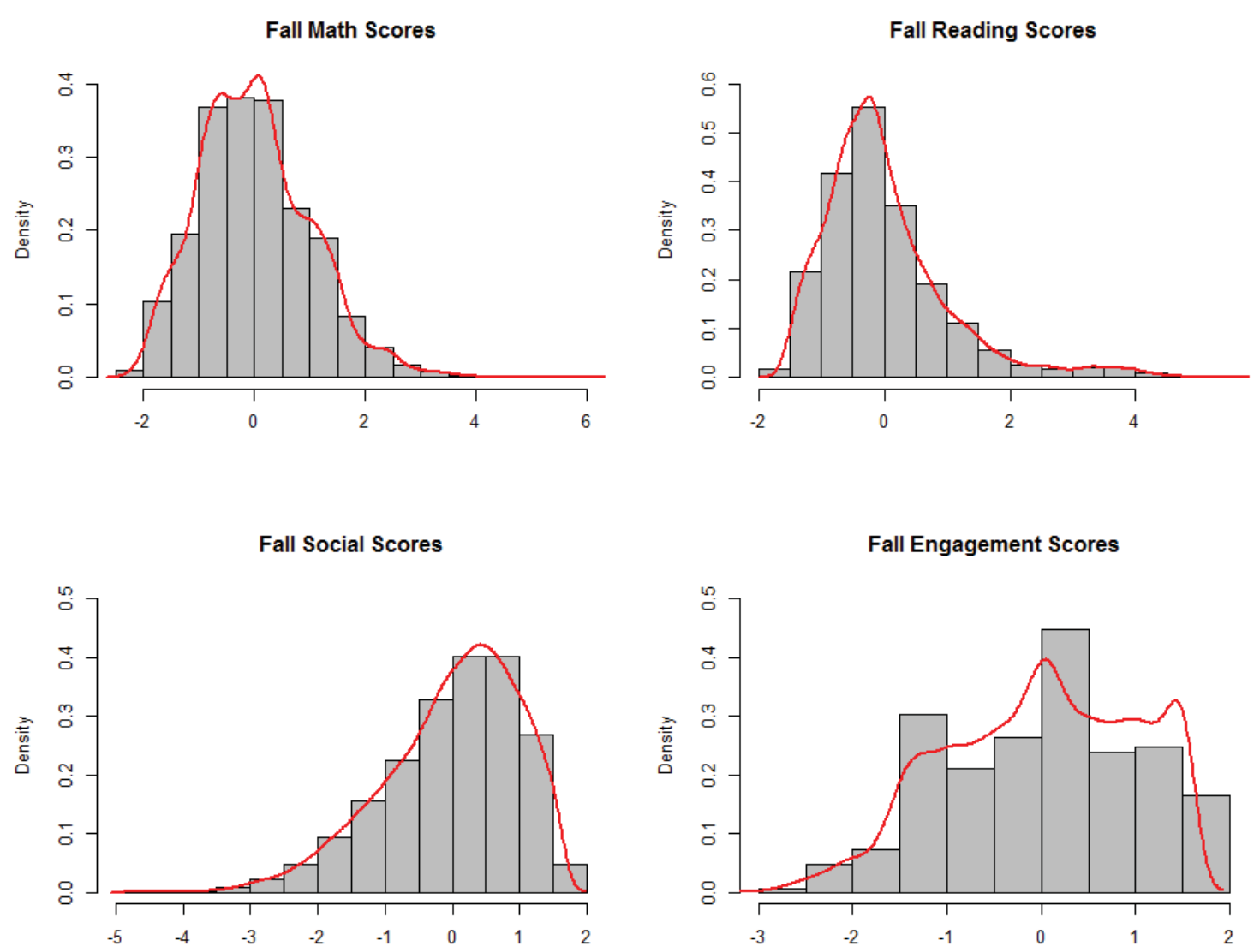

(e.g., letters of the alphabet for reading and numbers for mathematics) and asked children questions related to these images. Children responded by pointing or telling the assessor their answers.

As children were administered items appropriate for their skill level, not all children received the same set of items. Therefore, Item Response Theory (IRT) procedures were used to calculate overall scores for each child that could be compared to other children's scores, regardless of the items administered. IRT uses the difficulty level and probability of guessing the correct answer of each item, as well as each child's 
PROFILES OF SCHOOL READINESS

pattern of responses to the items he or she received to estimate each child's ability on the same continuous scale.

Reading. Reading assessment items were derived from the following published instruments: Peabody Individual Achievement Test - Revised, Peabody Picture Vocabulary Test - 3rd Edition, Preschool Language Assessment Scale, Test of Early Reading Ability - 3rd edition, and Test of Preschool Early Literacy (Duncan, \& De Avila, 1998; Dunn \& Dunn, 1997; Lonigan, Wagner, Torgesen, \& Rashotte, 2007; Markwardt, 1989; Reid, Hresko, \& Hammill, 2001). Delivered in the manner described above, the reading assessment included items that measured basic literacy skills (e.g., print familiarity, letter recognition, and word recognition), vocabulary knowledge, and reading comprehension (e.g., content recognition and complex inferences within and across texts).

Mathematics. The mathematics test items were derived from the following existing instruments: Peabody Individual Achievement Test - Revised, Test of Early Mathematics Ability - 3rd edition, Woodcock-Johnson Psychoeducational Battery -Third Edition (WJ-III) Applied Problems Test, and WJ-III - Calculations Test (Ginsburg \& Baroody, 1983; Pro-ed. Markwardt, 1989; Woodcock, McGrew, \& Mather, 2001). The mathematics assessment was designed to measure children's conceptual knowledge, procedural knowledge, and problem solving skills. Delivered in the manner described above, the assessment included items on such topics as number sense, geometry, probability, and patterns. In both stages, paper and pencil were offered to the children to use in solving the problems. In the second-stage, wooden blocks were available for 
PROFILES OF SCHOOL READINESS

children to use in solving the problems.

Social Skills. Items from the Social Skills Rating System were used to measure children's social skills (Gresham \& Elliott, 1990). In the fall of 2010, each child's kindergarten teacher reported how often the child exhibited certain social skills and behaviors using a four-option frequency scale: "Never", "Rarely", "Often”, and "Very Often." Teachers were also able to select "No opportunity to observe" for each item; if so selected, the item was treated as missing. The teacher reported on four social behaviors: interpersonal skills ( 5 items), self-control (4 items), externalizing problem behaviors (5 items), and internalizing problem behaviors (4 items). Item ratings in each behavior category were averaged to create an average score for that category if a child had one missing item or less. Higher scores indicated that the child exhibited the behavior represented by the scale more often. For profile formation, the scale scores were summed together (with both externalizing and internalizing problem behaviors reverse coded) to create a social skills composite score.

Engagement. Approaches toward learning items from the Social Skills Rating System were used to measure children's engagement in the kindergarten classroom (Gresham \& Elliott, 1990). Each child's kindergarten teacher completed a seven-item approaches toward learning questionnaire to report how often the child exhibited the following learning behaviors in the classroom: keeps belongings organized, shows eagerness to learn new things, works independently, easily adapts to changes in routine, persists in completing tasks, pays attention well, and follows classroom rules. Teachers rated a child's behaviors on a four-option frequency scale: "Never", "Rarely", "Often”, 
and "Very Often." Teachers were also able to select "No opportunity to observe" for each item; if so selected, the item was treated as missing. An average score was computed when the responding teacher provided a rating on at least four of the seven items. Higher scores indicated that the child exhibited positive learning behaviors in the classroom more often.

\section{Child and family demographic characteristics.}

Sex. Each child's sex (male or female) was provided both in parent/guardian interviews and by the child's school at the time of sampling.

Race. Parents/guardians indicated which of five race categories (White, Black or African American, Asian, Native Hawaiian or other Pacific Islander, American Indian or Alaska Native) described their child, and they were allowed to select more than one category. Five dichotomous race variables were created to separately note whether the child belonged to each of the five race categories. Additionally, one dichotomous variable was created to identify children who were described by their parent/guardians as belonging to more than one race category.

Ethnicity. Parents/guardians indicated whether or not their child was best described as Hispanic or non-Hispanic.

Primary language in the child's home. Parents/guardians were asked if any language other than English was regularly spoken in their home. Based on their responses, children were sorted into three categories: 1) English is the primary language in the home; 2) English is not the primary language spoken in the home; and 3) cannot choose primary language or two languages equally. 


\section{Primary nonparental care during the year prior to kindergarten.}

Parents/guardians of each child reported the average number of hours per week their child spent in different types of nonparental care arrangements (e.g., relative care in home, center-based care) in the year prior to their start of kindergarten. The child's primary nonparental care arrangement was determined by selecting the arrangement in which the child spent the most hours per week, as reported by their parent/guardians. The categories of primary nonparental care were 1) no nonparental care arrangements; 2) center-based care; 3) other nonparental care arrangements, and 4) an equal number of hours in two or more care arrangements.

SES. Socioeconomic status (SES) was computed at the household level using data from parent/guardian interviews. The SES variable was comprised of the following parent/guardian-report components: 1) parent(s)/guardian(s) education level; 2) parent(s)/guardian(s) occupational prestige scores (as defined by the 1989 General Social Survey (GSS)); and 3) household income. Each component was standardized such that it had a mean of 0 and a standard deviation of 1 . The SES variable was then determined by computing the average of the standardized score of all the components.

\section{Year-end Outcomes.}

Histograms of the proposed outcome variables as measured in the spring of 2011 are included as Figure 6.

\section{Academics.}

Reading. Reading skills were directly assessed on an individual basis by trained assessors in spring of 2011 using a procedure identical to that of fall 2010. 
Figure 6. Histograms of Achievement Outcomes
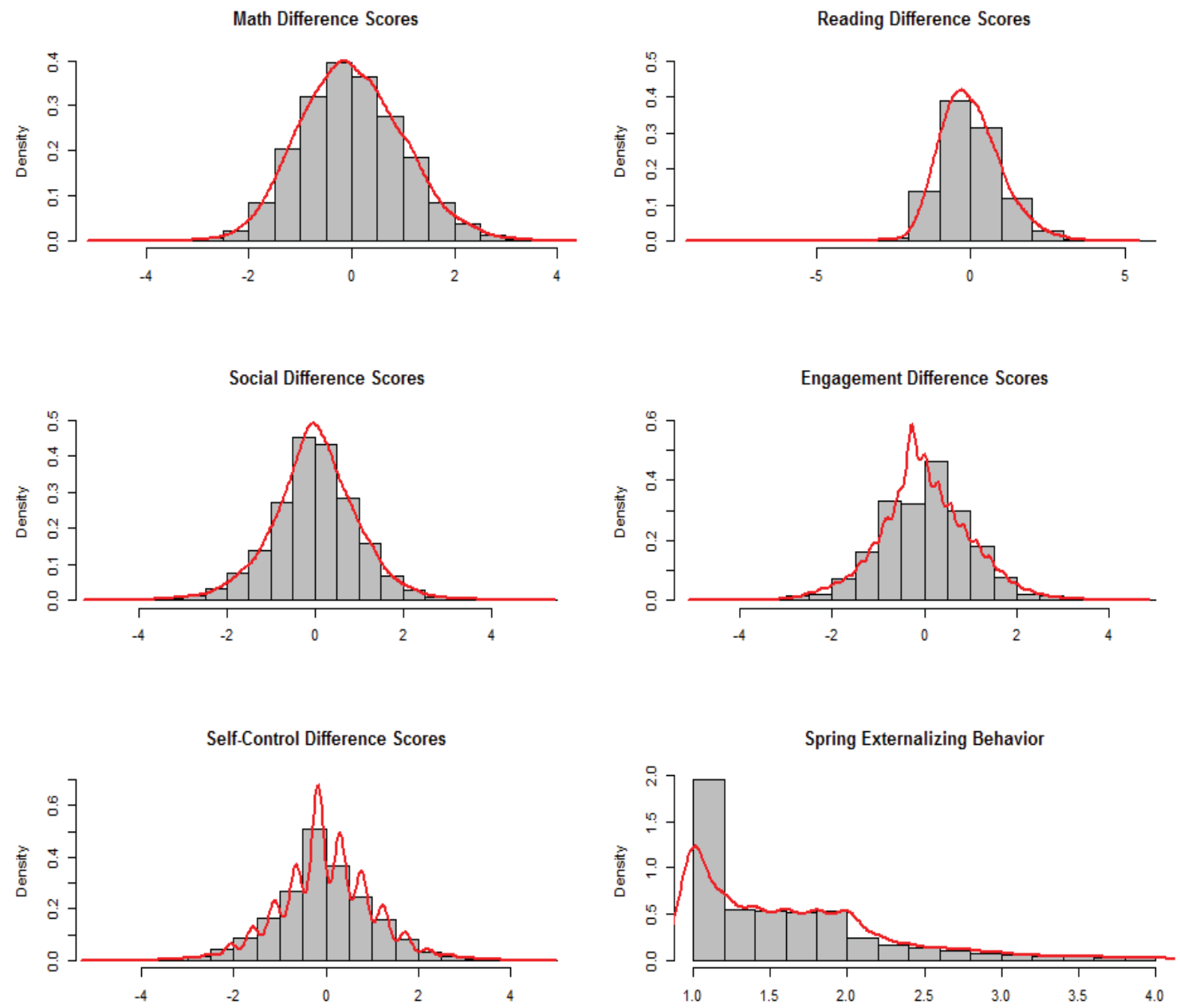

Mathematics. Mathematics skills were directly assessed on an individual basis by trained assessors in spring of 2011 using a procedure identical to that of fall 2010.

Social Skills. Social skills were reported by the kindergarten teacher in the spring of 2011 using a procedure identical to that of fall 2010. For the end-of-year analysis, the social skills composite score and two particular subscales of interest (self-control and externalizing problem behaviors) were treated as separate outcomes.

As seen in Figure 6, the distribution of externalizing problem behaviors had an 
extreme positive skew, such that teachers rate most students, on average, as never displaying externalizing problem behaviors. For this reason, externalizing problem behaviors was re-coded such that children whose teachers on average rated them as never or rarely displaying problem behaviors (children with a score of 2 or lower) were classified as not having an externalizing behavior problem. On the other hand, children whose teachers on average rated them as often or very often displaying problem behaviors (children with scores greater than 2) were classified as having an externalizing behavior problem.

Engagement. Engagement was reported by the kindergarten teacher in the spring of 2011 using a procedure identical to that of fall 2010.

\section{Chapter Summary}

This chapter described the participants, procedures, and measures from the ECLSK 2011 data set used in this study. The next chapter outline the analytic plan used to form the school readiness profiles based on fall math, reading, social, and behavioral engagement skills using model-based cluster analysis (Research Question One). 
Chapter 5: Analysis Plan, Part One

In the previous chapter, I described the ECLS-K data set's participants, procedures, and variables of interest to the current study. In the upcoming chapters, I will address my analysis plan for and results of my research questions. However, since my analysis plan for Research Questions Two, Three, and Four depended on the results of my exploratory cluster analysis, I decided to split my Analysis Plan and Results chapters into two parts for the sake of clarity. In this chapter, I outline the analysis plan used to conduct preliminary analyses and the analysis designed to address Research Question One.

\section{Preliminary Analyses}

I conducted the analysis for this study using $\mathrm{R}$ version 3.3.1 statistical computing software (R Core Team, 2016). Preliminary descriptive analyses, as well as a visual inspection, of all the data were conducted prior to addressing the research questions.

The first step in descriptive analyses was to compute the means, standard deviations, and ranges of each continuous variable involved in the profile formation process and subsequent analyses (Table 3). I also examined the distributions of all continuous variables to identify those that violated the assumption of normality.

Table 3

Descriptive Statistics of School Readiness Profile Components

\begin{tabular}{|c|c|c|c|c|}
\hline & & Standard & & \\
\hline & Mean & Deviation & Minimum & Maximum \\
\hline Fall Math & 30.80 & 10.90 & 6.26 & 95.23 \\
\hline Fall Reading & 37.63 & 9.61 & 21.51 & 90.35 \\
\hline Fall Social & 13.03 & 1.89 & 4.20 & 16.00 \\
\hline Fall Engagement & 2.97 & 0.68 & 1.00 & 4.00 \\
\hline
\end{tabular}

Next, I computed the bivariate correlation coefficients between the components intended for cluster formation. I also computed bivariate correlation coefficients between 
baseline scores and outcome measures. Baseline scores on child measures were be highly positively related $(r>0.5)$ to the outcome scores, indicating that a child's academic, social, and engagement skills at the beginning of the year are positively related to their academic, social, and engagement skills at the end of the year (Table 4).

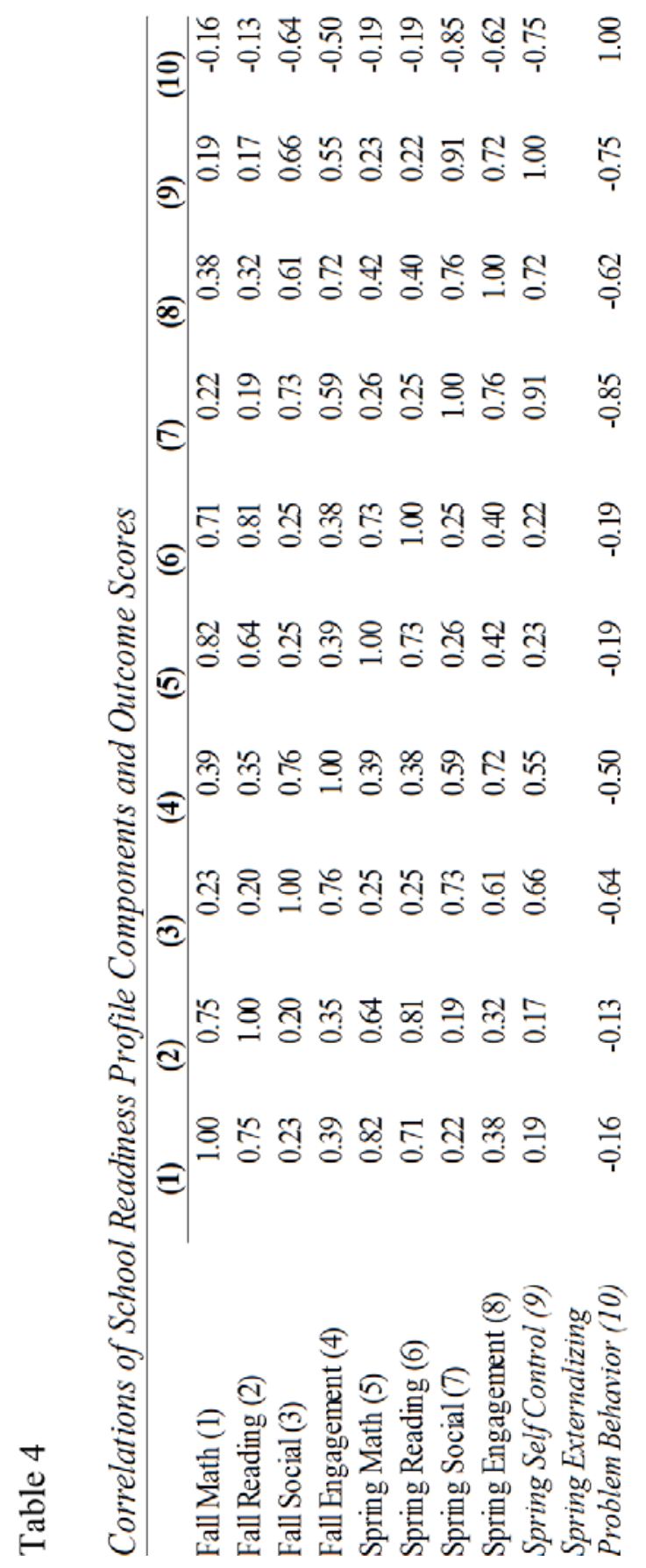




\section{Research Question One}

I used exploratory model-based cluster analysis in $\mathrm{R}$ using the package mclust to determine the school readiness profiles of entering kindergartners (Fraley, Raftery, Murphy, \& Scrucca, 2012). Model-based cluster analysis is a form of cluster analysis that proposes a series of formal statistical models that assume a population consists of a number of subpopulations (profiles or clusters). These subpopulations have their own unique multivariate probability density function. The whole population's probability density is determined by a mixture of subpopulations' probability density functions. These assumptions allow the problem of cluster analysis to be that of estimating the parameters of the assumed mixture and then using the estimated parameters to calculate the probabilities of cluster membership for each individual in the data (Everitt \& Hothorn, 2011). The family of mixture models applied to the data by the mclust package either restrict or allow to vary the shape, volume, and orientation of the clusters (see the Appendix for a description of the individual models available in mclust; Everitt \& Hothorn, 2011; Fraley et al., 2012). An exploratory mclust procedure determines which particular model and what number of clusters best fits the data.

The advantage of this procedure is that unlike other cluster analysis methods, the model-based clustering procedure is based on formal statistical models. Clustering methods such as agglomerative hierarchical and $k$-means are based on intuitive heuristics. Choosing the method to use and the "correct" number of clusters is subjective and not straightforward. Therefore, these methods are more appropriate for informal analyses. 
PROFILES OF SCHOOL READINESS

Model-based cluster analysis, on the other hand, has an objective procedure for choosing the correct model and number of clusters (Everitt \& Hothorn, 2011; Fraley \& Raftery, 2002).

I performed two exploratory model-based cluster analyses using the mclust $\mathrm{R}$ package (Fraley et al., 2012). The first potential cluster solution consisted of four dimensions of school readiness: children's standardized teacher-rated approaches toward learning scores as the indicator of student engagement, teacher-rated social skills, early literacy skills, and early math skills at the beginning of kindergarten. As early literacy and math scores were highly correlated $(0.75)$, I conducted a second potential cluster solution, consisting of children's standardized teacher-rated approaches toward learning scores as the indicator of student engagement, teacher-rated social skills, and a composite score of standardized early literacy skills and math skills (created by averaging the two scores and standardizing the average). While children's teacher-rated social and engagement skills were also highly related $(r=0.76)$, I had particular interest in including and distinguishing non-academic school readiness skills from academic skills in my operationalization of school readiness. Therefore, I determined to keep social skills and engagement independent in each cluster analysis.

I used three criteria to determine which of the two potential cluster solutions to select for Research Question One: Model Fit, Theoretical Interpretation, and Minimal Uncertainty.

Model Fit. The mclust package computes a Bayesian Information Criterion (BIC) to determine the optimal model and number of clusters (Fraley et al.2012; Fraley, 
Raftery, \& Scrucca, 2014).

Preliminary Theoretical Interpretation. I examined the best fitting model of each of the cluster analyses to determine if the solutions were theoretically interpret-able. I wanted to determine a parsimonious solution that offered intuitive labels for the clusters. I asked myself, "Would a teacher be able to recognize a student from each of these profiles in their classroom?" If either of the two best-fitting cluster solutions that were found theoretically uninterpretable, they would be eliminated from candidacy. If both of the potential solutions were eliminated, less well-fitting models from each analysis would have been examined for their interpret-ability.

Minimal Uncertainty. Finally, I compared the two cluster solution candidates in terms of their uncertainty. An assumption of model-based cluster analysis is that subpopulations (clusters) within the total population's distribution are normally distributed. This means that within each cluster, there will be children who sit in the tails of the distribution; these children are less likely to belong to a cluster than children who sit in the center of the distribution. As there are be multiple clusters in the cluster solution, there may be a child who sits at the border between one cluster and another: perhaps there is a $30 \%$ chance that she belongs to Cluster A and a $29 \%$ chance that she belongs to Cluster B. This is an example of uncertainty. While the mclust package will assign this child to Cluster A, a difference of $1 \%$ probability is keeping her out of Cluster B. Any predictions made about this child using her cluster classification will have a degree of uncertainty. Therefore, the cluster solution I chose should have had a small median level of uncertainty across the cluster assignments. 
To determine each cluster solution's uncertainty, an uncertainty variable was created for each child by subtracting their highest cluster probability from 1 . This is an indication of how confident I am about each child's cluster membership. I examined the descriptive statistics of this uncertainty variable and chose the cluster solution with the lowest median uncertainty.

\section{Chapter Summary}

The purpose of this chapter was to describe my criteria for the selection of the school readiness profiles. I compared the potential solutions on their model fit (BIC), preliminary theoretical interpretation, and the uncertainty of their assignments of kindergartners into the school readiness profiles. In the next chapter, I communicate the results of Research Question One, specifically my model selection and the description of my selected school readiness profiles. 


\section{Chapter 6: Results, Part One}

In Chapter 5, I discussed my analytic plan to define and select my school readiness cluster solution; the potential cluster solutions were to be evaluated on their model fit, preliminary theoretical interpret-ability, and level of uncertainty in cluster classifications. In the current chapter, I outline my selection of the cluster solution and describe the school readiness profiles found within the final solution I chose. In the following section, I refer to the cluster solution including fall math, reading, social skills, and engagement scores as Cluster Solution A and the cluster solution including fall social skills, engagement, and academic composite scores as Cluster Solution B.

\section{Research Question One}

\section{Cluster solution selection.}

Two potential cluster solutions were examined based on the proposed criteria.

Their descriptions, model fit information, and uncertainty medians and skew are included as Table 5 .

\section{Table 5}

\section{Descriptions of Potential Cluster Solutions}

\begin{tabular}{|c|c|c|}
\hline & Cluster Solution A & Cluster Solution B \\
\hline \multicolumn{3}{|l|}{ Descriptions } \\
\hline Model & $\begin{array}{l}\text { ellipsoidal, varying volume, } \\
\text { shape, and orientation (VVV) }\end{array}$ & $\begin{array}{l}\text { ellipsoidal, varying volume, } \\
\text { shape, and orientation (VVV) }\end{array}$ \\
\hline Number of Profiles & 5 & 5 \\
\hline \multicolumn{3}{|l|}{$\underline{\text { Model Fit }}$} \\
\hline$B I C$ & -108872.30 & -88141.34 \\
\hline \multicolumn{3}{|l|}{ Uncertainty } \\
\hline Median & 0.18 & 0.25 \\
\hline Skew & 0.51 & 0.27 \\
\hline
\end{tabular}

Note. Cluster Solution 1 consists of Fall Math, Reading, Social, and Engagement. Cluster Solution 2 consists of Fall Academic Composite, Social, and Engagement. For more information of mclust models, refer to the Appendix. In mclust, good model fit is distinguished by higher BIC (Fraley et al., 2014). 
Preliminary Theoretical Interpretation. The best fitting model for each cluster

iteration consisted of five school readiness profiles that were ellipsoidal, with varying volume, shape, and orientation (VVV; Fraley et al., 2014). Visualizations of the potential cluster solution are included in Figures 7 and 8 . Visual inspection of the two cluster solutions revealed no pronounced differences between the sets of school readiness profiles. Each solution offered five distinct profiles of school readiness, with similar preliminary interpretations. Thus, I relied on my other two criteria - model fit and uncertainty of classification - to select the cluster solution for further analysis.

Figure 7. Visualization of Potential Cluster Solution A

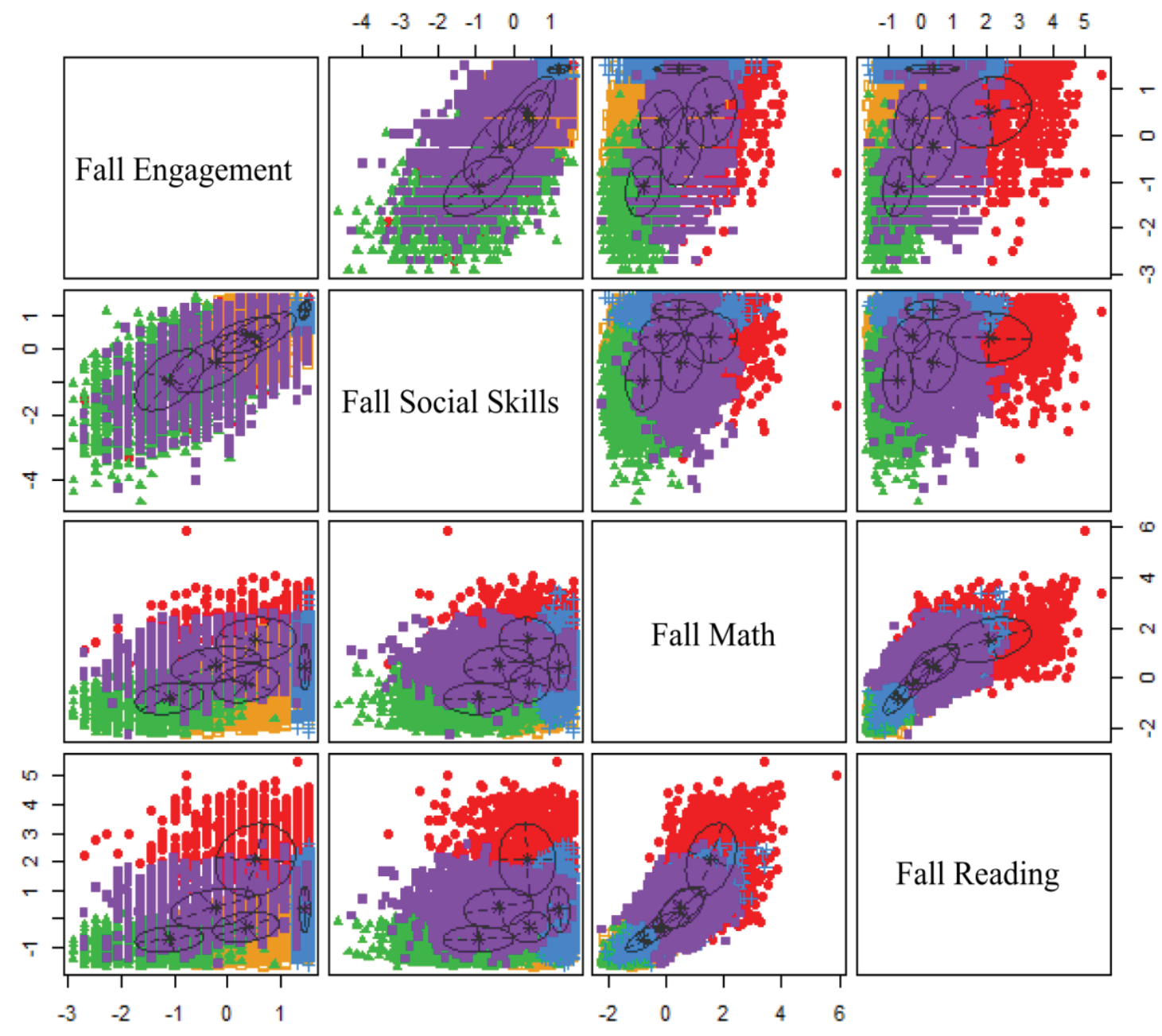


Figure 8. Visualization of Potential Cluster Solution B

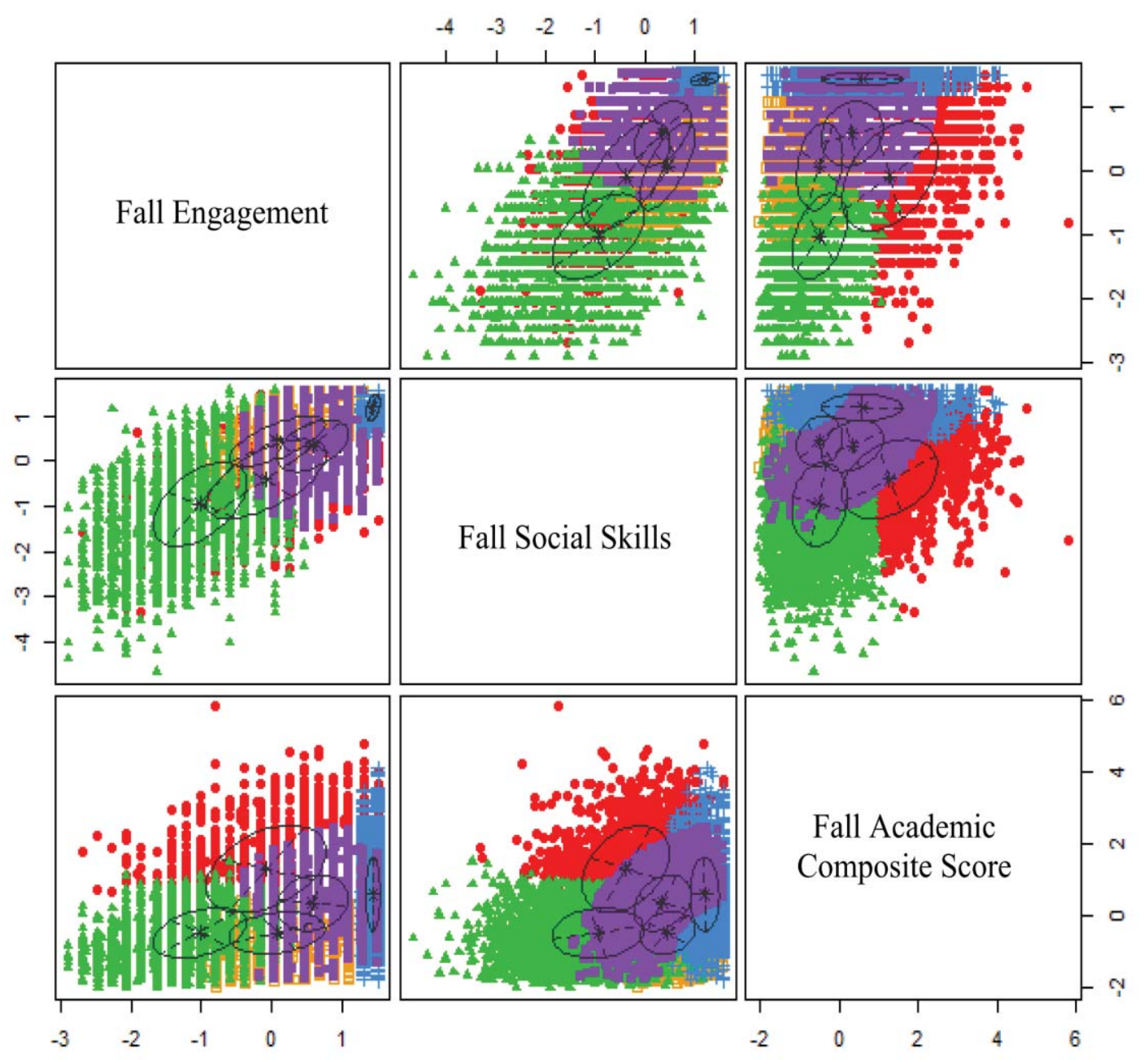

Model Fit. I compared the BICs of the two cluster solutions as an indication of

model fit (refer to Table 5). This comparison revealed that Cluster Solution B displayed better model fit than Cluster Solution $\mathrm{A}^{1}$.

Minimal Uncertainty. Cluster Solution A displayed lower median uncertainty than Cluster Solution B. This means that I was confident in the classifications (individual assignments to the profiles) of Cluster Solution A than the classifications of Cluster Solution B.

1 In mclust, good model fit is distinguished by higher BIC (Fraley et al., 2014). 
Conclusions. Preliminary visual inspection for theoretical interpret-ability of the two cluster were similar; Cluster Solution B showed better model fit, while Cluster Solution A showed lower median uncertainty in classifications. As the ultimate goal of this study was to use the profiles of school readiness as predictors of change across the academic year, I determined that it was most important to be confident in the classification of children into the profiles. Therefore, I determined to minimize classification uncertainty and select Cluster Solution A for the further analytic steps.

\section{Description of school readiness profiles.}

Five profiles of school readiness were detected with the model-based cluster analysis procedure described in the previous sections. With the input of a panel of developmental science experts, I assigned the profiles names based on their school readiness strengths and weaknesses. Table 6 shows the frequencies of assignment and the means and standard deviations for each of the school readiness components by school readiness profile, while Figure 9 provides a visualization of the school readiness components by school readiness profile.

Table 6

Means and Standard Deviations of School Readiness Components by Profile

\begin{tabular}{lcrrrrrrrr}
\hline & \multicolumn{4}{c}{$n$} & \multicolumn{2}{c}{ Math } & \multicolumn{2}{c}{ Reading } & \multicolumn{2}{c}{ Social } & \multicolumn{2}{c}{ Engagment } \\
\cline { 2 - 11 } On Par & 5191 & -0.19 & $(0.73)$ & -0.28 & $(0.51)$ & 0.44 & $(0.49)$ & 0.36 & $(0.54)$ \\
Scholastic & 845 & 1.75 & $(0.84)$ & 2.47 & $(1.08)$ & 0.38 & $(0.76)$ & 0.58 & $(0.75)$ \\
Room to Grow & 2977 & -0.86 & $(0.57)$ & -0.74 & $(0.42)$ & -1.03 & $(0.87)$ & -1.21 & $(0.55)$ \\
Super Regulator & 1328 & 0.45 & $(0.91)$ & 0.32 & $(0.79)$ & 1.21 & $(0.27)$ & 1.44 & $(0.10)$ \\
Wiggler & 2168 & 0.66 & $(0.64)$ & 0.53 & $(0.63)$ & -0.52 & $(0.85)$ & -0.30 & $(0.79)$ \\
\hline
\end{tabular}

Note. Standard deviations are noted in parentheses. Scores are standardized at the grand mean. 
Figure 9. Visualization of Fall School Readiness Components by Profile

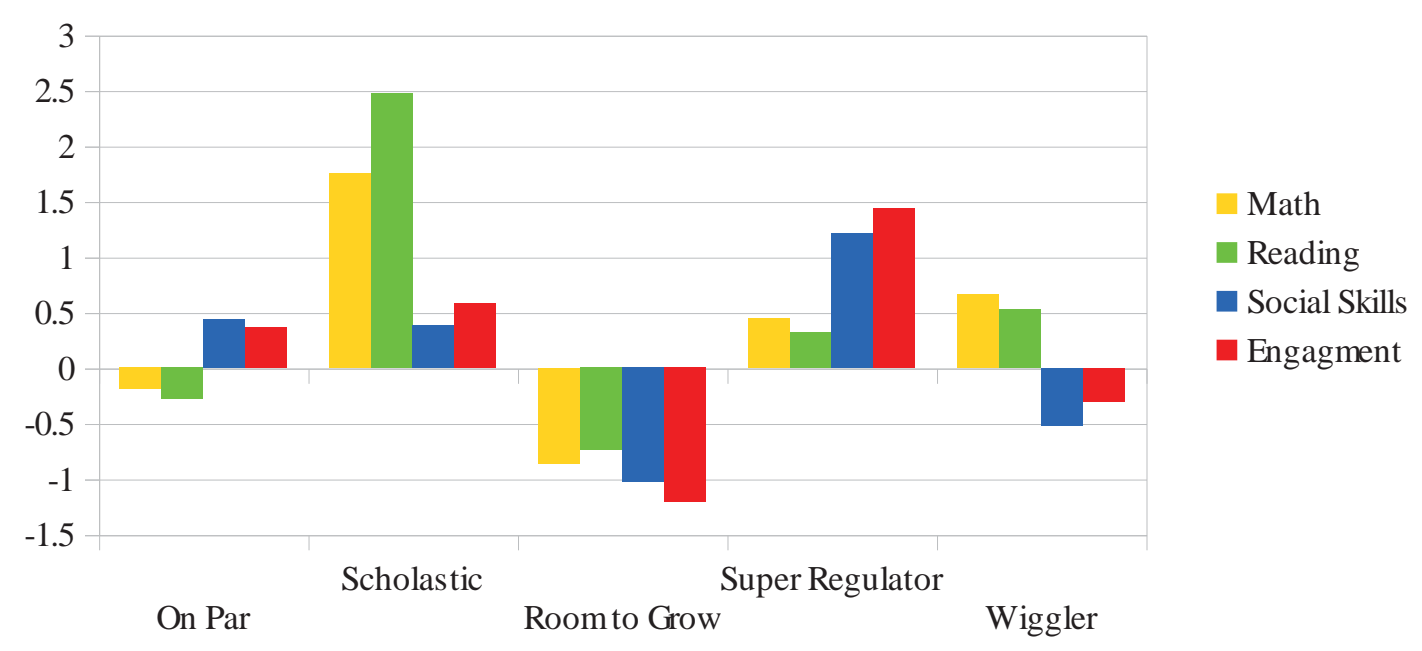

Scholastic profile. 845 children were assigned to the school readiness profile I called Scholastic. On average, children in the Scholastic profile entered kindergarten with above average school readiness skills. Their strengths, however, were by far their academic skills, particularly their reading skills (2.47 standard deviations [SDs] above the grand mean, on average). Their weakest points were their teacher-reported social and engagement skills, which averaged at 0.38 and $0.58 \mathrm{SDs}$ above the grand mean, respectively.

On Par profile. 5,191 children were assigned to the school readiness profile I called On Par. The school readiness skills of children in the On Par profile remained within $0.5 \mathrm{SDs}$ of the grand mean. Their strengths were their social skills (0.44 SDs above the grand mean) and their weaknesses were their reading skills ( 0.28 SDs below 
PROFILES OF SCHOOL READINESS

the grand mean). Yet, again, their scores across the board remained very close to the grand average.

Room to Grow profile. 2,977 children were assigned to the school readiness profile I called Room to Grow. Children in the Room to Grow profile came into kindergarten with school readiness skills 0.74-1.21 SDs below the grand means. Their biggest weakness was their engagement in the classroom, as reported by their kindergarten teacher. I chose to call this profile the Room to Grow profile because, while the children in this group came into kindergarten far below average on the skills I chose to include in the cluster analysis, they also have the most opportunity for change.

Super Regulator profile. 1,328 children were assigned to the school readiness profile I called Super Regulator. The Super Regulator profile was defined by their teacher-rated engagement and social skills (1.44 and 1.21 SDs above the grand mean, respectively). Since behavioral engagement and social interactions in the classroom involve regulation of attention and behavior, I called this profile the Super Regulator profile.

Wiggler profile. Finally, 2,168 children were assigned to the school readiness profile I called Wiggler. The children in the Wiggler profile came into kindergarten with above average academic skills, particularly their math skills (0.66 SDs above the grand mean). Their social skills, on the other hand, were rated by their teachers as 0.52 SDs below the grand mean, on average. I called this group of children the "wigglers," because, while they came into kindergarten with notable academic skills, their below average ability to interact with children and teachers in the classroom suggests to me a 
lack of behavioral regulation.

\section{Chapter Summary}

In the current chapter, I described the process of determining the school readiness profiles via model-based cluster analysis. Children in this sample displayed five profiles of school readiness. I gave these profiles the following names: 1) Scholastic, 2) On Par, 3) Room to Grow, 4) Super Regulator, and 5) Wiggler. In the next chapter, I outline the analysis plan to address Research Questions Two, Three, and Four. 
Chapter 7: Analysis Plan, Part 2

In the previous chapter, I described the results of my model-based cluster analysis procedure to determine school readiness profiles based on children's math, reading, social, and engagement skills upon entering kindergarten. Five profiles of school readiness were found. In the next chapter, I lay out my analytical plans to describe the children in each profile based on their demographic characteristics (Research Question Two), explore the predictive validity of the profiles on six indicators of kindergarten success (Research Question Three), and compare my person-centered techniques to more traditional, variable-centered techniques (Research Question Four).

\section{Research Question Two}

Once I selected the cluster solutions based on the previously mentioned criteria, I described the children in each of school readiness profiles by their demographic characteristics. I determined the percentages of sex, race, ethnicity, SES, primary nonparental care during the year prior to kindergarten, and primary language spoken at home within each profile. I compared the percentages of the demographic variables within each profile to the demographic composition of the grand population to determine if particular characteristics were over- or under-represented within each profile.

In addition to percentages, I used a series of multinomial logistic regressions to determine the likelihood of profile membership for children with particular demographic characteristics. In each multinomial logistic regression model, the On Par school readiness profile was used as the referent profile. 
PROFILES OF SCHOOL READINESS

\section{Research Question Three}

I used a series of regression models to determine the predictive validity of the selected school readiness profiles on six key indicators of kindergarten success: 1)

reading achievement, 2) math achievement, 3) teacher-rated engagement, 4) teacher-rated social skills, particularly 5) teacher-rated self control and 6) teacher-rated externalizing problem behaviors. Specifically, as I was interested in how these indicators of success changed from fall to spring, I used change scores - defined as the difference between Spring and Fall scores - for each continuous outcome measure (1-5). Recall that externalizing problem behaviors displayed a positively skewed distribution, such that teachers reported the majority of children as never or rarely displaying problem behaviors. Therefore, externalizing problem behaviors, when isolated from the larger social skills scale, was dichotomized such that children who on average never or rarely displayed externalizing problem behaviors received a 0 and children who on average often or very often displayed externalizing problem behavior received a 1. Because of this, I used logistic regression models to predict the likelihood of children displaying externalizing problem behaviors in spring ( 0 or 1$)$ from their cluster membership and whether or not they displayed such behaviors in fall.

To determine if these models needed to reflect the nested nature of schools (children nested within schools ${ }^{2}$ ), I calculated intra-class correlations (ICCs) to determine how much variance in the outcomes was attributed to the nested structure of the data.

2 In educational research, children are often nested within classrooms, and classrooms within schools. However, in the publicly-released version of the ECLS-K data, teacher or class identifications were suppressed. 
The ICCs of each outcome are included in Table 7. The ICCs ranged from 0.05 to

0.19 , indicating that $5-19 \%$ of the variance in the outcome is due to the nested structure of the data. To keep analyses consistent across outcomes, I chose to use multilevel modeling for all analyses.

Table 7

\begin{tabular}{lc} 
Intra-Class Correlations (ICCs) for Outcome Variables \\
\hline \multirow{2}{*}{ Math DS } & ICCs \\
\cline { 2 - 2 } Reading DS & 0.176 \\
Engagement DS & 0.193 \\
Social DS & 0.082 \\
$\quad$ Self Control DS & 0.070 \\
\multicolumn{2}{c}{ Dichotomous Externalizing } \\
$\quad$ Problem Behaviors
\end{tabular}

Note. Difference Score is abbreviated DS.

The person-centered, multilevel equations with math, reading, social, engagement, and self-control change scores as outcomes are included in Equation 1.

(1) Level-1: $y_{i j}=b_{0 \mathrm{j}}+b_{1 \mathrm{j}}\left(\right.$ Scholastic $\left._{i j}\right)+b_{2 \mathrm{j}}\left(\right.$ Room to Grow $\left._{i j}\right)$

$+b_{3 \mathrm{j}}\left(\right.$ Super Regulator $\left._{i j}\right)+b_{4 \mathrm{j}}\left(\right.$ Wiggler $\left._{i j}\right)$

$+b_{5 \mathrm{j}}\left(\right.$ Uncertainty $\left._{i j}\right)+e_{i j}$

Level-2: $b_{0 \mathrm{j}} \sim \mathrm{Y}_{00}+u_{0 \mathrm{j}}$

Combined: $y_{i j}=\mathrm{Y}_{00}+b_{1 \mathrm{j}}\left(\right.$ Scholastic $\left._{i j}\right)+b_{2 \mathrm{j}}\left(\right.$ Room to Grow $\left._{i j}\right)$

$+b_{3 j}\left(\right.$ Super Regulator $\left._{i j}\right)+b_{4 j}\left(\right.$ Wiggler $\left._{i j}\right)$

$+b_{5 j}\left(\right.$ Uncertainty $\left._{i j}\right)+u_{0 \mathrm{j}}+e_{i j}$ 
In these equations, the predictors will be school readiness profile membership, controlling for the level of uncertainty in school readiness profile assignment. Uncertainty in profile assignment was included in the models to increase confidence in the effect of school readiness profile assignment on year-end outcomes. As 0 uncertainty is reasonable and meaningful (represents a perfect assignment), the predictor of uncertainty was not centered in the models. Fall pre-test scores were not included as predictors in these models, as the school readiness profiles were determined based on fall math, reading, social, and engagement skills; while fall self-control scores were not specifically included in the creation of the school readiness profiles, they were included as a component of fall social skills scores. The person-centered, multilevel equation of year-end, dichotomous, externalizing problem behaviors is included in Equation 2.

(2) Level-1: $\operatorname{logit}($ yes $)=b_{0 \mathrm{j}}+b_{1 \mathrm{j}}\left(\right.$ Scholastic $\left._{i j}\right)+b_{2 \mathrm{j}}\left(\right.$ Room to Grow $\left._{i j}\right)$

$+b_{3 \mathrm{j}}\left(\right.$ Super Regulator $\left._{i j}\right)+b_{4 \mathrm{j}}\left(\right.$ Wiggler $\left._{i j}\right)$

$+b_{5 \mathrm{j}}\left(\right.$ Fall Externalizing Problem Behavior $\left._{i j}\right)$

$+b_{6 \mathrm{j}}\left(\right.$ Uncertainty $\left._{i j}\right)+e_{i j}$

Level-2: $\quad b_{0 \mathrm{j}}=\mathrm{Y}_{00}+u_{0 \mathrm{j}}$

Combined: logit $($ yes $)=\mathrm{Y}_{00}+b_{1 \mathrm{j}}\left(\right.$ Scholastic $\left._{i j}\right)+b_{2 \mathrm{j}}\left({\left.\text { Room to } \text { Grow }_{i j}\right)}\right)$

$+b_{3 \mathrm{j}}\left(\right.$ Super Regulator $\left._{i j}\right)+b_{4 \mathrm{j}}\left(\right.$ Wiggler $\left._{i j}\right)$

$+b_{5 \mathrm{j}}\left(\right.$ Fall Externalizing Problem Behavior $\left._{i j}\right)$

$+b_{6 \mathrm{j}}\left(\right.$ Uncertainty $\left._{i j}\right)+e_{i j}+u_{0 \mathrm{j}}$

Like the previous person-centered models, this model controlled for each child's level of uncertainty in school readiness profile assignment. In this equation, I added dichotomous fall externalizing problem behavior scores as a predictor. This is because, 
while fall externalizing problem behaviors was included as a continuous sub-scale of the fall social skills composite score (along with interpersonal skills, self control, internalizing problem behaviors) in school readiness profile creation, the dichotomous conceptualization of externalizing problem behaviors was not. For each person-centered model, I used the On Par school readiness profile as the reference group.

\section{Research Question Four}

To compare the person-centered analysis to more traditional variable-centered analyses, I created a set of variable-centered models utilizing the same outcomes as the person-centered models. The predictor variables, however, were replaced with standardized fall math, reading, social, and engagement skill scores, such that the scores had a mean of 0 and a standard deviation of 1 . Thus, the intercepts in these models represented the outcome for a child who entered kindergarten with average school entry scores. The equations for the variable-centered models are included as Equations 3 and 4.

(3) Level-1: $y_{i j}=b_{0 \mathrm{j}}+b_{1 \mathrm{j}}\left(\right.$ Standardized Fall Math $\left.{ }_{i j}\right)$

$+b_{2 j}\left(\right.$ Standardized Fall Reading $\left.{ }_{i j}\right)$

$+b_{3 \mathrm{j}}\left(\right.$ Standardized Fall Social $\left._{i j}\right)+b_{4 \mathrm{j}}\left(\right.$ Standardized Fall Engagement $\left._{i j}\right)$

$$
+e_{i j}
$$

Level-2: $b_{0 \mathrm{j}} \sim \mathrm{Y}_{00}+u_{0 \mathrm{j}}$

Combined: $y_{i j}=\mathrm{Y}_{00}+b_{1 \mathrm{j}}\left(\right.$ Standardized Fall Math $\left.{ }_{i j}\right)$

$+b_{2 \mathrm{j}}\left(\right.$ Standardized Fall Reading $\left._{i j}\right)$

$+b_{3 \mathrm{j}}\left(\right.$ Standardized Fall Social $\left._{i j}\right)+b_{4 \mathrm{j}}\left(\right.$ Standardized Fall Engagement $\left._{i j}\right)$

$$
+u_{0 j}+e_{i j}
$$


(4) Level-1: $\operatorname{logit}($ yes $)=b_{0 \mathrm{j}}+b_{1 \mathrm{j}}\left(\right.$ Standardized Fall Math $\left.{ }_{i j}\right)$

$+b_{2 \mathrm{j}}\left(\right.$ Standardized Fall Reading $\left._{i j}\right)+b_{3 \mathrm{j}}\left(\right.$ Standardized Fall Social $\left._{i j}\right)$

$+b_{4 \mathrm{j}}\left(\right.$ Standardized Fall Engagement $\left.{ }_{i j}\right)$

$+b_{5 \mathrm{j}}\left(\right.$ Fall Externalizing Problem Behavior $\left._{i j}\right)+e_{i j}$

Level-2: $\quad b_{0 \mathrm{j}}=\mathrm{Y}_{00}+u_{0 \mathrm{j}}$

Combined: logit $($ yes $)=\mathrm{Y}_{00}+b_{1 \mathrm{j}}\left(\right.$ Standardized Fall Math $\left.{ }_{i j}\right)$

$+b_{2 \mathrm{j}}\left(\right.$ Standardized Fall Reading $\left._{i j}\right)+b_{3 \mathrm{j}}\left(\right.$ Standardized Fall Social $\left._{i j}\right)$

$+b_{4 \mathrm{j}}\left(\right.$ Standardized Fall Engagement $\left._{i j}\right)$

$+b_{5 \mathrm{j}}\left(\right.$ Fall Externalizing Problem Behavior $\left._{i j}\right)+e_{i j}+u_{0 \mathrm{j}}$

\section{Chapter Summary}

In this chapter, I briefly outlined my analytical plan to answer Research Questions

Two, Three, and Four. Descriptive percentages were used to describe the demographic compositions of the children within the profiles compared the grand population.

Additionally, multinomial regression was used to predict school readiness profile membership by key demographic variables (sex, race, ethnicity, SES, primary care prior to kindergarten, and primary language spoken at home), while multi-level regression and multi-level logistic regression was used to test the predictive validity of the school readiness profiles to end-of-year kindergarten outcomes. In the upcoming chapter, I describe the results these analytic methods revealed. 


\section{Chapter 8: Results, Part 2}

Chapter 7 discussed the analytic methods I used to address Research Questions Two, Three, and Four. The current chapter communicates the results of these analyses. I begin by describing the results of the multinomial logistic regressions that predict school readiness profile membership by key demographic variables. Then, I describe how school readiness profile membership predicts the development of math, reading, engagement, and social skills, specifically teacher-valued classroom behaviors of self-control and externalizing problem behaviors. Finally, I describe the results of the variable-centered analysis and compare it to the results of the person-centered analysis.

\section{Research Question Two}

Demographic compositions of the grand population and of the five school readiness profiles are included in Table 8 . Results of the multinomial logistic regressions predicting school readiness profile membership from the demographic variables of Race, Ethnicity, Primary Care Prior to Kindergarten, Sex, SES, and Primary Language at Home are included in Tables 9-14. Notable demographic features of the school readiness profiles and Odds Ratios are outlined below.

\section{On Par.}

Percentages and means. The On Par profile had the highest percentage of White students (73.95\%), the second lowest percentage of Asian students (6.02\%), and the lowest percentage of multiracial students (5.52\%) of the school readiness profiles. Compared to the grand population, White and Hawaiian/Pacific Islander students were over-represented in the On Par profile, while Asian, Black, and multiracial students were 


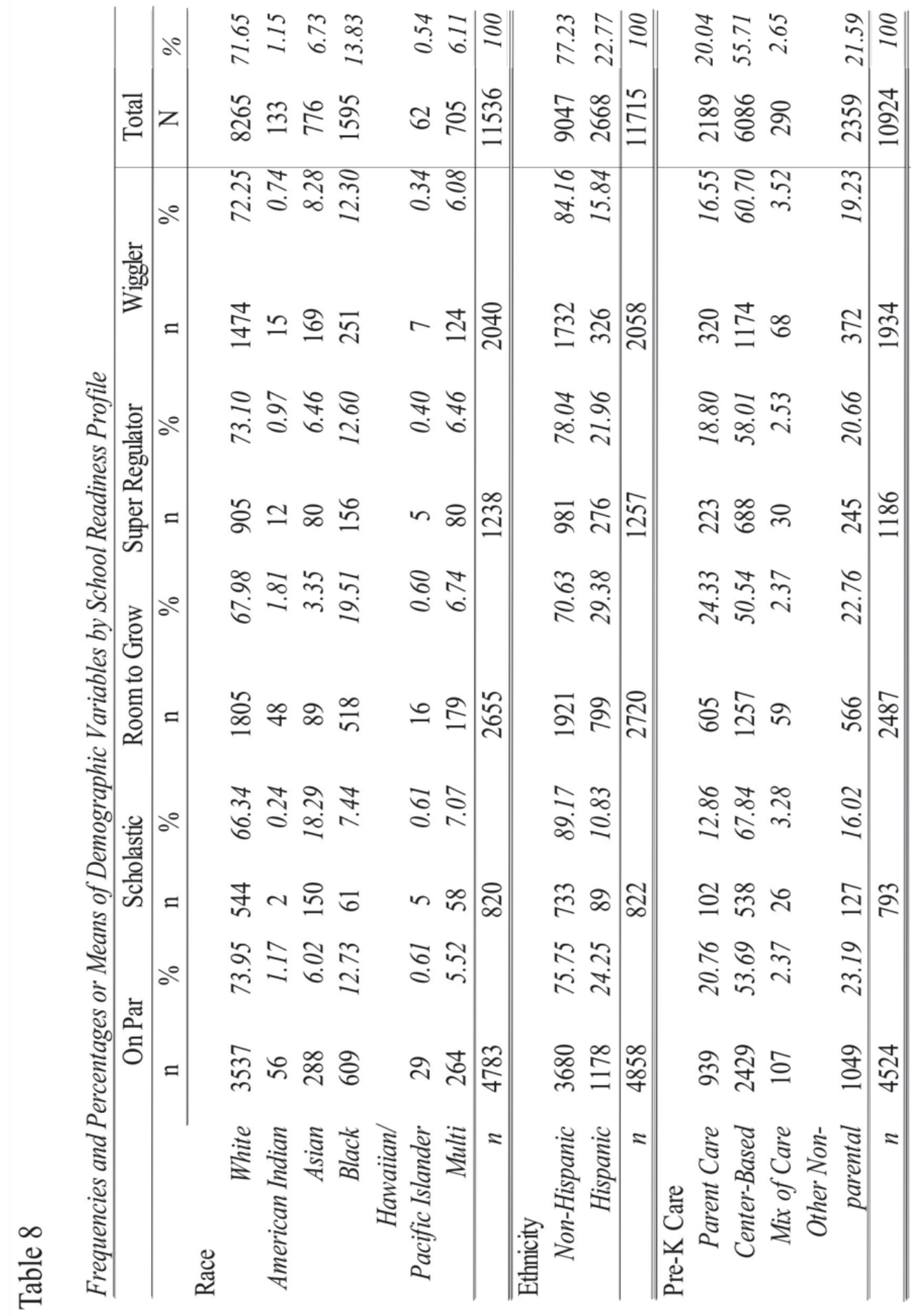


PROFILES OF SCHOOL READINESS

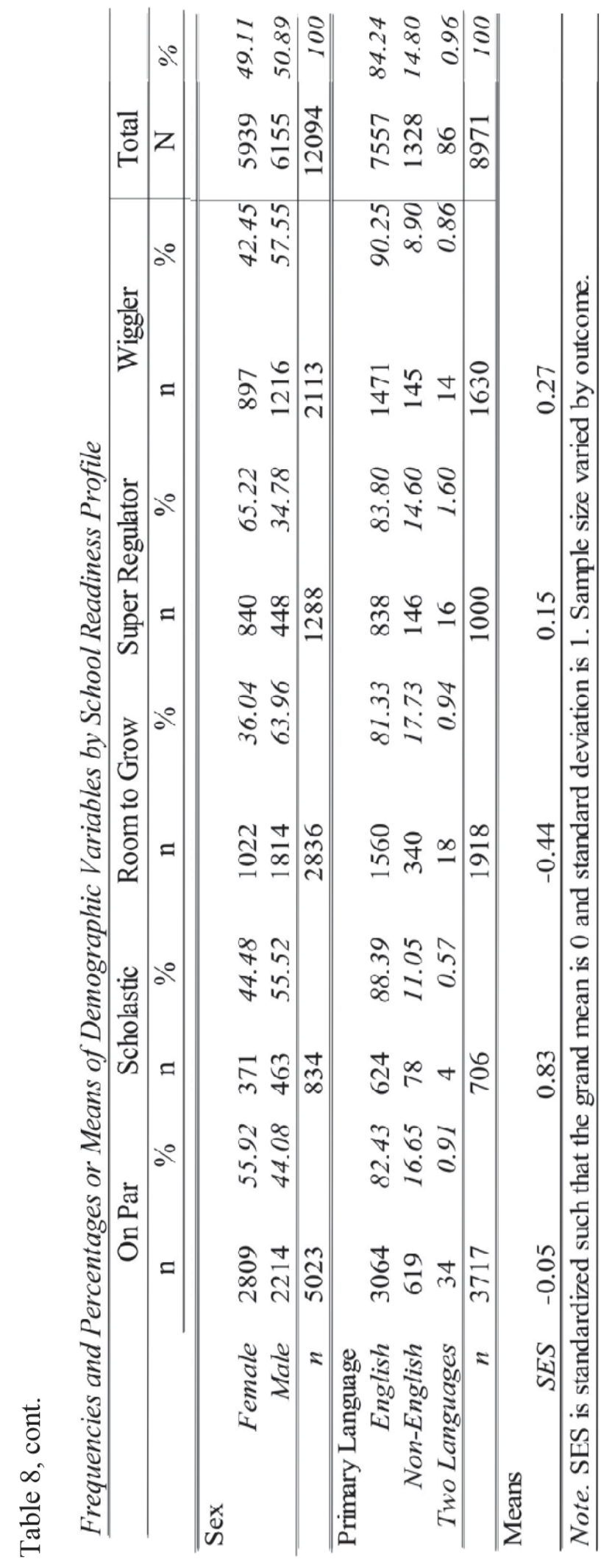




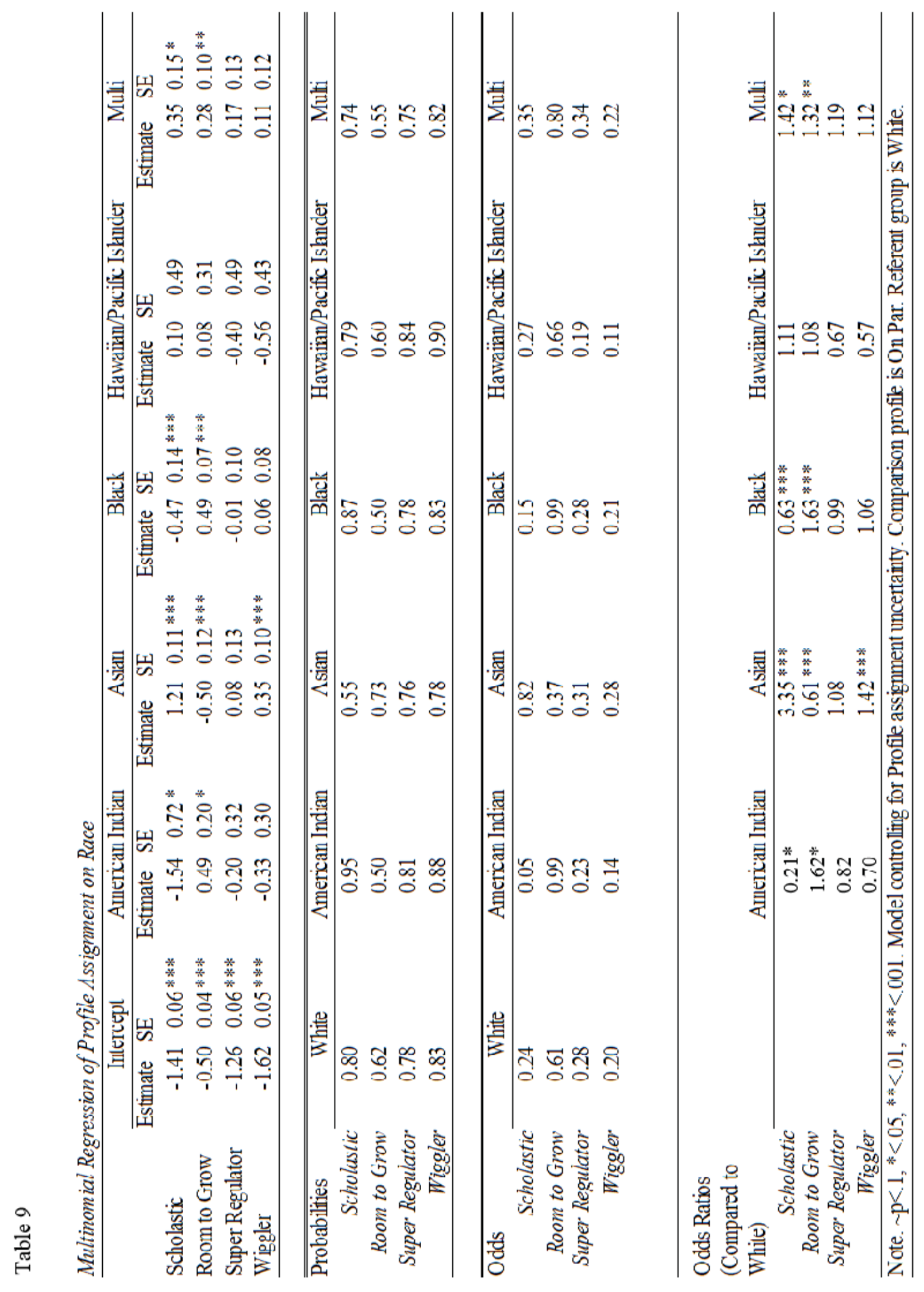


Table 10

Multinomial Regression of Profile Assignment on Ethnicity

\begin{tabular}{|c|c|c|}
\hline & Intercept & Hispanic \\
\hline & Estimate $\mathrm{SE}$ & Estimate $\mathrm{SE}$ \\
\hline Scholastic & $-1.150 .06 * * *$ & $-1.010 .12 * * *$ \\
\hline Room to Grow & $-0.46 \quad 0.04 * * *$ & $0.24 \quad 0.05 * * *$ \\
\hline Super Regulator & $-1.220 .05 * * *$ & $-0.14 \quad 0.07 \sim$ \\
\hline Wiggler & $-1.490 .05 * * *$ & $-0.48 \quad 0.07 * * *$ \\
\hline Probabilities & Non-Hispanic & Hispanic \\
\hline Scholastic & 0.76 & 0.90 \\
\hline Room to Grow & 0.61 & 0.55 \\
\hline Super Regulator & 0.77 & 0.80 \\
\hline Wiggler & 0.82 & 0.88 \\
\hline$\overline{\text { Odds }}$ & Non-Hispanic & Hispanic \\
\hline Scholastic & 0.32 & 0.12 \\
\hline Room to Grow & 0.63 & 0.80 \\
\hline Super Regulator & 0.30 & 0.26 \\
\hline Wiggler & 0.23 & 0.14 \\
\hline
\end{tabular}

Odds Ratios

(Compared to

Non-Hispanic)

Hispanic

Scholastic

$0.36 * * *$

Room to Grow

$1.27 * * *$

Super Regulator

$0.87 \sim$

Wiggler

$0.62 * * *$

Note. $\sim \mathrm{p}<.1, *<.05, * *<.01, * * *<.001$. Model controlling for

Profile assignment uncertainty. Comparison profile is Average Joe.

Referent group is Non-Hispanic. 


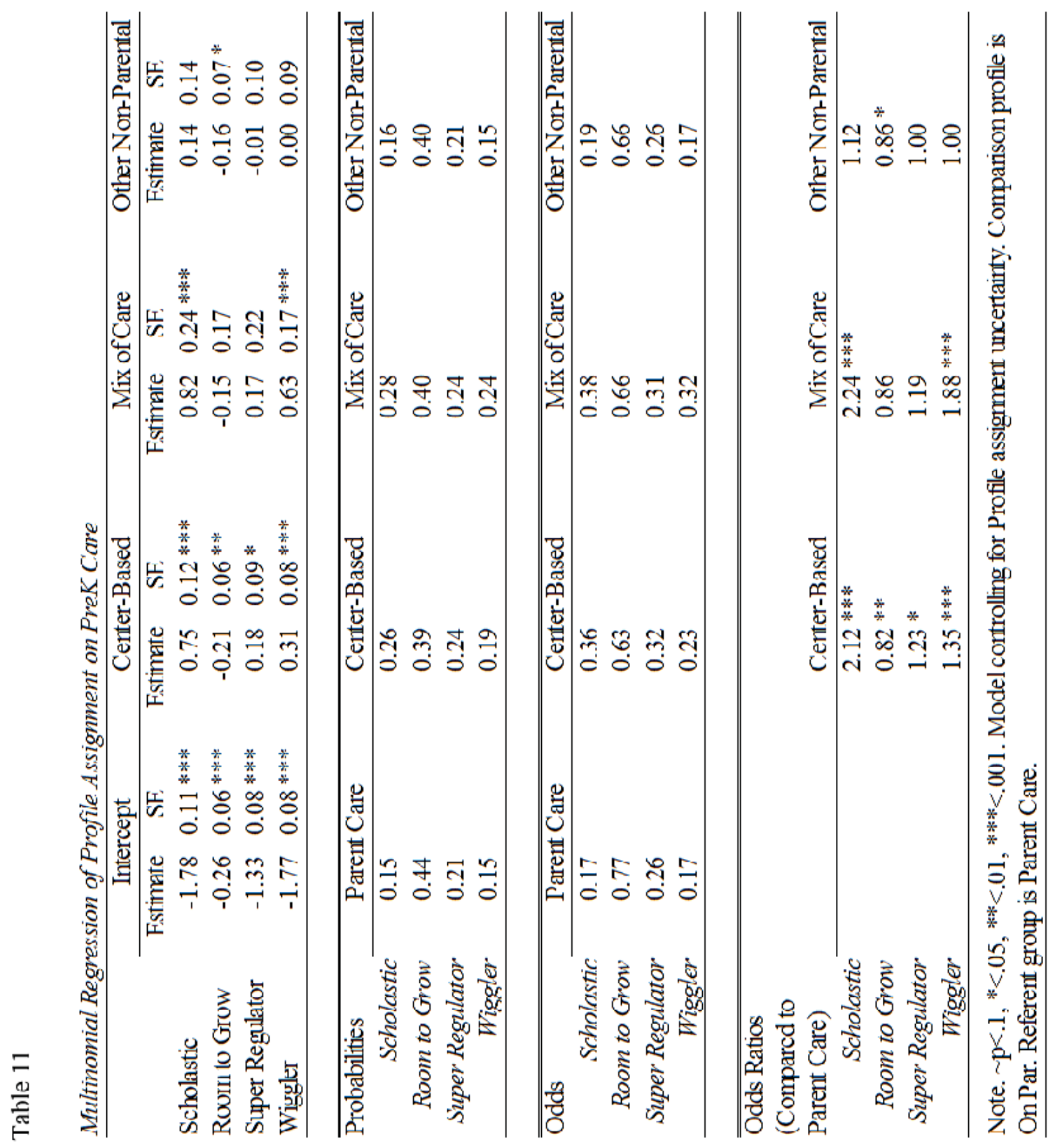


Table 12

Multinomial Regression of Profile Assignment on Sex

\begin{tabular}{|c|c|c|}
\hline & Intercept & Female \\
\hline & Estimate $\quad \mathrm{SE}$ & Estimate \\
\hline Scholastic & $-1.14 \quad 0.07 * * *$ & $-0.47 \quad 0.08 * * *$ \\
\hline Room to Grow & $0.01 \quad 0.04$ & $\begin{array}{ll}-0.82 & 0.05 * * *\end{array}$ \\
\hline Super Regulator & $-1.50 \quad 0.07 * * *$ & $0.39 \quad 0.07 * * *$ \\
\hline Wiggler & $-1.330 .06 * * *$ & $-0.53 \quad 0.05 * * *$ \\
\hline Probabilities & Male & Female \\
\hline Scholastic & 0.24 & 0.17 \\
\hline Room to Grow & 0.50 & 0.31 \\
\hline Super Regulator & 0.18 & 0.25 \\
\hline Wiggler & 0.21 & 0.14 \\
\hline$\overline{\text { Odds }}$ & Male & Female \\
\hline Scholastic & 0.32 & 0.20 \\
\hline Room to Grow & 1.01 & 0.44 \\
\hline Super Regulator & 0.22 & 0.33 \\
\hline Wiggler & 0.26 & 0.16 \\
\hline
\end{tabular}

Odds Ratios

(Compared to

Male

Female

\begin{tabular}{rr} 
Scholastic & $0.63 * * *$ \\
Room to Grow & $0.44 * * *$ \\
Super Regulator & $1.50 * * *$ \\
Wiggler & $0.62 * * *$ \\
\hline
\end{tabular}

Note. $\sim \mathrm{p}<.1, *<.05, * *<.01, * * *<.001$. Model controlling for Profile assignment uncertainty. Comparison profile is On Par. Referent group is Male. 
Table 13

Multinomial Regression of Profile Assignment on SES

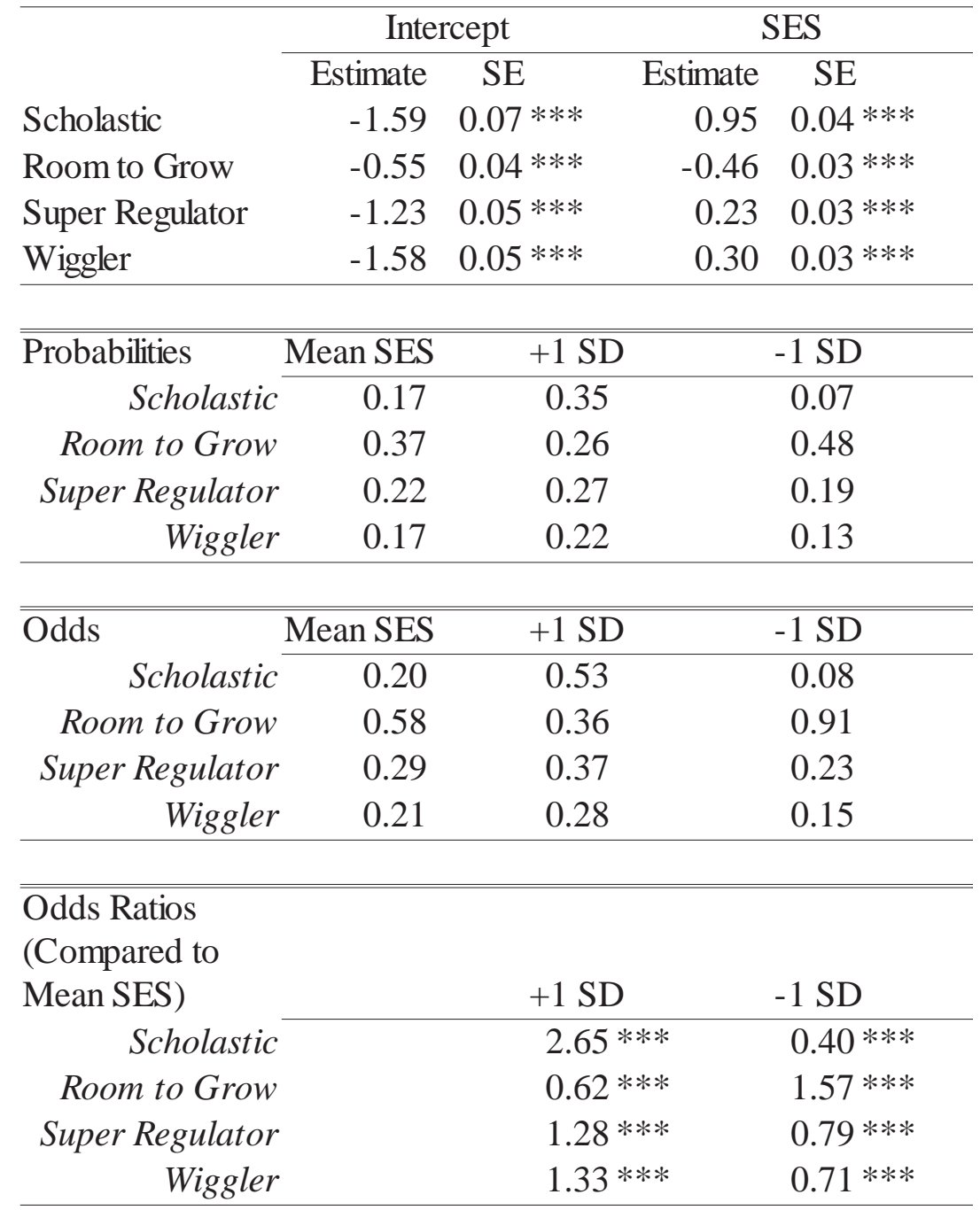

Note. $\sim \mathrm{p}<.1, *<.05, * *<.01, * * *<.001$. Model controlling for Profile assignment uncertainty. Comparison profile is On Par. SES is standardized, such that the mean is 0 and standard deviation is 1 . 
Table 14

Multinomial Regression of Profile Assignment on Primary Language Spoken At Home

\begin{tabular}{|c|c|c|c|}
\hline & Intercept & Non-English Language & Two Languages \\
\hline & Estimate & Estimate & Estimate \\
\hline Scholastic & $-1.08 \quad 0.07 * * *$ & $-0.550 .13 * * *$ & $-0.55 \quad 0.29$ \\
\hline Room to Grow & $-0.520 .05 * * *$ & $0.06 \quad 0.07$ & $0.04 \quad 0.18$ \\
\hline Super Regulator & $-1.190 .06 * * *$ & $-0.16 \quad 0.10$ & $0.54 \quad 0.22 \sim$ \\
\hline Wiggler & $-1.50 \quad 0.06 * * *$ & $-0.630 .10 * * *$ & $-0.19 \quad 0.18 * * *$ \\
\hline Probabilities & English & Non-English Language & Two Languages \\
\hline Scholastic & 0.25 & 0.17 & 0.17 \\
\hline Room to Grow & 0.37 & 0.36 & 0.38 \\
\hline Super Regulator & 0.23 & 0.21 & 0.34 \\
\hline Wiggler & 0.18 & 0.11 & 0.15 \\
\hline$\overline{\overline{O d d s}}$ & English & Non-English Language & Two Languages \\
\hline Scholastic & 0.34 & 0.20 & 0.20 \\
\hline Room to Grow & 0.59 & 0.56 & 0.62 \\
\hline Super Regulator & 0.30 & 0.26 & 0.52 \\
\hline Wiggler & 0.22 & 0.12 & 0.18 \\
\hline \multicolumn{4}{|l|}{$\begin{array}{l}\text { Odds Ratios } \\
\text { (Compared to }\end{array}$} \\
\hline & & Non-English Language & Two Languages \\
\hline Scholastic & & $0.59 * * *$ & 0.59 \\
\hline Room to Grow & & 0.95 & 1.05 \\
\hline Super Regulator & & 0.87 & $1.73 \sim$ \\
\hline Wiggler & & $0.55 * * *$ & $0.82 * * *$ \\
\hline
\end{tabular}

Note. $\sim \mathrm{p}<.1, *<.05, * *<.01, * * *<.001$. Model controlling for Profile assignment uncertainty.

Comparison profile is On Par. Referent group is English speakers. 
underrepresented. More female students belonged to the On Par profile than male students, though this difference was minor (55.92\% female). Finally, the On Par profile had the level of SES closest to the grand mean (-0.05 SDs below the grand mean).

Odds Ratios. In all multinomial logistic regression analyses, the reference school readiness profile was the On Par profile.

\section{Scholastic.}

Percentages and means. The Scholastic profile had the lowest percentage of White kindergartners (66.34\%), the lowest percentage of American Indian kindergartners $(0.24 \%)$, the lowest percentage of Black students $(7.44 \%)$, and the highest percentage of Asian kindergartners (18.29\%) of all the school readiness profiles. Compared to the overall population, Asian, Multiracial, and Pacific Islander students were overrepresented in the Scholastic profile, while White, American Indian, and Black students were underrepresented. It also had an under-representation of Hispanic kindergartners $(10.83 \%)$ and an over-representation of students who attended center-based preschools (67.84\%). The Scholastic profile was primarily made up of males, though the difference was minor (55.52\% male). Finally, children in the Scholastic profile had the highest average SES (0.83 SDs above the grand mean).

Odds Ratios. The reference profile for this analysis was the On Par profile. Race and ethnicity. Asian kindergartners were 3.35 times more likely and multiracial kindergartners 1.42 times more likely to be in the Scholastic profile than White kindergartners. On the other hand, White kindergartners were 1.59 times more likely to be in the Scholastic profile than Black kindergartners (1/0.63) and 4.76 times 
more likely to be in the Scholastic profile that American Indian kindergartners (1/0.21). Non-Hispanic kindergartners were 2.78 times more likely to be in the Scholastic profile than Hispanic kindergartners (1/0.36).

Primary care prior to kindergarten. Children who attended center-based

preschool were 2.12 times more likely and children who had a mix of preschool care experiences were 2.24 times more likely to be in the Scholastic profile than those who had only parental care.

Sex. Boys were 1.59 times more likely to be in the Scholastic profile than girls $(1 / 0.63)$.

SES. Children one SD above the grand mean in SES were 2.65 times more likely to be in the Scholastic profile than children with average SES.

Primary language spoken at home. English speaking kindergartners were 1.69 times more likely to be in the Scholastic profile than non-English speaking kindergartners.

\section{Room to Grow.}

Percentages and means. The Room to Grow profile had the highest percentage of American Indian kindergartners (1.81\%) and Black kindergartners (19.51\%), and also had the lowest percentage of Asian kindergartners (3.35\%). Compared to the overall population, White and Asian students were underrepresented in the Room the Grow profiles, while Black, American Indian, Pacific Islander, and multiracial kindergartners were over-represented. This profile also had the greatest over-representation of Hispanic students (29.38\%). Additionally, the Room to Grow profile had the highest percentage of 
children who had primarily parental care $(24.33 \%)$ and the lowest percentage of children who attended center-based preschool (50.54\%). Male kindergartners (63.96\%) and nonEnglish speakers (17.73\%) were over-represented in the Room the Grow profile. Finally, the Room to Grow profile had the lowest average SES (0.44 SDs below the grand mean).

Odds Ratios. The reference profile for this analysis was the On Par profile.

Race and ethnicity. Black kindergartners were 1.63 times more likely, American Indian kindergartners 1.62 times more likely, and multiracial kindergartners 1.32 times more likely to be in the Room to Grow profile than White kindergartners. On the other hand, White students were 1.64 times more likely than Asian kindergartners (1/0.61) to be in the Room to Grow profile. Hispanic students were 1.27 times more likely to be in the Room to Grow profile than non-Hispanic kindergartners.

Primary care prior to kindergarten. Children who only had parent care prior to kindergarten were 1.21 times more likely than those who attended center-based care $(1 / 0.82)$ and 1.16 times more likely that those who had other non-parental care $(1 / 0.86)$ to be in the Room to Grow profile.

Sex. Boys were 2.27 times more likely to be in the Room to Grow profile than girls (1/0.44).

SES. Children one SD below the grand mean in SES were 1.57 times more likely to be in the Room to Grow profile than children with average SES.

\section{Super Regulator.}

Percentages and means. The Super Regulator profile had highest percentage of female kindergartners $(65.22 \%)$ of all the school readiness profiles. This was the primary 
feature that distinguished it from the other profiles. Compared to the grand population, White, Asian, and multiracial students were over-represented, while American Indian, Black, and Pacific Islander kindergartners were underrepresented. The ethnic breakdown of the Super Regulator profile was similar to that of the grand population. Kindergartners with Center-based care Pre-K care were slightly over-represented, while kindergartners with parent care were slightly under-represented. Kindergartners who were exposed to two languages equally at home were slightly over-represented in the Super Regulator profile. Finally, the Super Regulator profile had slightly above average SES (0.15 SDs above the grand mean).

Odds Ratios. The reference profile for this analysis was the On Par profile. Ethnicity. Non-Hispanic students were 1.15 times more likely that Hispanic students to be in the Super Regulator profile (1/0.87; marginally significant).

Primary care prior to kindergarten. Children who attended center-based preschool prior to kindergarten were 1.23 times more likely than children who had only parental care to be in the Super Regulator profile.

Sex. Girls were 1.50 times more likely to be in the Super Regulator profile than boys.

SES. Children one SD above the grand mean in SES were 1.28 times more likely to be in the Super Regulator profile than children with average SES.

Primary language spoken at home. Children who spoke two language at home were 1.73 times more likely to be in the Super Regulator profile than those who spoke only English (marginally significant). 
PROFILES OF SCHOOL READINESS

Wiggler.

Percentages and means. The Wiggler profile had the lowest percentage of Pacific Islander kindergartners $(0.34 \%)$ of all the profiles. Compared to the grand population, Pacific Islander, Black, and American Indian kindergartners were underrepresented in the Wiggler profile, while Asian students were over-represented. It also had an overrepresentation of kindergartners with a mix preschool care experiences $(3.52 \%)$ and those who attended center-based care $(66.70 \%)$, while there was an under-representation of kindergartners with only parent care experiences. Male kindergartners were overrepresented in the Wiggler profile (57.55\%). Additionally, the Wiggler profile had the highest percentage of English speakers $(90.25 \%)$, while children with who hear nonEnglish languages or two languages equally at home were underrepresented compared to the grand population. Finally, the Wiggler profile had the second highest SES of the profiles (0.27 SDs above the grand mean).

Odds Ratios. The reference profile for this analysis was the On Par profile.

Race and ethnicity. Asian kindergartners were 1.42 times more likely to be in the Wiggler profile than White kindergartners. Non-Hispanic children were 1.61 times more likely to be in the Wiggler profile than Hispanic children (1/0.62).

Primary care prior to kindergarten. Children who attended center-based care were 1.35 times more likely and children who had a mix of care experiences were 1.88 times more likely than those who only had parental care prior to kindergarten to be in the Wiggler profile. 
PROFILES OF SCHOOL READINESS

Sex. Boys were 1.62 times more likely to be in the Wiggler profile than girls $(1 / 0.62)$.

SES. Children one SD above the grand mean in SES were 1.33 times more likely to be in the Wiggler profile than children with average SES.

Primary languages spoken at home. Children who spoke English at home were 1.82 times more likely than non-English speakers (1/0.55) and 1.21 times more likely than those who spoke two languages at home (1/0.82) to be in the Wiggler profile.

\section{Research Questions Three and Four}

Results of the person-centered and variable-centered models looking at the primary achievement outcomes (math, reading, social skills, and engagement difference scores) are included as Table 15. Results of the person-centered and variable-centered models looking at the secondary achievement outcomes (self-control difference score and dichotomous externalizing problem behaviors) are included as Table 16.

\section{Research Question Three.}

Figures 10 and 11 display model-estimated change scores for math, reading, social skills, engagement, and self control for members within the school readiness profiles. Table 17 displays the means and standard deviations of spring math, reading, social skills, engagement, self control, and dichotomous externalizing problem behaviors by profile. Figures 12 through 16 include fall and spring mean levels of each continuous outcomes by profile. In the upcoming sections, I describe how the kindergartners within the school readiness profiles ranked in the outcomes of interest at the end of the year and how they changed across the year (between fall and spring). 


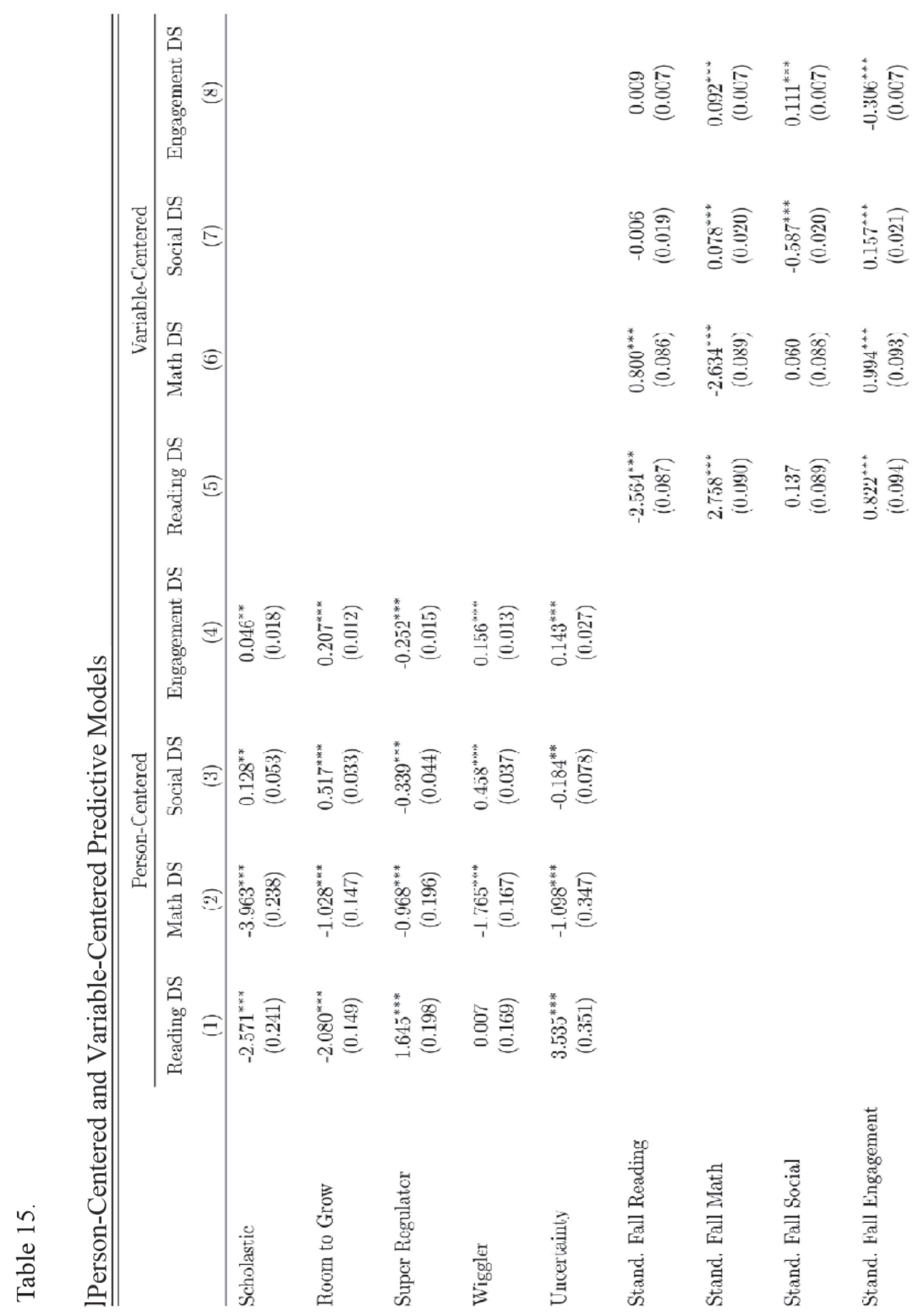




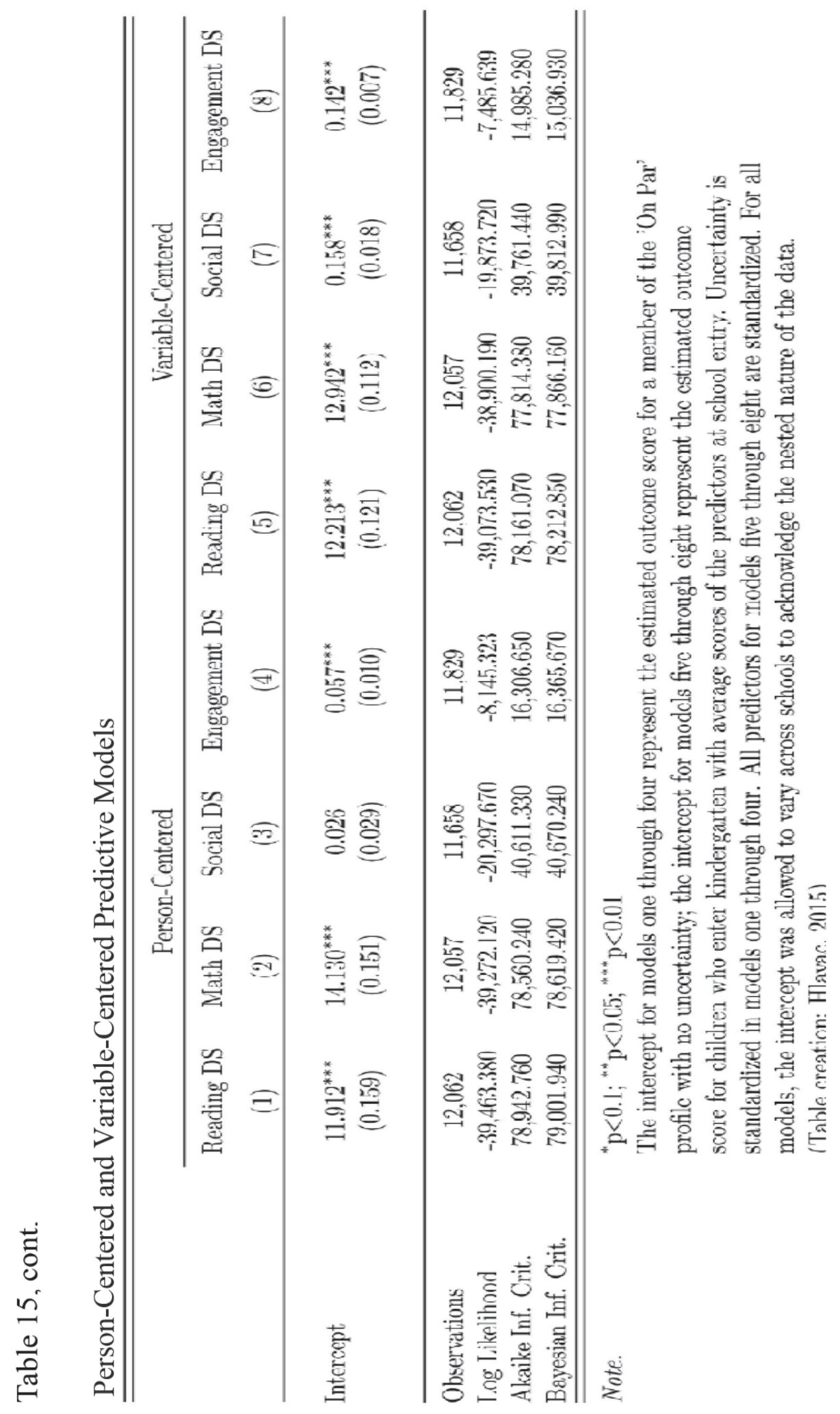


PROFILES OF SCHOOL READINESS

Table 16

Secondary Person-Centered and Variable-Centered Predictive Models

\begin{tabular}{|c|c|c|c|c|}
\hline & \multicolumn{2}{|c|}{ Self Control Difference Score } & \multicolumn{2}{|c|}{$\begin{array}{c}\text { Spring Dichotomous Externalizing Problem } \\
\text { Behaviors }\end{array}$} \\
\hline & $\begin{array}{c}\text { Person-Centered } \\
\text { (1) }\end{array}$ & $\begin{array}{l}\text { Variable-Centered } \\
\text { (2) }\end{array}$ & $\begin{array}{c}\text { Person-Centered } \\
\text { (3) }\end{array}$ & $\begin{array}{c}\text { Variable-Centered } \\
\text { (4) }\end{array}$ \\
\hline \multirow[t]{2}{*}{ Scholastic } & $0.040 *$ & & $0.296^{*}$ & \\
\hline & $(0.020)$ & & $(0.136)$ & \\
\hline \multirow{2}{*}{ Room to Grow } & $0.165 * * *$ & & $2.163 * * *$ & \\
\hline & $(0.012)$ & & $(0.073)$ & \\
\hline \multirow[t]{2}{*}{ Super Regulator } & $-0.132 * * *$ & & $-1.601 * * *$ & \\
\hline & $(0.016)$ & & $(0.259)$ & \\
\hline \multirow[t]{2}{*}{ Wiggler } & $0.143 * * *$ & & $1.833 * * *$ & \\
\hline & $(0.014)$ & & $(0.081)$ & \\
\hline \multirow[t]{2}{*}{ Uncertainty } & $-0.063 *$ & & $-1.842 * * *$ & \\
\hline & $(0.029)$ & & $(0.172)$ & \\
\hline \multicolumn{5}{|l|}{ Fall Dichotomous } \\
\hline \multicolumn{5}{|l|}{ Externalizing Problem } \\
\hline \multirow[t]{2}{*}{ Behaviors } & & & $0.855^{* * *}$ & $0.466 * * *$ \\
\hline & & & $(0.068)$ & $(0.073)$ \\
\hline \multirow[t]{2}{*}{ Stand. Fall Reading } & & 0.002 & & 0.043 \\
\hline & & $(0.007)$ & & $(0.050)$ \\
\hline \multirow[t]{2}{*}{ Stand. Fall Math } & & $0.023 * *$ & & -0.006 \\
\hline & & $(0.007)$ & & $(0.050)$ \\
\hline \multirow[t]{2}{*}{ Stand. Fall Social } & & $-0.169 * * *$ & & $-1.488 * * *$ \\
\hline & & $(0.007)$ & & $(0.050)$ \\
\hline \multirow[t]{2}{*}{ Stand. Fall Engagement } & & $0.028 * * *$ & & $-0.193 * * *$ \\
\hline & & $(0.008)$ & & $(0.050)$ \\
\hline \multirow[t]{2}{*}{ Intercept } & $0.057 * * *$ & $0.095 * * *$ & $-2.920 * * *$ & $-2.544 * * *$ \\
\hline & $(0.011)$ & $(0.007)$ & 0.088 & $(0.071)$ \\
\hline
\end{tabular}

\begin{tabular}{lcccc}
\hline Observations & 11,777 & 11,777 & 11,789 & 11,789 \\
Log Likelihood & $-8,868.514$ & $-8,607.944$ & $-4,474.76$ & $-3,895.888$ \\
Akaike Inf. Crit. & $17,753.030$ & $17,229.890$ & $8,965.52$ & $7,805.776$ \\
Bayesian Inf. Crit. & $17,812.020$ & $17,281.510$ & $9,024.519$ & $7,857.401$ \\
Deviance & & & $8,949.500$ & $7,791.800$ \\
\hline \hline
\end{tabular}

Note. The intercept for models one and three represent the estimated outcome score for a member of the 'On Par' profile with no uncertainty; the intercept for models two and four represent the estimated outcome score for children who enter kindergarten with average scores of the predictors at school entry. Uncertainty is standardized in models one and three. All predictors for models two and four are standardized. For all models, the intercept was allowed to vary across schools to acknowledge the nested nature of the data. Models three and four are logistic regressions. 
Figure 10. Model Estimated Math and Reading Difference Scores by Profile

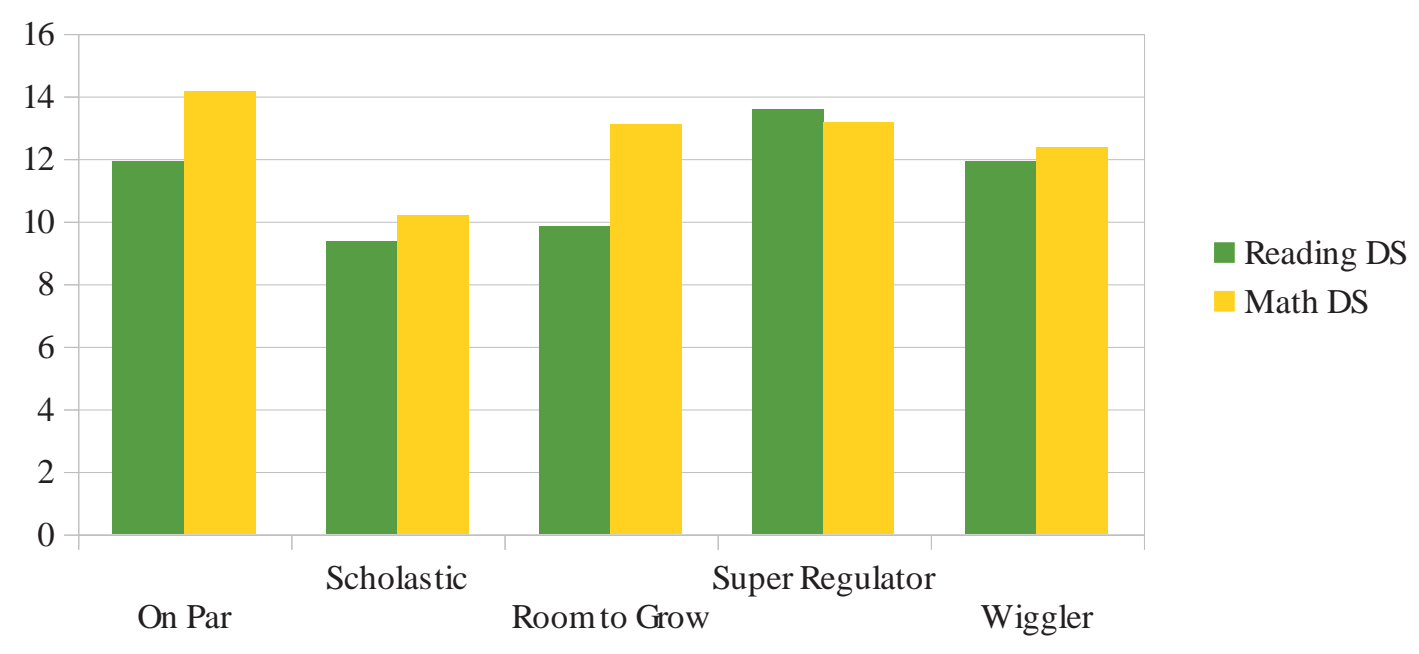

Figure 11. Model Estimated Social, Engagement, and Self Control Difference Scores by Profile

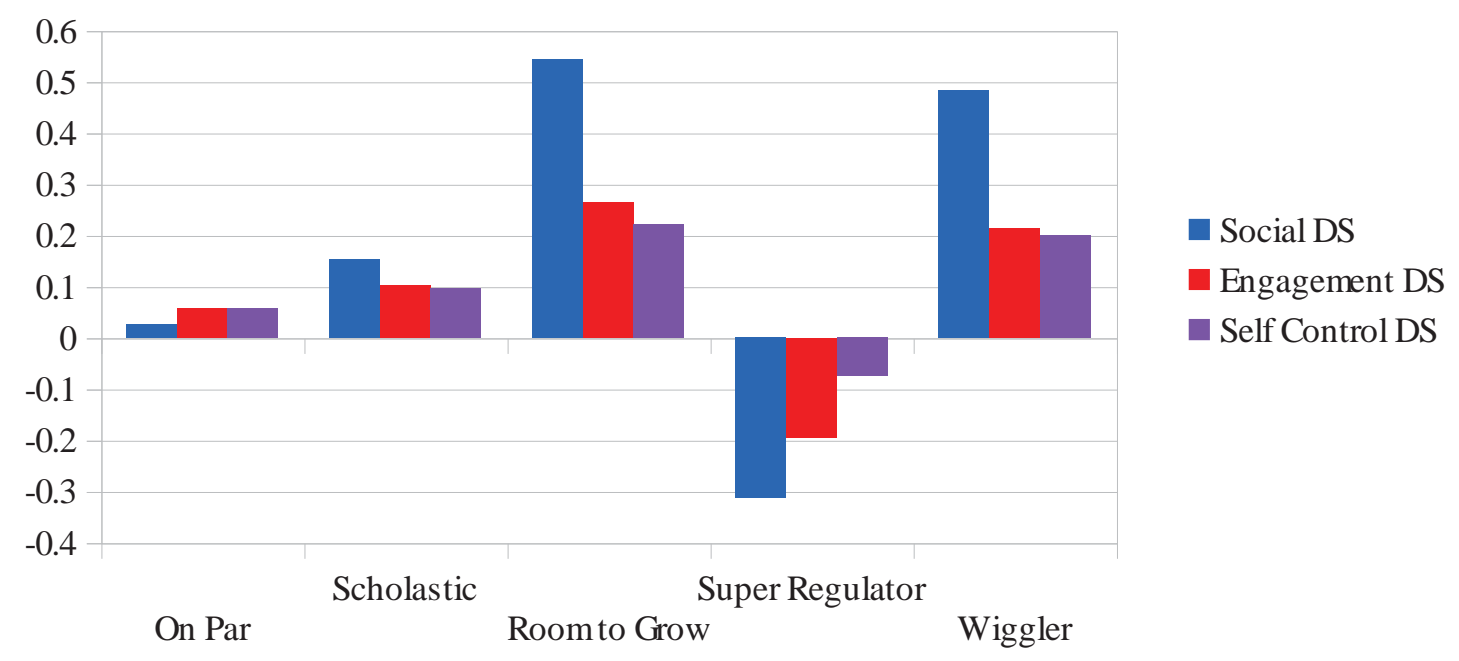




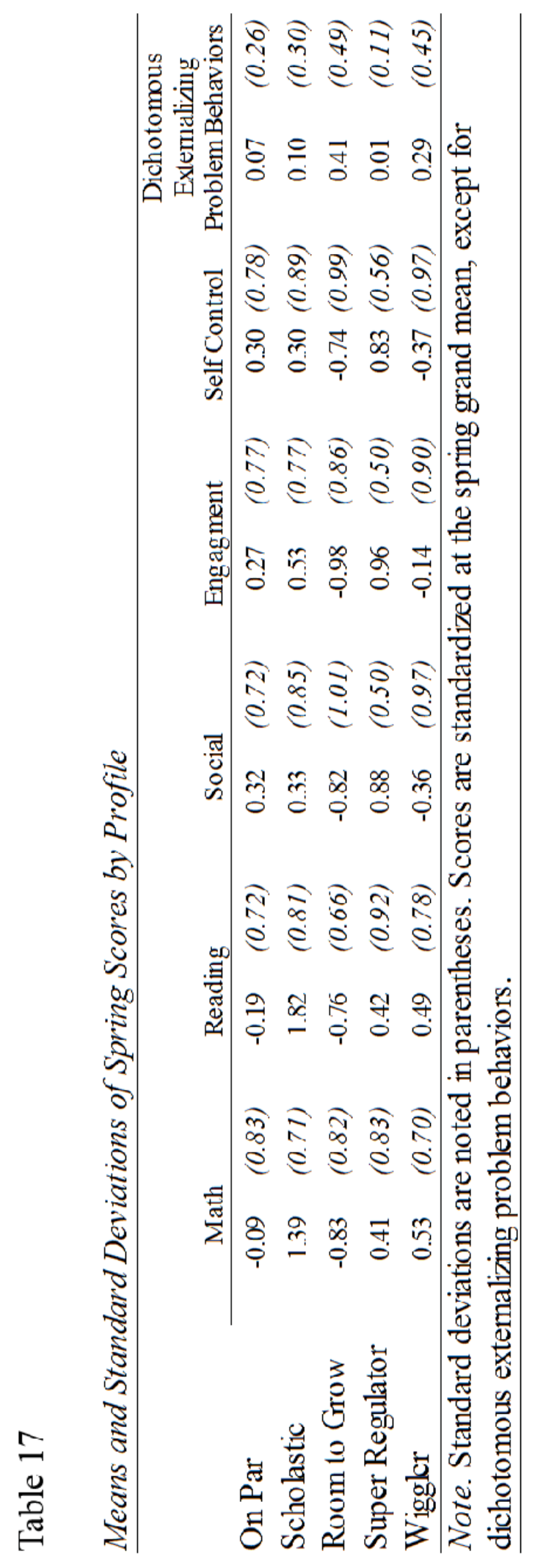


Figure 12. Fall and Spring Mean Levels of Math by Profile

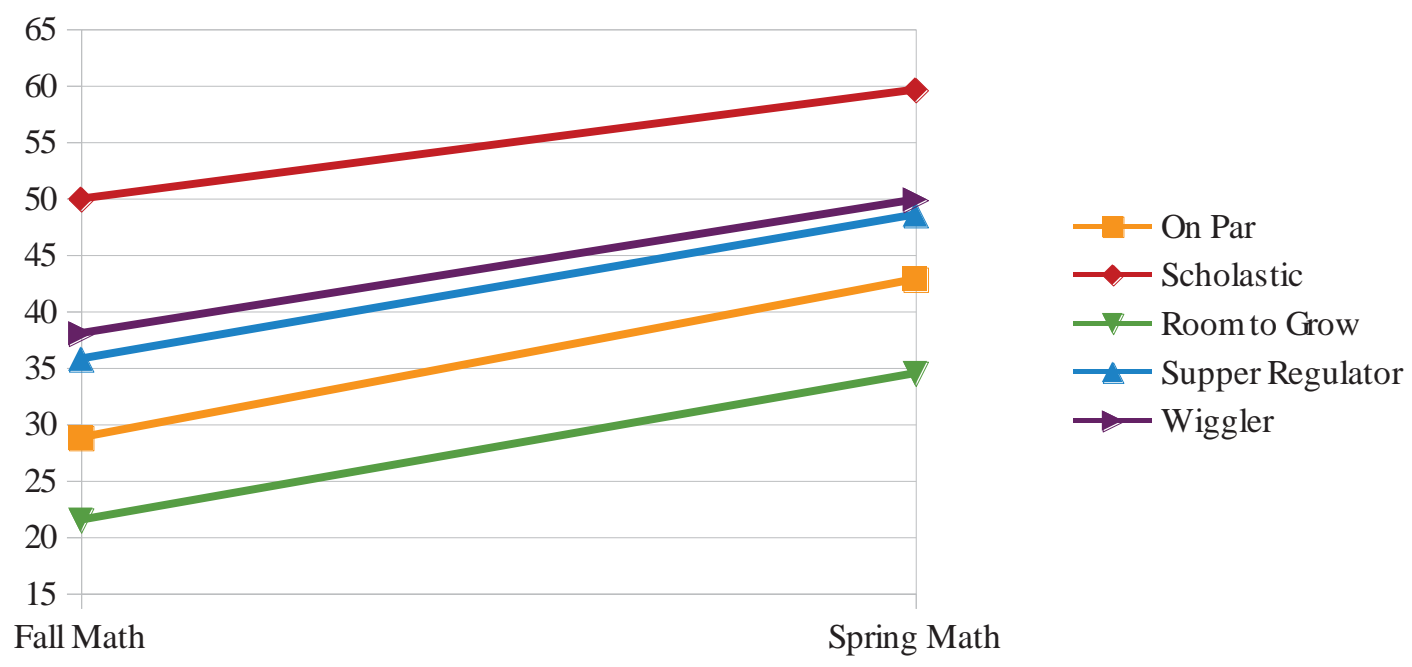

Figure 13. Fall and Spring Mean Levels of Reading by Profile

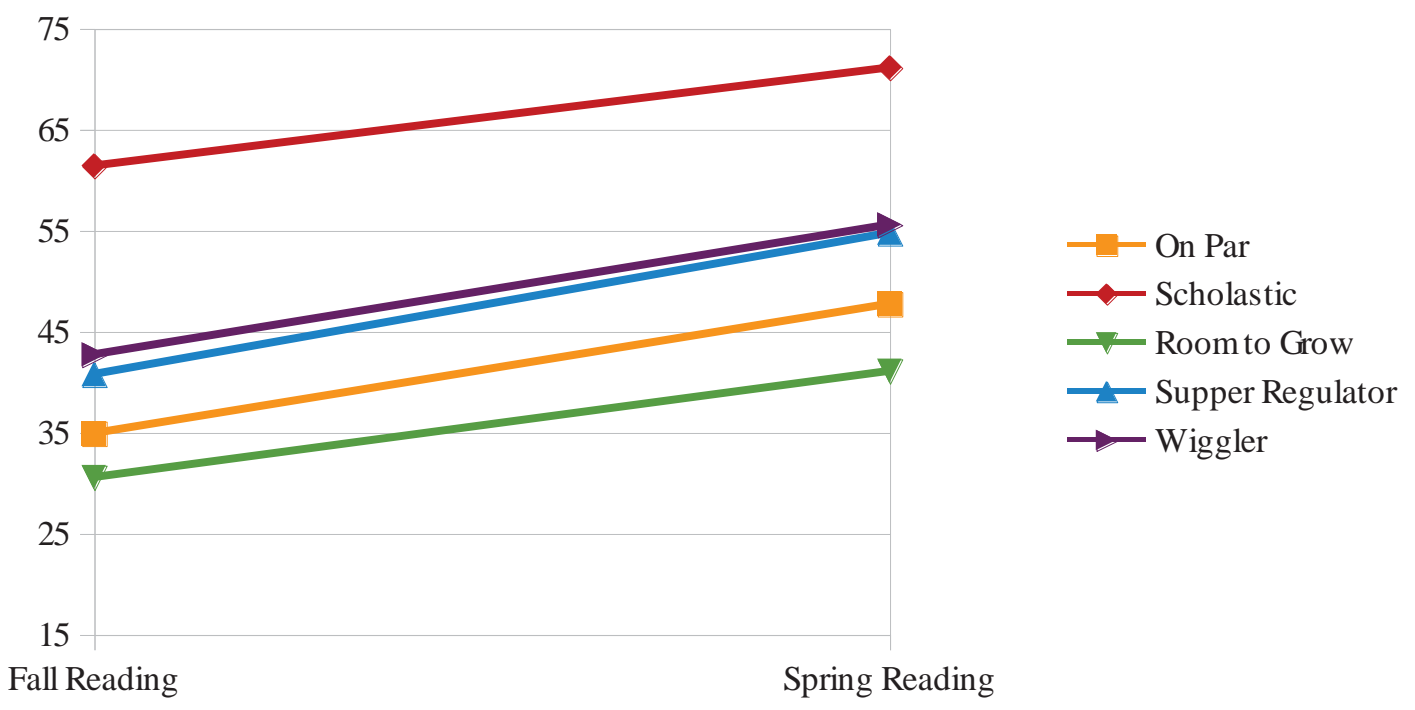


Figure 14. Fall and Spring Mean Levels of Social Skills by Profile

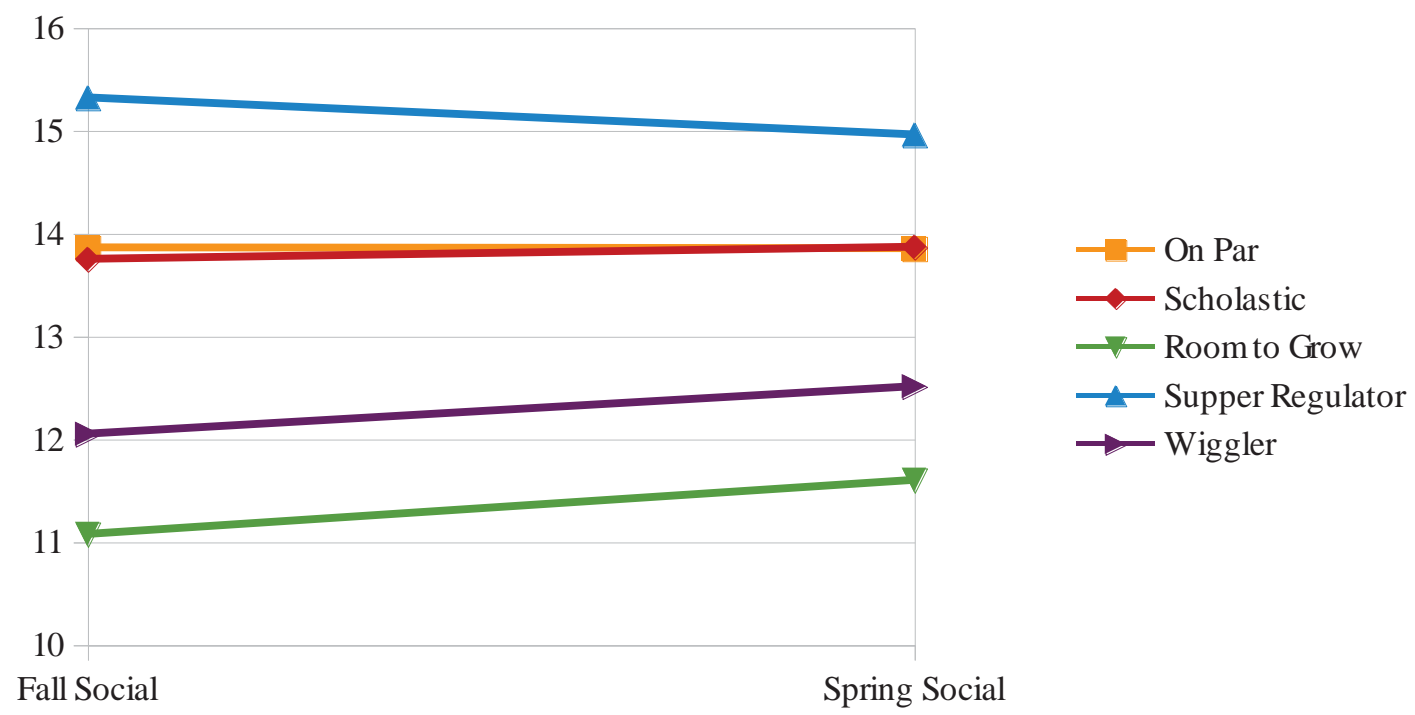

Figure 15. Fall and Spring Mean Levels of Engagement by Profile
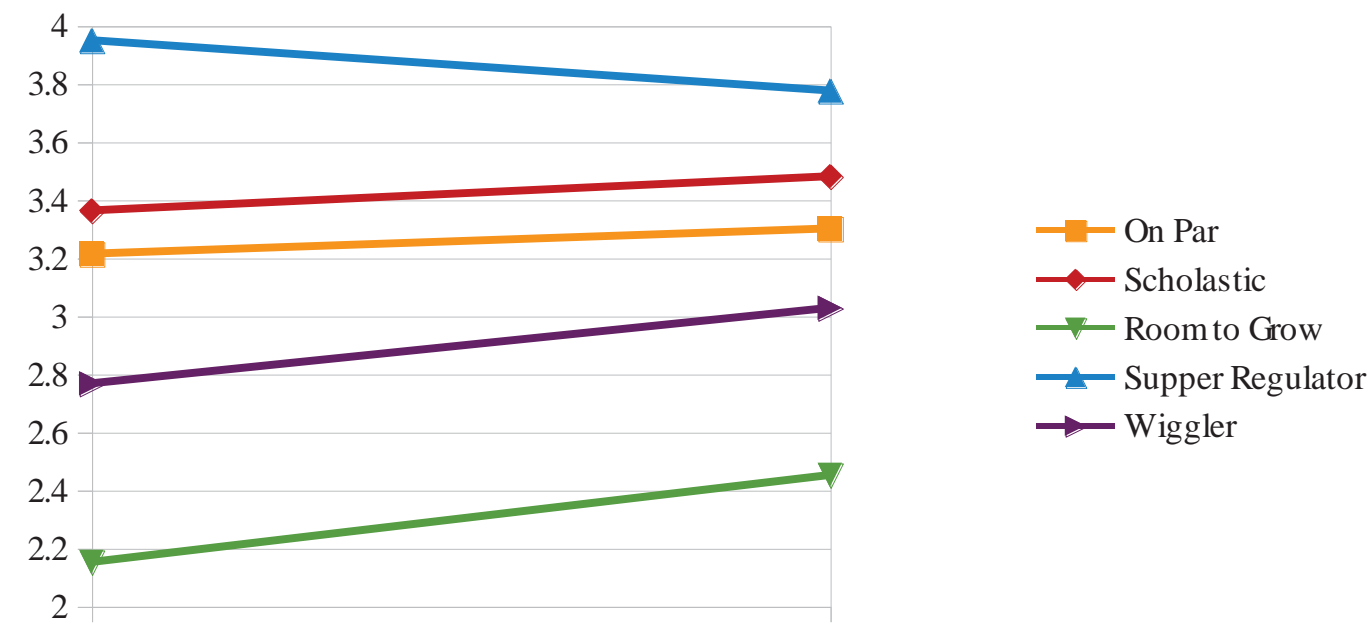

Fall Engagement

Spring Engagement 
Figure 16. Fall and Spring Mean Levels of Self Control by Profile

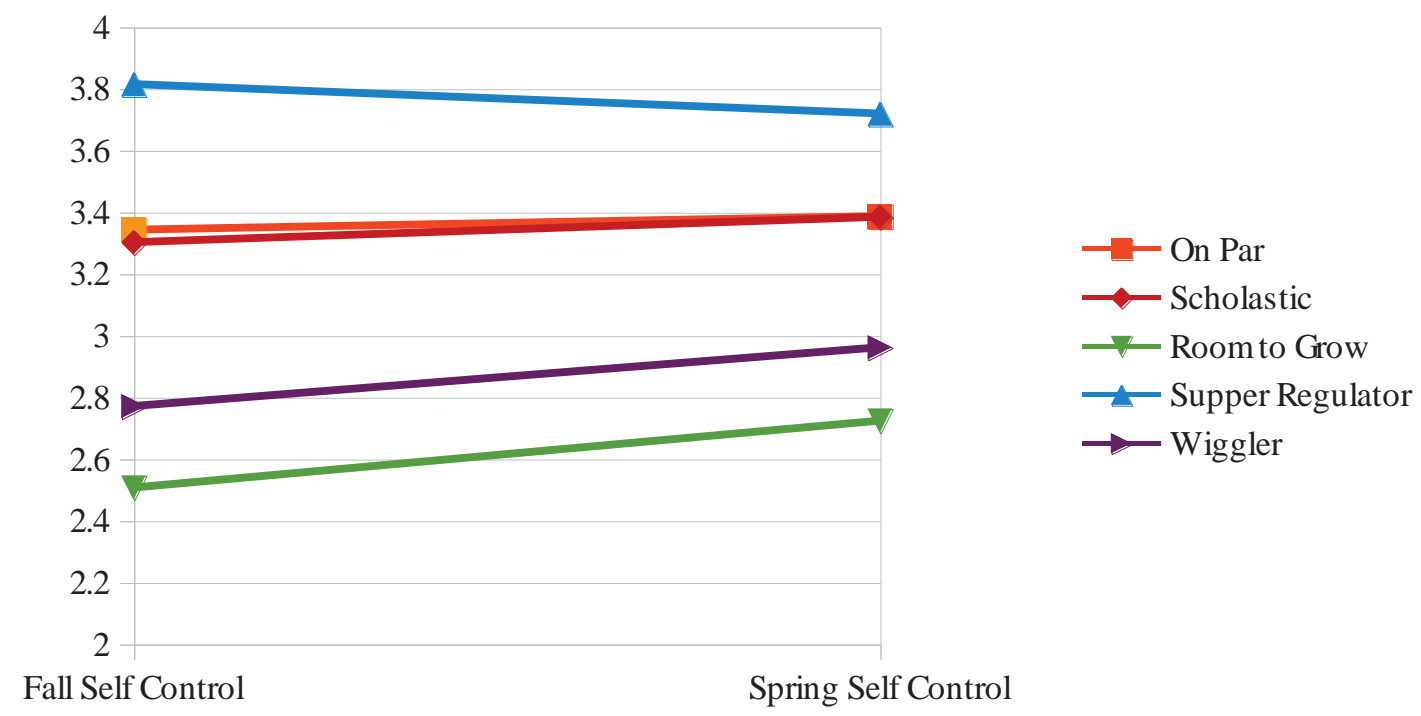

Math and reading. At the end of the year, children in the Scholastic profile had the highest on average math and reading scores, followed by the children in the Wiggler profile, the Super Regulator profile, the On Par profile, and, finally, the Room to Grow profile. This is the same relative ranking that the groups held at school entry.

The models predicting difference scores in these outcomes estimated that children in each school readiness profile improved on math and reading scores from fall to spring. Children in the Super Regulator profile showed more improvement in these academic domains than children in the Room to Grow or Wiggler profiles. Interestingly, the kindergartners in the Room to Grow group improved more in math across the year than they did in reading. This trend is also seen in the On Par group, though they improved more overall than those in the Room to Grow group. Children in the Scholastic profile improved less than all children in all other profiles on these academic skills. 
Engagement. The Super Regulator profile had the highest levels of behavioral engagement at the end of the kindergarten year, followed by children in the Scholastic profile, the On Par profile, the Wiggler profile, and finally, the Room to Grow profile. This is the same relative ranking as was present at the beginning of kindergarten.

Most children improved in engagement across the kindergarten year, according to the model. The children in the Super Regulator profile, however, did not improve in this domain; their engagement decreased across the year. The children in the Room to Grow profile showed the greatest increase in scores, closely followed by children in the Wiggler profile. The Scholastic profile and the On Par profile showed moderate improvement in behavioral engagement across the year.

Social Skills and Self Control. Like behavioral engagement, children in the Super Regulator ended the school year with the highest average social skills and level of self control. The children in the On Par and Scholastic profiles came followed with approximately the same levels of social skills and self control, followed by the children in the Wiggler profile and the Room to Grow profile. This is similar to the rankings present at the beginning of kindergarten, however the On Par profile and Scholastic profile are closer in levels at the end of the year than the beginning of the year.

Children in the Room to Grow profile showed the greatest improvement in social skills and self control across the kindergarten year, followed by the children in the Wiggler profile. The Super Regulator profile, on the other hand, did not improve across the year; on average, their social skills and self control decreased across the year. The 
Scholastic profile and On Par profile showed moderate to minimal increases in these domains.

Externalizing problem behaviors. At the end of the kindergarten year, $41 \%$ of the Room to Grow profile and $29 \%$ of the Wiggler profile were rated by their teachers as displaying externalizing problem behaviors. The logistic regression confirmed this observation; the odds that children would display externalizing problem behaviors at the end of the year - controlling for if they displayed these behaviors in fall - for the Room to Grow profile were 0.46 and for the Wiggler profile were 0.34. Compare these odds to 0.05 for the On Par profile, 0.01 for the Super Regulator profile, and 0.07 for the Scholastic profile.

Research Question Four. Tables 15 and 16 display person-centered and variablecentered predictive models for the primary and secondary achievement outcomes side by side. I compare the two sets of models based on model fit and interpretation.

Model fit comparisons. Across the board, the variable-centered displayed better model fit indices (i.e., BIC, AIC, and - in the case of the logistic models - Deviance) than the person-centered models. This is to be expected, based on the data reduction process of model-based cluster analysis. The model fits were, however, in the same relative ranges across the model types.

Interpretation. The primary difference I noticed between the two sets of models was the lack of significance of certain predictors in the variable-centered models. In particular, social skills in fall did not significantly predict growth or decline in literacy and math; reading knowledge in fall did not significantly predict growth or decline in 
social skills, engagement, or self control; and neither fall reading nor math knowledge significantly predicted the display of externalizing problem behaviors. The variablecentered models suggest that early math and engagement are the most consistent predictors of achievement outcomes. The person-centered models, however, suggest that the variables considered non-significant in the variable-centered models may have a role in the development of these outcomes. For example, the Super Regulator and Wiggler profiles show relatively similar reading and math skills at school entry, yet differ drastically in levels of social skills. Yet, the children in the Super Regulator profile showed more growth in reading skills and - to a lesser extent - math skills across the kindergarten year.

Additionally, I propose that the person-centered models offer more information in a more easily interpret-able package. I will discuss this more in the upcoming chapter.

\section{Chapter Summary}

In this chapter, I reviewed the results of my analyses addressing Research Questions Two, Three, and Four. There were key demographic differences in the likelihood of children's assignment to the school readiness profiles. The children in the profiles displayed unique change across the kindergarten year in various achievement outcomes. Finally, I compared the person-centered models examined in Research Question Three to more traditional variable-centered models. In the upcoming chapter, I discuss my findings in light of this study's limitations and propose the impact of my work on the literature. 


\section{Chapter 9: Discussion}

In the previous chapter, I outlined the results of Research Questions Two, Three, and Four. In the current chapter, I briefly summarize the findings of all four research questions, review the strengths and limitations of my measures and methods, and - given these strengths and limitations - communicate the potential implications of this work on the field of early childhood development and education.

\section{Summary of Results}

\section{Research Question One.}

My process of model-based cluster analysis determined the presence of five profiles of school readiness: 1) the Scholastic profile, comprised of children with very high levels of reading and math skills, and above average levels of behavioral engagement and social skills; 2) the On Par profile, comprised of children with school readiness scores than remained close to the grand mean levels; 3) the Room to Grow profile, comprised of children who enter kindergarten with school readiness skills far below grand average levels, particularly their behavioral engagement; 4) the Super Regulator profile, comprised of children with high levels of engagement and social skills, and above average math and reading skills; and 5) the Wiggler profile, comprised of children who enter kindergarten with above average academic skills, particularly math skills, and below average classroom engagement and social skills. Of the 12,509 children included in this analysis, 5,191 were assigned to the On Par profile, 845 were assigned to the Scholastic profile, 2,977 were assigned to the Room to Grow profile, 1,328 were assigned to the Super Regulator profile, and 2,168 were assigned to the Wiggler profile. 
PROFILES OF SCHOOL READINESS

Research Question Two.

My analysis of the demographic characteristics of the children within the school readiness profiles allowed me to describe the key characteristics that predicted profile membership. This analysis revealed that, in general, children in the On Par profile came from families with average SES and were generally White; children in the Scholastic profile were more likely to be Asian and non-Hispanic, have attended a center-based preschool, come from a higher SES background, and speak English; children in the Room to Grow profile were more likely to be Black and/or Hispanic boys and come from a lower SES background; children in the Super Regulator profile were more likely to be girls, have attended center-based preschool, and come from families with above average SES; and children in the Wiggler profile were more likely to be Asian, Non-Hispanic, boys, have a mix of pre-kindergarten care experiences, and speak English. These trends aligned with my hypotheses and previous research.

\section{Research Question Three.}

The relative rank of achievement scores by school readiness profile did not change across the kindergarten year. For example, the Scholastic kindergartners ended the kindergarten year still ahead of their peers academically, while the Room to Grow kindergartners ended the kindergarten year still behind their peers across all dimensions. However, children across the school readiness profiles showed different levels of change across the kindergarten year. Many of the results support my hypothesis of compensatory relationships among school readiness skills. For example, children in the Super Regulator profile showed more growth in academic domains than their counterparts in the Wiggler 
profile, while children in the Wiggler profile showed positive change in behavioral engagement and social skills compared to their counterparts in the Super Regulator profile. This suggests that the Super Regulator strengths of engagement and social skills at the beginning of kindergarten supported their academic change, while the academic strengths of the children in the Wiggler profile supported their improvements in behavioral engagement, social skills, and self control.

Some findings, however, were not aligned with my hypotheses. For example, I proposed that the children who enter kindergarten without key school readiness variables would show less positive change across the kindergarten year, while children who start with higher levels of school readiness skills would show more positive change across the kindergarten year. However, it seems that there may be a ceiling effect present. This can be seen in the estimated change scores of the Scholastic, Super Regulator, and Room to Grow profiles. While the children in the Scholastic profile started with the highest levels of academic skills, they showed the lowest levels of growth in reading and math; while the children in the Super Regulator profile entered with the highest levels of engagement and social skills, their teacher-rated scores decreased across the kindergarten year; and while children in the Room to Grow profile entered school with far below average school readiness skills, they showed comparable increases in math skills and more improvement in social skills, engagement, and self control than their peers across the kindergarten year. This suggests that one's ability to improve on achievement outcomes may be limited by where one starts and the space available for detectable growth. This finding may also be related to types of activities in the kindergarten classroom. For children entering 
kindergarten with academic mastery, the academic instruction in kindergarten may be too basic to further support their learning. Likewise, children with strong social and engagement skills at kindergarten entry may not encounter situations that challenge them enough to promote growth in these domains.

\section{Research Question Four.}

The person-centered models and variable-centered models came to similar conclusions. However, my proposed compensatory relationship was partially detectable in the person-centered models and not detectable in the basic, yet commonly used, variable-centered models included here. To detect compensatory relationships between the four school readiness variables in a variable-centered manner, a researcher would need to utilize more complex analyses that include multiple statistical interactions. However, by creating the school readiness profiles and assigning them intuitive, easily comprehend-able labels prior to predicting development across the year, I was able to explore the interplay of school readiness skills in a simple way that can be more easily communicated to policymakers and practitioners who may or may not be trained in interpreting complex statistics.

The person-centered and variable-centered analyses also suggest different implications for early education interventions. The variable-centered analyses suggest that early math skills and engagement skills in the classroom are the most consistent predictors of positive development across the year. Policymakers may take this information and support interventions that focus solely on math skills or engagement to achieve the highest return on their investment. This tact, however, ignores the fact that 
school readiness skills are related to each other within each child. The person-centered findings, on the other hand, acknowledge the relation among the school readiness indicators. It is clear from the findings, for example, that children who are skilled in math at school entry are also likely to be skilled in reading at school entry. The person-centered analysis suggests that more holistic approaches to interventions may be the best able to support achievement skills.

Finally, while variable-centered analyses can be used to estimate outcomes for children with specific levels of school readiness variables, without some form of prior person-centered approaches, researchers cannot be certain that the levels they chose are representative of the combinations of skills that kindergartners typically bring to the classroom. I argue that the person-centered analytic techniques offer more information in a way that can be more readily applied to the classroom environment.

\section{Strengths and Limitations}

Every empirical study has both strengths and limitations. In this section, I will overview the strengths and limitations of this study.

\section{Measures.}

Definition of school readiness. The multidimensional operationalization of school readiness utilized in this study is a strength. Math, reading, engagement (an conceptual-adaptation of approaches toward learning), and social skills are the most consistent predictors of later achievement (Duncan et al., 2007; Halle et al., 2012; Pagani et al., 2010). The choice to include these four indicators in my definition of school readiness is parsimonious and supported by empirical evidence. 
Additionally, my choice to include engagement and social skills as indicators of school readiness, in addition to academic skills, coincide with the opinions of early education stakeholders. Kindergarten teachers recognize the importance of the ability to engage with classroom tasks and interact with peers and teachers in appropriate ways in the kindergarten classroom (Rimm-Kauffman et al., 2000); parents and policymakers are interested in the role of academic preparedness in school readiness (Diamond et al., 2000).

The study's definition of school readiness is also a limitation: I focused on the indicators of school readiness with the most empirical evidence, but by doing so, I am omitting indicators of school readiness from other dimensions as defined by the NEGP and ELF, such as fine and gross motor skills. By omitting these other indicators, I may have failed to capture some of the complexity of school readiness.

Achievement outcomes. In response to a key limitation of previous research, I am including non-academic outcomes (i.e., engagement, social skills, self control, and externalizing problem behaviors) in addition to the more traditional academic achievement outcomes. This is certainly a strength of this study. However, these nonacademic outcomes are reported by the kindergarten teacher rather than measured objectively, and therefore may include some biases that are not present in the academic achievement outcomes.

\section{Analyses.}

The use of person-centered analyses is a distinct strength of this study. Not only did I provide a relatively novel perspective into studying school readiness and analyzing 
the phenomenon of school readiness a way that more closely represents the way it appears in an applied setting, this analytic technique allows me to more easily communicate my findings to important stakeholders (e.g., practitioners, parents, and policy makers).

A challenge of model-based cluster analysis is determining what meaningful labels to apply to the profiles. The labels applied to the school readiness profiles in this study were informed by the mean levels of the school readiness variables within each profile, focusing primarily their school readiness strengths. However, the analyses conducted after initial profile formation (i.e., the representation of demographic characteristics across profiles and the trajectories across the kindergarten year of children within each profile) may have offered important insights into the label creation process. In future studies, it would be beneficial to take an iterative approach to naming the profiles, such that the names are revisited and revised as more is learned about the characteristics and trajectories of the students within each profile.

\section{Theoretical Perspective.}

Finally, my application of the CLT framework to this context theoretically informed my analyses and proposed mechanisms of how school readiness skills can influence later development. However, as this theory is cognitively-based, it limits my ability to account for interactions between children, their teachers, and the tasks themselves. To begin to make conclusions regarding classroom practices that may deferentially support children from different school readiness profiles, I will need to expand my theory to include proximal processes in the classroom environment. 
PROFILES OF SCHOOL READINESS

\section{Implications and Contributions}

The findings of this study support my belief that school readiness skills are not all-or-nothing. Instead, school readiness skills are resources that children can use in the classroom in unique ways to develop. Additionally, there are common patterns of school readiness skills that are influenced by the experiences that children have prior to kindergarten. Children with risk factors, such as low SES and marginalized racial and ethnic status, may come in with skills that can buffer their dearth of skills in other school readiness dimensions. Ultimately, there are multiple routes to success in school.

This study makes distinct contributions to the research on school readiness. First, my use of rigorous person-centered analytic techniques will help set a standard for future analyses of this type. Second, the person-centered theoretical and methodological strengths of this study will allow easier and more intuitive dissemination of findings to early education stakeholders, such as parents, teachers, and policymakers.

\section{Next Steps}

Next steps in this line of research include replicating the formation of school readiness profiles across different samples and populations. This study found school readiness profiles in a nationally representative sample. However, there is beginning to be a national trend of individual states assessing the school readiness skills of their entering kindergartners. As individual states can have different education policies that influence the quality and availability of early childhood education, it may be worthwhile to investigate if the five school readiness profiles identified in this study are detectable or if different profiles arise at the state-level. 
I also plan to seek the input of preschool and kindergarten teachers in the development of school readiness profiles in the future. The goal of this study was to determine profiles of school readiness that are meaningful to early education practitioners. I plan to present these profiles with their labels to teachers and use qualitative analytic techniques to ask the teachers if these profiles seem true to the students they encounter in their classrooms.

Examining how school readiness profiles change over time is also a fascinating future direction. What patterns exists in the sets of skills with which children, adolescents, and adults enter $3^{\text {rd }}$ grade, $9^{\text {th }}$ grade or college? Additionally, I hope to investigate how individual children's memberships in school readiness profiles change across time. It is likely that some children will transition out of one profile into another as their skills and interests develop.

Exploring the patterns of profile transitions and determining what factors predict profile transitions has practical considerations: how can practitioners help a child in a less adaptive profile develop the skills necessary to transition into a more adaptive profile? Future research should incorporate information about classroom experiences that can facilitate or hinder development across the school year. Determining what type of classroom characteristics (e.g., class size, teacher education level), indicators of quality (e.g., emotional support, classroom organization, and instructional support), and classroom activities (e.g., small group work, individual worksheets) support the development of children within specific profiles can give teachers and early childhood practitioners research-supported tools to address the unique needs of their students. These 
PROFILES OF SCHOOL READINESS

next steps will help extend the scope of this line of research as well as provide relevant and meaningful information to key stakeholders - practitioners, parents, policy makers, and researchers - in early childhood education. 
References

Administration for Children and Families. (2015). Head Start early learning outcome framework: Ages birth to five. Washington, DC: U.S. Office of Head Start.

Aldenderfer, M. S. \& Blashfield, R. J. (1984). Cluster analysis (Sage University Paper Series of Quantitative Applications in the Social Sciences, No. 07-044). Beverly Hills, CA: Sage

Bassok D., Latham, S. \& Rorem A. (2015) Is Kindergarten the new first grade? EdPolicyWorks Working Paper Series, No. 20. Retrieved from: http://curry.virginia.edu/uploads/resourceLibrary/20_Bassok_Is_Kindergarten_Th e_New_First_Grade.pdf

Blair, C. (2002). School Readiness: Integrating Cognition and Emotion in a Neurobiological Conceptualization of Children's Functioning at School Entry. American Psychologist, 57, 111-127.

Blair, C. \& Raver, C. C. (2015). School Readiness and Self-Regulation: A Developmental Psychobiological Approach. Annual Review of Psychology, 66, 711-731. doi:10.1146/annurev-psych-010814-015221.

Blair, C. \& Razza, R. P. (2007). Relating effortful control, executive function, and false belief understating to emerging math and literacy ability in kindergarten. Child Development, 78, 647-663.

Brock, L. L, Rimm-Kaufman, S. E., Nathanson, L., \& Grimm, K. J. (2009). The contributions of 'hot' and 'cool' executive function to children's academic achievement, learning-related behaviors, and engagement in kindergarten. Early 
PROFILES OF SCHOOL READINESS

Childhood Research Quarterly, 24, 337-349.

Bronfenbrenner, U. (1994). Ecological models of human development. In International Encyclopedia of Education, Vol. 3, $2^{\text {nd }}$ Ed. Oxford: Elsevier. Reprinted in: Gaucain, M. \& Cole, M. (Eds.), Reading on the development of children, $2^{\text {nd }} E d$. (1993, pp. 37-43). NY: Freeman.

Burchinal, M., Vandergrift, N., Pianta, R., Mashburn, A. (2010). Threshold Analysis of Association Between Child Care Quality and Child Outcomes for Low-income Children in Pre-kindergarten Programs, Early Childhood Research Quarterly, 25, 166-176.

Bush Administration (2001). Head Start Policy Book. Retrieved from http://georgewbushwhitehouse.archives.gov/infocus/earlychildhood/hspolicybook/text/02.html

Callahan, R. E. (1962). Education and the cult of effeciency. Chicago: University of Chicago ress.

Carlton, M. \& Winsler, A. (1999). School Readiness: The Need for a Paradigm Shift. School Psychology Review, 28(3), 338-352.

Chatterji, M. (2005). Achievement Gap's and Correlates of Early Mathematics Achievement: Evidence from the ECLS K-First Grade Sample. Education Policy Analysis Archives, 13(46), 1-38.

Clotfelter, C. T., Ladd, H. F., \& Vigdor, J. L. (2009). The academic achievement gap in grades 3 to 8. The Review of Economics and Statistics, 91(2), 398-419.

Common Core State Standards Initiative (2010). Common Core State Standards for 
English Language Arts \& Literacy in History/Social Studies, Science, and Technical Subjects. Retrieved from http://www.corestandards.org/wpcontent/uploads/ELA_Standards1.pdf

Currie. J. (2005). Health Disparities and Gaps in School Readiness. The Future of Children, 15(1), 117-138.

Diamond, K. E., Reagan, A. J., \& Bandyk, J. E. (2000). Parents' Conception of Kindergarten Readiness: Relationships with Race, Ethnicity, and Development. The Journal of Educational Research, 94(2), 93-100. doi:10.1080/00220670009598747.

Duncan, G. J., Dowsett, C. J., Claessens, A., Magnuson, K., Huston, A. C., Klebanov, P., ... \& Sexton, H. (2007). School readiness and later achievement. Developmental psychology, 43(6), 1428.

Duncan, G. J., \& Magnuson, K. (2011). The nature and impact of early achievement skills, attention skills, and behavior problems. Whither opportunity, 47-70.

Duncan, S. E., \& De Avila, E. A. (1998). PreLAS 2000. Monterey, CA: CTB/McGrawHill.

Dunn, L. M., \& Dunn, L. M. (1997). PPVT-III: Peabody picture vocabulary test. Circle Pines, MN: American Guidance Service.

Else-Quest, N. M., Hyde, J. S., Goldsmith, H. H., \& Van Hulle, C. A. (2006). Gender Differences in Temperament: A Meta-Analysis. Psychological Bulletin, 132(1), 33-72.

Everitt, B. \& Hothorn, T. (2011). An introduction to applied multivariate analysis with $R$. 
PROFILES OF SCHOOL READINESS

New York, NY: Springer Science+Business Media, LLC.

Fraley, C. \& Raftery, A. (2002). Model-based clustering, discriminant analysis, and density estimation. Journal of the American Statistical Association, 97, 611-631.

Fraley, C., Raftery, A. E., Murphy, T. B., \& Scrucca, L. (2012). mclust Version 4 for R: Normal Mixture Modeling for Model-Based Clustering, Classification, and Density Estimation Technical Report No. 597, Department of Statistics, University of Washington.

Fraley, C., Raftery, A., \& Scrucca, L. (2014). Package 'mclust' [PDF]. Retrieved from http://cran.r-project.org/web/packages/mclust/mclust.pdf.

Fryer Jr., R.G. \& Levitt, S.D. (2004). Understanding the Black-White Test Score Gap in the First Two Years of School. The Review of Economics and Statistics, 82(2), 447-464.

Ginsburg, H., \& Baroody, A. J. (1983). The test of early mathematics ability. Pro-ed.

Gresham, F. M., \& Elliott, S. N. (1990). Social skills rating system (SSRS). American Guidance Service.

Grissmer, D. W., \& Eiseman, E. (2008). Can gaps in the quality of early environment and non-cognitive skills help explain persisting Black-White achievement gaps? In K. Magnuson \& J. Waldfogel (Eds.), Steady gains and stalled progress: Inequality and the Black-White test score gap. New York, NY: Sage.

Grissmer, D., Grimm, K. J., Aiyer, S. M., Murrah, W. M., \& Steele, J. S. (2010). Fine motor skills and early comprehension of the world: two new school readiness indicators. Developmental Psychology, 46(5), 1008-1017. 
Hair, E., Halle, T., Terry-Humen, E., Lavelle, B., \& Calkins, J. (2006). Children's school readiness in the ECLS-K: Predictions to academic, health, and social outcomes in first grade. Early Childhood Research Quarterly, 21, 431-454.

Halle, T. G., Hair, E., Wandner, L. D., \& Chien, N. C. (2012). Profiles of school readiness among 4-year-old Head Start Children. Early Childhood Research Quarterly, 27, 613-626.

Hamre, B. K. \& Pianta, R. C. (2001). Early Teacher-Child Relationships and the Trajectory of Children's School Outcomes through Eighth Grade. Child Development, 72(2), 625-638.

Hlavac, M. (2015). Stargazer: Well-Formatted Regression and Summary Statistics Tables. R package version 5.2. http://CRAN.R-project.org/package=stargazer Janus, M. \& Duku, E. (2007). The School Entry Gap: Socioeconomic, Family, and Health Factors Associated with Children's School Readiness to Learn. Early Education and Development, 18(3), 375-403.

Kagan, S. L., Moore, E., \& Bradekamp, S. (1995). Reconsidering children's early development and learning: Toward common views and vocabulary. Washington, DC: National Education Goals Panel Goal 1 Technical Planning Group.

Konold, T. R. \& Pianta, R. C. (2005). Empirically-derived person-oriented patterns of school readiness in typically-developing children: Description and prediction to first-grade achievement. Applied Developmental Science, 9, 174-187.

Kwon, K., Kim, E., \& Sheridan, S. (2012). Behavioral competence and academic functioning among early elementary children with externalizing problems. School 
PROFILES OF SCHOOL READINESS

Psychology Review, 41, 123-140.

Ladd, G. W. \& Burgess, K. B. (2001). Do Relational Risks and Protective Factors Moderate the Linkages between Childhood Aggression and Early Psychological and Social Adjustment? Child Development, 72(5), 1579-1601.

Ladd, G. W., Herald, S. L., \& Kochel, K. P. (2006). School Readiness: Are There Social Prerequisites? Early Education and Development,17(1), 115-150. doi: 10.1207/s15566935eed1701_6.

Lee, J. (2002). Racial and ethnic achievement gap trends: Reversing the progress toward equity?. Educational researcher, 31(1), 3-12.

Lin, H., Lawrence, F. R., \& Gorrell, J. (2003). Kindergarten Teacher's Views of Children's Readiness for School. Early Childhood Research Quarterly, 18, 225-237.

Lonigan, C. J., Wagner, R. K., Torgesen, J. K., \& Rashotte, C. A. (2007). Test of preschool early literacy. Austin, TX: Pro-Ed.

Magnuson, K. A., Meyers, M. K., Ruhm, C. J., \& Waldfogel, J. (2004). Inequality in preschool Education and School Readiness. American Educational Research Journal, 41(1), 115-157. doi: 10.3102/00028312041001115

Markwardt, F. C. (1989). Peabody individual achievement test-revised. Circle Pines, MN: American Guidance Service.

Mashburn, A. J. \& Pianta, R. C. (2006). Social Relationships and School Readiness. Early Education and Development, 17(1), 151-176. doi: 10.1207/s15566935eed1701_7.

Mashburn, A. J., Pianta, R. C., Hamre, B. K., Downer, J. T., Barbarin, O. A., Bryant, D., 
... \& Howes, C. (2008). Measures of classroom quality in prekindergarten and children's development of academic, language, and social skills. Child Development, 79(3), 732-749.

Mascareno, M., Doolaard, S., \& Bosker, R. (2014). Profiles of Child Developmental Dimensions in Kindergarten and the Prediction of Achievement in the First and Second Grades of Primary School. Early Education and Development, 25, 703722.

Matthews, J. S., Ponitz, C. C., \& Morrison, F. J. (2009). Early gender differences in selfregulation and academic achievement. Journal of Educational Psychology, $101(3), 689$.

McWayne, C., Green, L., \& Fantuzzo, J. (2009). A Variable- and Person-Oriented Investigation of Preschool Competencies and Head Start Children's Transition to Kindergarten and First Grade. Applied Developmental Science, 13(1), 1-15.

National Education Goals Panel. (1999). Goals Work! Retrieved from http://govinfo.library.unt.edu/negp/page1-5.htm.

Obama Administration (2015a). Early Learning. Retrieved from https://www.whitehouse.gov/issues/education/early-childhood.

Obama Administration (2015b). Health Care that Works for Americans. Retrieved from https://www.whitehouse.gov/healthreform/healthcare-overview.

Office of Head Start. (2011). The Head Start Child Development and Early learning Framework: Promoting Positive Outcomes in Early Childhood Programs Serving Children 3-5 Years Old. Washington, DC: U.S. Office of Head Start. Retrieved 
from http://eclkc.ohs.acf.hhs.gov/hslc/tta-

system/teaching/eecd/Assessment/Child\%20Outcomes/HS_Revised_Child_Outco mes_Framework(rev-Sept2011).pdf sr/approach/pdf/ohsapproach-to-school-readiness_complete.pdf.

Office of Head Start. (2012). Head Start approach to school readiness. Washington, DC:

U.S. Office of Head Start. Retrieved from http://eclkc.ohs.acf.hhs.gov/hslc/hs/ sr/approach/pdf/ohsapproach-to-school-readiness_complete.pdf.

Ostrov, J. M., \& Keating, C. F. (2004). Gender differences in preschool aggression during free play and structured interactions: An observational study. Social Development, 13(2), 255-277.

Pagani, L. S., Fritzpatrick, C., Archambault, I., \& Janosz, M. (2010). School Readiness and Later Achievement: A French Canadian Replication and Extension. Developmental Psychology, 46(5), 984-994. doi: 10.1037/a0018881.

Paas, F., van Gog, T., \& Sweller, J. (2010). Cognitive Load Theory: New Conceptualizations, Specifications, and Integrated Research Perspectives. Education Psychology Review, 22, 115-121. doi: 10.1007/s10648-010-9133-8.

R Core Team (2015). R: A language and environment for statistical computing. $R$ Foundation for Statistical Computing, Vienna, Austria. URL: https://www.Rproject.org/.

Raver, C. C. \& Knitzer, J. (2002). Ready to Enter: What Research Tells Policymakers About Strategies to Promote Social and Emotional Readiness Among Three- and Four-Year-Old Children. 
Reardon, S. F. (2011). The widening academic achievement gap between the rich and the poor: New evidence and possible explanations. Whither Opportunity, 91-116.

Reid, D. K., Hresko, W. P., \& Hammill, D. D. (2001). Test of Early Reading Ability: TERA-3. Pro-ed.

Rimm-Kauffman, S. E., Curby, T. W., Grimm, K. J., Nathanson, L., \& Brock, L. L. (2009). The Contribution of Children's Self-Regulation and Classroom Quality to Children's Adaptive Behaviors in the Kindergarten Classroom. Developmental Psychology, 45(4), 958-972. doi: 10.1037/a0015861.

Rimm-Kauffman, S. E., Pianta, R. C., \& Cox, M. J. (2000). Teachers' Judgments of Problems in the Transition to Kindergarten. Early Childhood Research Quarterly, 15(2), 147-166.

Roeser, R. W., Eccles, J. S. \& Sameroff, A. J. (2000). School as a Contest of Early Adolescents' Academic and Social-Emotional Development: A Summary of Research Findings. The Elementary School Journal, 100(5), 443-471. Retrieved from http://www.jstor.org/stable/1002279.

Schmidt, M. E., Demulder, E. K., \& Denham, S. A. (2002). Kindergarten SocialEmotional Competence: Developmental Predictors and Psychosocial Implications. Early Childhood Development and Care, 172, 451-462. doi: 10.1080/0300443022000034979.

Snow, K. L. (2006). Measuring School Readiness: Conceptual and Practical Considerations. Early Education and Development, 17(1), 7-41. doi:10.1207/s15566935eed1701_2. 
PROFILES OF SCHOOL READINESS

Sweller, J. (1994). Cognitive load theory, learning difficulty, and instructional design. Learning and Instruction, 4(4), 295-312.

Tourangeau, K., Nord, C., Lê, T., Wallner-Allen, K., Hagedorn, M.C., Leggitt, J., \& Najarian, M. (2015). Early Childhood Longitudinal Study, kindergarten class of 2010-11 (ECLS-K: 2011): User's manual for the ECLS-K:2011 kindergarten-first grade datafile and electric cookbook, public version. (NCES 2015-078). U.S. Department of Education. Washington, DC: National Center for Education Statistics.

Wesley, P.W. \& Buysse, V. (2003). Making Meaning of School Readiness in Schools and Communities. Early Childhood Research Quarterly, 18, 351-375. doi:10.1016/S0885-2006(03)00044-9.

West, J., Germino-Hausken, E., \& Collins, M. (1995). Readiness for kindergarten: Parent and teacher beliefs (Statistics in brief). Washington, DC: National Center for Education Statistics.

Woodcock, R. W., McGrew, K. S., \& Mather, N. (2001). Woodcock-Johnson III tests of cognitive abilities (pp. 371-401). Riverside Pub.

Zelazo, P. D., Carter, A., Reznick, J. S., \& Frye, D. (1997). Early development of executive function: A problem solving framework. Review of General Psychology, 1, 198-226.

Zill, N., \& West, J. (2001). Entering Kindergarten: A Portrait of American Children When They Begin School. Findings from the Condition of Education, 2000.

Ziv, Y. (2013). Social Information Processing Patterns, Social Skills, and School 
PROFILES OF SCHOOL READINESS

Readiness in Preschool Children. Journal of Experimental Child Psychology, 114, 306-320. doi:10.1016/j.jecp.2012.08.009. 
Appendix

Abbreviations and Brief Descriptions of Models Available in mclust

EII spherical, equal volume

VII spherical, unequal volume

EEI diagonal, equal volume and shape

VEI diagonal, varying volume, equal shape

EVI diagonal, equal volume, varying shape

VVI diagonal, varying volume and shape

EEE ellipsoidal, equal volume, shape, and orientation

EEV ellipsoidal, equal volume and shape

VEV ellipsoidal, equal shape

VVV ellipsoidal, varying volume, shape, and orientation 